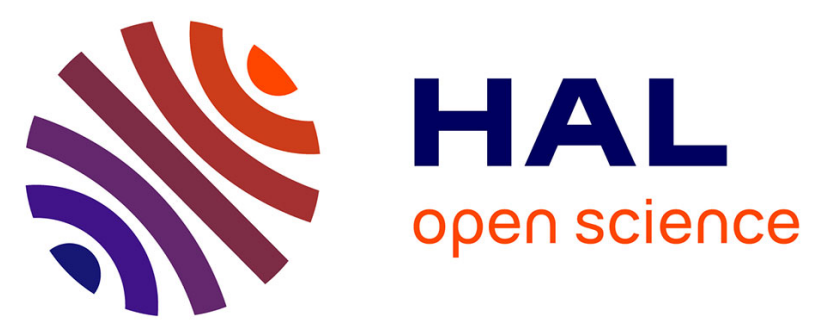

\title{
Premières données sur le traitement des corps humains à la transition du Néolithique récent et du Néolithique final dans le Bas-Rhin : dimensions culturelles
} Frédérique Blaizot, Xavier Boës, Dominique Lalai, Nelly Le Meur, Yolaine Maigrot

\section{- To cite this version:}

Frédérique Blaizot, Xavier Boës, Dominique Lalai, Nelly Le Meur, Yolaine Maigrot. Premières données sur le traitement des corps humains à la transition du Néolithique récent et du Néolithique final dans le Bas-Rhin : dimensions culturelles. Gallia Préhistoire - Archéologie de la France préhistorique, 2001, 43, pp.175-235. 10.3406/galip.2001.2178 . hal-02353625

\section{HAL Id: hal-02353625 \\ https://hal.science/hal-02353625}

Submitted on 21 Jan 2020

HAL is a multi-disciplinary open access archive for the deposit and dissemination of scientific research documents, whether they are published or not. The documents may come from teaching and research institutions in France or abroad, or from public or private research centers.
L'archive ouverte pluridisciplinaire HAL, est destinée au dépôt et à la diffusion de documents scientifiques de niveau recherche, publiés ou non, émanant des établissements d'enseignement et de recherche français ou étrangers, des laboratoires publics ou privés.

\section{(ㅇ)(1) $\$$}

Distributed under a Creative Commons Attribution - NonCommercial - NoDerivatives| 4.0 


\title{
PREMIÈRES DONNÉES SUR LE TRAITEMENT DES CORPS HUMAINS À LA TRANSITION DU NÉOLITHIQUE RÉCENT ET DU NÉOLITHIQUE FINAL DANS LE BAS-RHIN
}

\section{Dimensions culturelles}

\section{Frédérique BlaIzoT}

avec la collaboration de Xavier Bö̈s, Dominique LALAÏ, Nelly LE Meur et Yolaine MAIGroT

Mots-clés. Inhumations en fosses circulaires, tombe-bûcher à crémations multiples, Néolithique récent II, Néolithique final I, Alsace, Bas-Rhin.

Key-words. Inhumations in round pits, funeral pyre with multiple cremation, Late Neolithic II, Sub Neolithic I, Alsace, Bas-Rhin.

Résumé. Le site de Reichstett-Mundolsheim-Souffelweyersheim "rue Ampère ", a livré des restes humains dans six fosses circulaires; cinq d'entre elles renferment des inhumations, dont une double, altribuées à la fin du Néolithique récent II et la sixième contient les restes d'une. crémation primaire simultanée de onze individus datée du début du Néolithique final. Cét article propose d'analyser par les méthodes de l'archéo-anthropologie les différents rituels rencontrés, à partir d'une étude détaillée des modes d'inhumation et du processus crématoire. La crémation représente la première fosse sépulcrale du Néolithique final alsacien, et le mode de traitement des corpss s'écarte fondamentalement de ce que l'on rencontre à l'ouest et au sud de la région. Les seules comparaisons possibles sont élablies avec l'Europe de l'tist.

\begin{abstract}
Human remains have been found in six round pits on the site of Reichstett-Mundolsheim; five of these pits conlain inhumations, one of which is dual, dating from the end of the Late Neolithic II. In the last one, eleven bodies burnt altogether, belong to the begining of the Sub Neolithic period. In this paper; the detailed study of the different rituals which have been noticed (burial practices and cremation process) was carried out with archaeo-anthropological methods. Cremation is the earliest evidence for the treatment of the corpses concerning the Sub Neolithic in Alsace, and the practice recognized is radically different from what we meet in the west and south parts of this area. But in other hand, parallels can be found in Eastern Europe.
\end{abstract}

Frédérique BIAlzot, AFAN Rhône-Alpes-Auvergne, 12, rue Maggiorini, F-69500 Bron.

Xavier BOÉs, Étudiant en géo-archéologie à l'université Paris X-Nanterre et 20bis, rue Alspach, F-68000 Colmar. Dominique LAdil, AFAN Rhône-Alpes-Auvergne, 12, rue Maggiorini, F-69500 Bron.

Nelly L.F. Mrtr, SRA Île-de-France, 6, rue de Strasbourg, F-93200 Saint-Denis.

Yolaine MAG(RoT, Laboratoire de chrono-écologie, UMR 6565 du CNRS, 16, route de Gray, F-25030 Besançon cedex. 
Malgré les nombreuses interventions archéologiques effectuées en Alsace, la première séquence du Néolithique final, qui correspond à l'horizon Horgen/ Dachstein (3500-2900 en ${ }^{14} \mathrm{C}$ cal.), est encore mal connue (Jeunesse, Schneider, 1985). En effet, deux sites sont imputés à cette période, qui n'ont livré que quelques fosses domestiques, dont une seule dans le Bas-Rhin sur le site de Dachstein (Jeunesse, Schneider, 1985, p. 120). Le Néolithique récent est en revanche beaucoup mieux représenté par les cultures de Michelsberg et de Munzingen, mais les vestiges s'y rapportant n'ont été que relativement peu explorés au sud-ouest de Strasbourg, puisque ne sont publiées que quelques découvertes anciennes de fosses grossièrement datées, comme celles de Chamli à un kilomètre du site (Thévenin, 1978, p. 549-552), de Grossolang entre Souffelweyersheim et Reichstett (Wernert, 1958), de Mundolsheim (EichFrancke, 1967), et de Lampertheim sur la commune de Hausbergen (Thévenin, 1974, p. 543 ; 1978, p. 548) (fig. 1, encadré). La plupart des inhumations en fosses, seuls témoins des pratiques mortuaires du Néolithique récent, ont été fouillées anciennement et restent mal datées (Jeunesse, 1982) ; elles sont donc attribuées de manière large à " la culture de Michelsberg ". En Alsace, on ne connaissait ainsi aucun squelette attesté du Néolithique récent II ni de la prcmic̀rc moitić du Néolithique final. Les structures exhumées sur le site de Reichstett-Mundolsheim-Souffelweyersheim (BasRhin) constituent les premières données relatives au traitement des corps humains pour cet horizon chronoculturel.

\section{PRÉSENTATION}

Le site se trouve entre les communes de Reichstett, de Mundolsheim et de Souffelweyersheim, à environ $7 \mathrm{~km}$ au nord-ouest de Strasbourg (fig. 1, encadré). La fouille, dirigée par N. Le Meur en 1997-1998 dans le cadre d'une opération préventive liée aux travaux d'aménagement d'une ZAC, a été financée en partie par l'aménageur (CUS) et par le ministère de la Culture. Une surface d'environ huit hectares et demi fut explorée, livrant, pour la Préhistoire, des occupations de nature domestique qui relèvent des cultures du Néolithique ancien (groupe rubané), du Néolithique moyen (groupes de Grossgartach et de Rössen), du Néolithique récent (groupe de Michelsberg), et de l'Âge du Bronze (BM, BFIIb, BFIIIb) (Le Meur, 19992000).

Les couches d'occupation sont absentes; seules les structures en creux sont préservées. Toutes s'ouvrent au même niveau toutes périodes confondues, directement sous la terre végétale. Elles ne sont conservées que sur la partie qui s'inscrit dans le terrain naturel, constitué de lœess remanié (parfois improprement désigné sous le terme de lehm) qui repose sur du lœss proprement dit.

L'occupation domestique du Néolithique récent, attribuée par N. Le Meur à l'horizon Michelsberg IV, est caractérisée par 54 fosses avérées (fig. 1). Aucune trace d'habitat stricto sensu n'a été relevée (maisons, fossés, palissades), les structures étant constituées de fosses dont seule la fonction secondaire (rejet) a pu être déterminée. Celles-ci se concentrent de part et d'autre d'un paléovallon, dans la partie sud-est de la surface décapée. L'analyse des artefacts contenus dans le comblement de ces fosses tend à indiquer que les fosses situées au nord du paléovallon sont riches en dépôts organiques et en vases, alors que celles qui se trouvent au sud de ce paléovallon ne comportent que de rares tessons ; il est ainsi possible d'envisager que les habitations sont localisées au nord du paléovallon, mais à l'est de l'emprise explorée (Le Meur, 1999-2000, t. IV).

Les fosses sépulcrales sont situées dans le secteur qui comporte l'ensemble des structures en creux attribuées au Néolithique récent, et plus particulièrement au sud du paléovallon (fig. 1). Il s'agit de fosses circulaires qui ne se distinguent pas, ni par leur taille ni par leur forme, des fosses domestiques de la culture Michelsberg reconnues un peu partout sur le site. Cinq d'entre elles contiennent des inhumations, dont une double, datées de la fin du Néolithique récent $(19,102$, 152, 393, 481). La sixième, datée du début du Néolithique final, peut être définie comme une tombebûcher (143). Mise à part cette dernière, il n'existe aucun vestige du Néolithique final sur le site, et aucune production Munzingen B (fin du Néolithique récent) n'a été reconnue.

Seule la sépulture 481 est en relation stratigraphique avec une structure ancienne datée qui la recoupe. La sépulture 393 est en partie détruite par une tranchée militaire de la seconde guerre mondiale. 


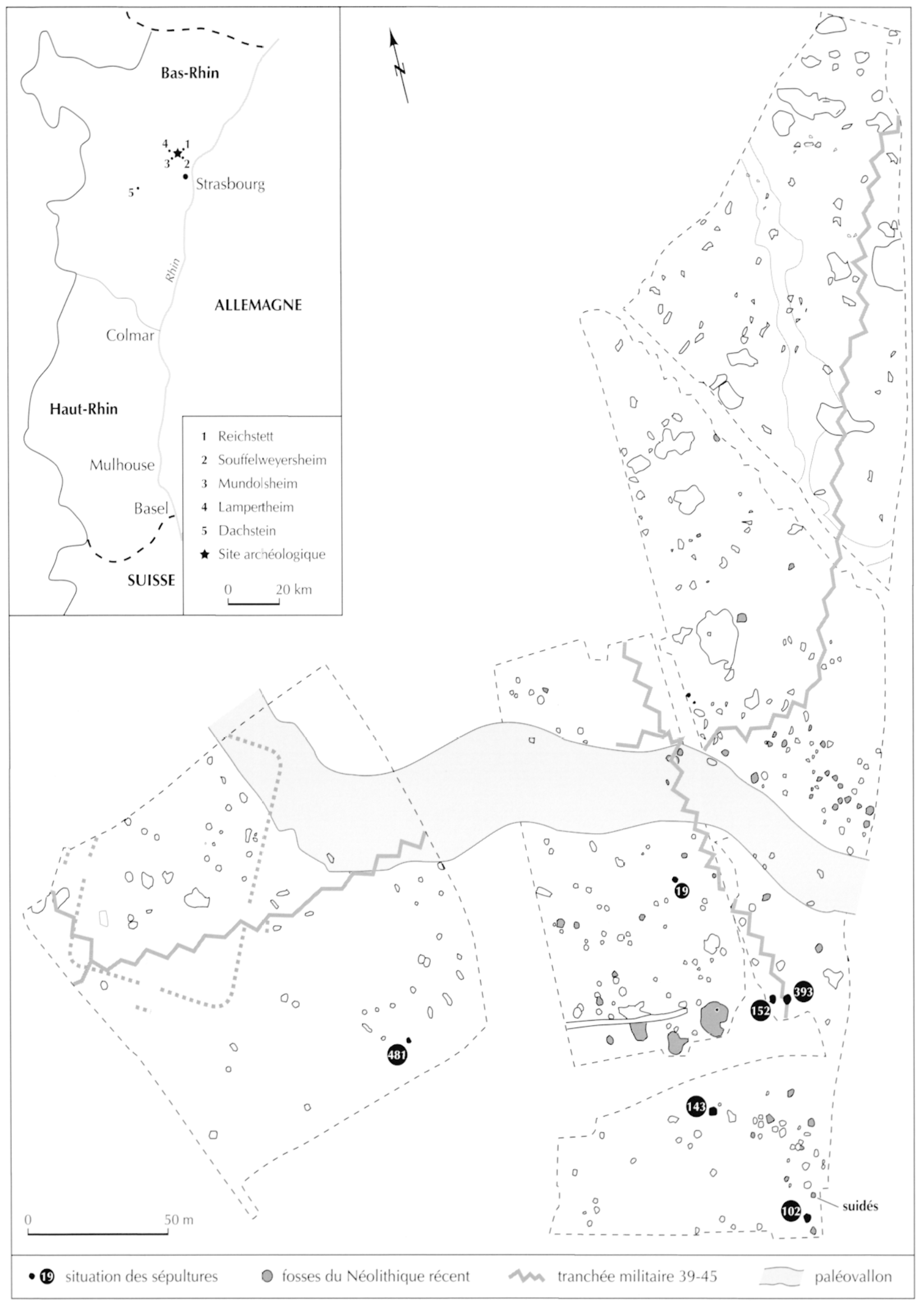

Fig. 1 - Situation des restes humains el orcupation du Nëolithique récent (dessin N. Le Meur, P. Pernot, DAO F. Blaizot). 


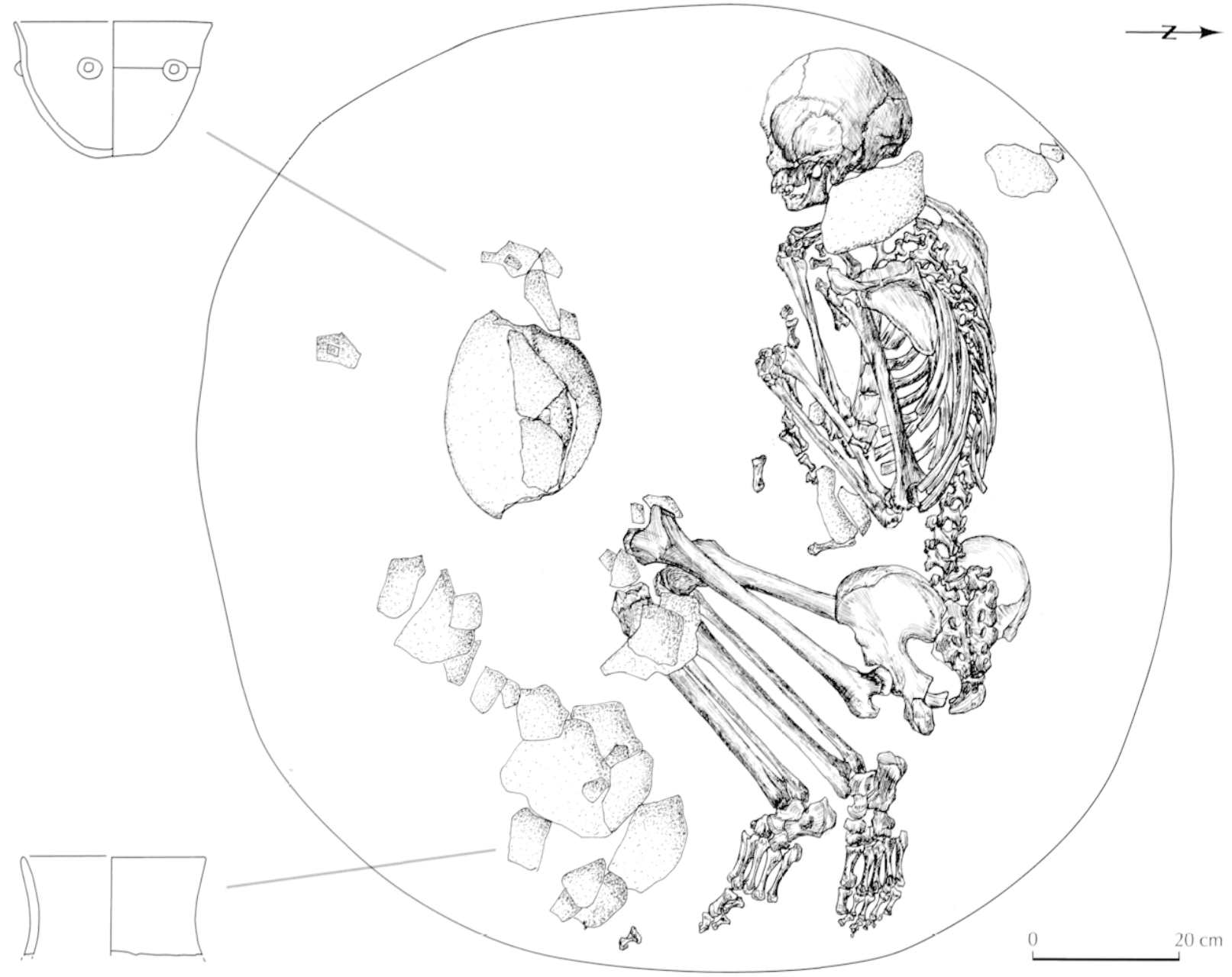

Fig. 2 - Fosse 102, squelette in situ (dessin F. Blaizot).

\section{LES INHUMATIONS EN FOSSES DU NÉOLITHIQUE RÉCENT II}

\section{ANALYSE DU MODE DE DÉPÔT}

\section{LA FOSSE 102}

Les ossements sont inclus dans un sédiment limoneux compact et homogène (loess altéré), d'une fine granulométrie, relativement plastique, qui comprend quelques tessons d'un poids total de $23 \mathrm{~g}$. Le squelette est celui d'un adulte masculin (tabl. I) inhumé sur le côté droit, la tête à l'ouest et les pieds à l'est (fig. 2). Il repose sur le fond d'une fosse circulaire de $1,30 \mathrm{~m}$ de diamètre, conservée sur $0,50 \mathrm{~m}$ de profondeur, dont il occupe la moitié nord ; la moitié sud comporte un vase archéologiquement complet représentant une jatte à deux boutons appariés sous le col et de grands tessons appartenant à une jarre ou grande "bouteille à col " (fig. 3). Les membres inférieurs du squelette sont fléchis, les genoux faisant un angle de $25^{\circ}$. Les deux coudes présentent également une flexion, de $21^{\circ}$ à gauche et de $30^{\circ}$ à droite, et les mains sont ramenées dans la moitié supérieure du corps : la droite se situe directement en aval ${ }^{1}$

1. La position respective des différentes pièces du squelette est décrite par rapport à la position anatomique de référence dans laquelle le squelette est placé debout, les membres en extension parallèles à l'axe longitudinal du corps. Ia nomenclature définit un système de plans horizontaux (perpendiculaires à l'axe longitudinal du corps) et deux systèmes de plans verticaux: les plans sagittaux (dirigés d'aant en arrière dont le plan médian dit plan de symétrie est un cas particulier) 
du menton et la gauche est placée en arrière de l'avantbras droit. Les poignets sont fléchis.

Le sol d'inhumation affecte une forme en légère cuvette, puisque le crâne et les pieds sont situés respectivement $6 \mathrm{~cm}$ et $8 \mathrm{~cm}$ moins profondément que les os coxaux. Les pieds s'appuient contre le bord est de la fosse par leurs phalanges.

L'attitude du corps est responsable de l'importante verticalisation des côtes gauches, résultat de l'affaissement du volume du thorax. À droite, les côtes sont restées bloquées sur le fond de la fosse. La fermeture des angles intersegmentaires est remarquable, notamment au niveau des membres inférieurs, et correspond soit à la seule gravité soit à la poussée progressive des sédiments périphériques durant la décomposition (Duday, 1990).

Le squelette se caractérise par le maintien en connexion d'un certain nombre d'éléments labiles placés en situation instable. On notera tout particulièrement ce phénomène à la scapula gauche, en place sur la face latérale des côtes et restée en connexion avec l'humérus, aux os des poignets et à l'articulation coxofémorale gauche. De même, les pieds sont en connexion stricte malgré leur pendage.

Par ailleurs, des disjonctions d'une amplitude limitée sont observées, telles que la migration de la clavicule gauche en amont de l'épaule et la dislocation de l'articulation persistante des genoux surtout à gauche.

Enfin, des petites pièces ont effectué des déplacements d'une amplitude plus importante. Il s'agit de petits os appartenant aux extrémités, comme le premier métacarpien droit qui s'est déplacé à distance de l'avantbras gauche et le cinquième métacarpien gauche qui se retrouve en avant du coude. De même, la phalange distale de l'hallux droit est éloignée de $10 \mathrm{~cm} \mathrm{du}$ pied.

et, perpendiculaires aux précédents, les plans frontaux (droit ou gauche). Le plan médian distingue un versant droit et un versant gauche; les plans sagittaux autres que le plan médian définissent un versant latéral (le plus éloigné du plan médian) et un versant médial (qui regarde vers le plan médian). Par rapport aux plans frontaux, il existe un versant antéricur et un versant postérieur. Par rapport aux plans horizontaux, la terminologie anatomique distingue les versants supérieur (au-dessus) et inférieur (au-dessous), ce qui entraine une confusion avec la terminologie habituelle en archéologie qui, elle, se rapporte à l'horizontale dans l'espace et non pas à un sujet en position anatomique. C'est pour cela que nous remplacerons les termes " audessus " et " au-dessous " par " cn amont " et " en aval ", l'extrémité amont du corps étant la tête et l'aval correspondant aux pieds.).
Ces différentes informations rendent compte de phénomènes contradictoires. La préservation d'équilibres instables sur les pièces labiles traduit un colmatage progressif du volume du corps, tandis que les ossements qui ont migré en dehors du volume initial du cadavre indiquent que le corps a évolué dans un espace vide. L'action éventuelle d'un fouisseur en espace colmaté ne peut être démontrée dans la mesure où les os déplacés se situent sur le sol d'inhumation et non pas en suspension dans le sédiment, et nous devons dans ce cas privilégier l'hypothèse d'un espace vide autour du corps. Ces dislocations se sont produites en ordre paradoxal, puisqu'on
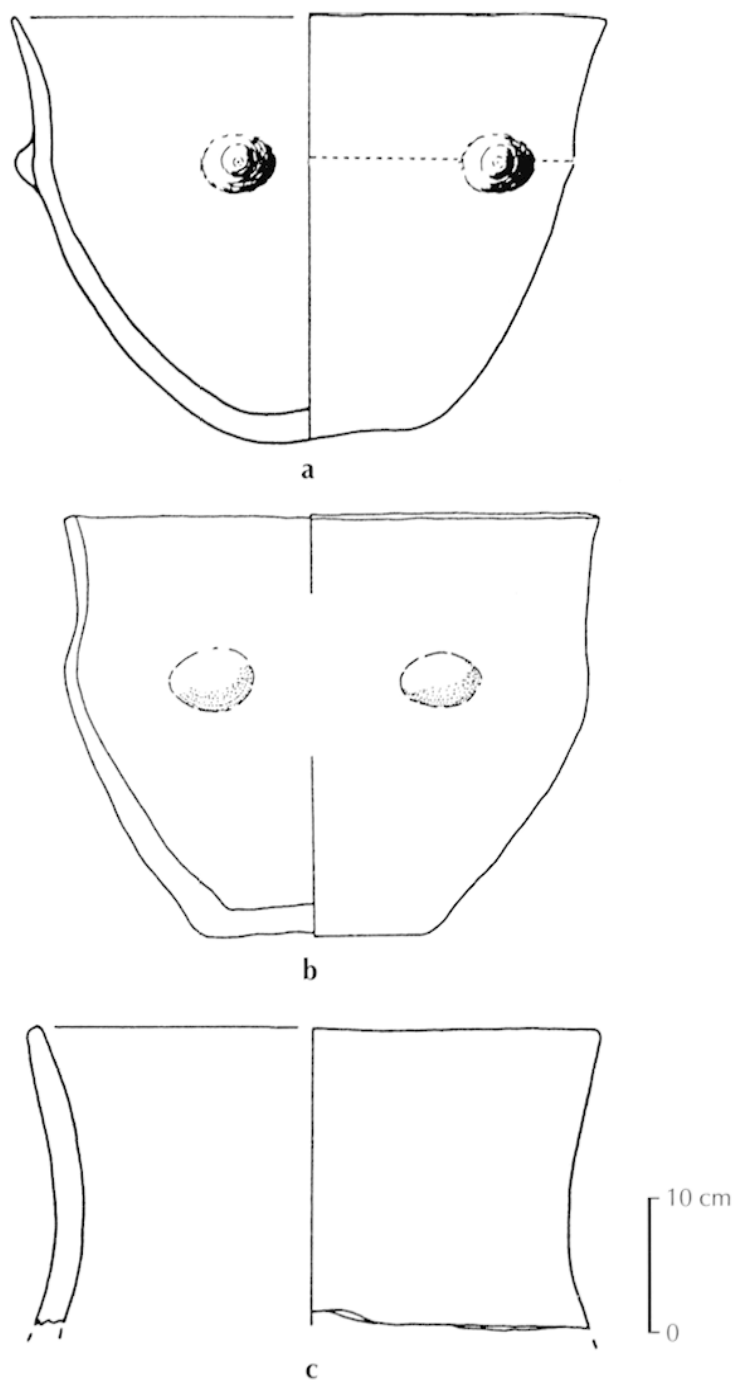

Fig. 3 - Fosse 102, mobilier d'accompagnement et éléments de comparaison : a, Reichstett, jatte à boutons appariés sous le col (dessin T. Logel) ; b, céramique d'Alkofen, d'après Petrasch, 1985. 1986, p. 61 ; c, Reichstell, jarre (dessin T. Logel). 
Tabl. I - Lstimation du sexe et de l'âge au décès des sujets adultes. Pour l'estimation du sexe, les codes sont ceux de Bruzek, 1991 et Bruzek et al., 1996.

$H$ : homme; $F:$ femme ; A : adulte de stade de maturation indéterminé ; AJ : adulte jeune; AM : adulte mature ; coeff. : coefficient ; regr. : régressions; pop. stand. : population standardisée.

\begin{tabular}{|c|c|c|c|c|c|c|c|c|c|}
\hline \multirow[t]{3}{*}{$N^{\circ} \mathrm{SP}$} & \multicolumn{3}{|c|}{ SEXE } & \multirow{2}{*}{\multicolumn{4}{|c|}{$\begin{array}{c}\text { ÂGE ADULTES (sutures crâniennes) } \\
\text { Masset, } 1982\end{array}$}} & \multirow{3}{*}{$\begin{array}{l}\text { 1. SACRUM } \\
\text { Lovejoy et al., } 1985 \\
\text { 2. PUBIS } \\
\text { Katz, Myers-Suchey, } 1986\end{array}$} & \multirow[t]{3}{*}{ Estimation } \\
\hline & \multicolumn{3}{|c|}{$\begin{array}{c}\text { ADULTES SUB-ADULTES } \\
(\text { os coxaux })\end{array}$} & & & & & & \\
\hline & $\begin{array}{c}\text { Bruzek, } \\
1991\end{array}$ & $\begin{array}{l}\text { Bruzek } \\
\text { et al., } \\
1996\end{array}$ & sexe & $\begin{array}{c}\text { coeff. } \\
\text { exo }\end{array}$ & $\begin{array}{l}\text { âge regr. } \\
\text { (pop. stand.) }\end{array}$ & $\begin{array}{l}\text { coeff. } \\
\text { endo }\end{array}$ & $\begin{array}{l}\text { âge regr. } \\
\text { (pop. stand.) }\end{array}$ & & \\
\hline \multicolumn{10}{|c|}{ INHUMATIONS } \\
\hline 19.1 & $\begin{array}{l}\text { Aa1 } \\
\text { Aa1 } \\
-\mathrm{a} 1\end{array}$ & $-1-1+1$ & $\mathrm{~F}$ & 0,2 & 42,2 & 0 & 32,6 & $\begin{array}{l}1: 40-44 \text { ans } \\
2: 37-65 \text { ans }\end{array}$ & $\mathrm{AM}$ \\
\hline 19.2 & $\begin{array}{l}\mathrm{Bb} 2 \\
\mathrm{Bb} 2 \\
--\end{array}$ & $0+1+1$ & $\mathrm{H}$ & 0,1 & 32,7 & 0 & 32,6 & $\begin{array}{l}1: 30-34 \text { ans } \\
2: 19-35 \text { ans }\end{array}$ & AJ \\
\hline 102 & $\begin{array}{l}\mathrm{Bb} 2 \\
\mathrm{Bb} 2 \\
\mathrm{Bb}-\end{array}$ & $+1+1+1$ & $\mathrm{H}$ & 1 & $\begin{array}{c}48,9 \\
\text { (métopique) }\end{array}$ & 0,4 & $\begin{array}{c}25,8 \\
\text { (métopique) }\end{array}$ & $\begin{array}{l}1: 40-44 \text { ans } \\
2: 23-59 \text { ans }\end{array}$ & AM \\
\hline 481 & 1 & +1 - & $\mathrm{H}$ ? & / & / & 1 & 1 & & A \\
\hline \multicolumn{10}{|c|}{ FOSSE 143} \\
\hline D9/C9 & $\begin{array}{ll}\cdots \\
B b 1 \\
\cdots\end{array}$ & $+1 /+1$ & $\mathrm{H}$ & 1 & 1 & 1 & 1 & $\begin{array}{l}1: 45-49 \text { ans } \\
2: /\end{array}$ & $\mathrm{AM}$ \\
\hline $\begin{array}{l}\mathrm{H} 10 / \mathrm{E} 7 \\
\mathrm{~F} 6 / \mathrm{F} 8\end{array}$ & $\begin{array}{l}-\mathrm{a}- \\
\mathrm{Aa} 2 \\
--\cdot\end{array}$ & $-1-1-1$ & $\mathrm{~F}$ & I & 1 & 1 & 1 & $\begin{array}{l}1: 40-44 \text { ans } \\
2: /\end{array}$ & $\mathrm{AM}$ \\
\hline $17 / \mathrm{N} 24$ & $\begin{array}{l}\mathrm{Aa} 1 \\
-\mathrm{a} 2 \\
-\cdots\end{array}$ & $00-1$ & $\mathrm{~F}$ & / & / & / & I & $\begin{array}{l}1: 45-49 \text { ans } \\
2: /\end{array}$ & $\mathrm{AM}$ \\
\hline D11 & $\begin{array}{l}\cdots \\
\cdots \\
\cdots\end{array}$ & $+1+1 /$ & $\mathrm{H}$ & / & / & 1 & 1 & $\begin{array}{l}1: 40-44 \text { ans } \\
2: /\end{array}$ & AM \\
\hline
\end{tabular}

observe une rupture sur l'articulation persistante du genou, tandis que certaines parmi les plus labiles sont respectées. Compte tenu de l'humidité de la région, l'hypothèse d'un colmatage succinct et naturel du cadavre peut être avancée. En effet, des infiltrations d'eau dans un espace vide auraient pour résultat de faire gonfler les particules d'argile qui, en se redéposant, créent une masse suffisante pour combler les vides créés par la disparition des chairs et maintenir les connexions.

L'examen in situ des céramiques placées dans la moitié sud de la fosse appelle les remarques suivantes : la jatte est renversée, son col est cassé et les fragments qui lui correspondent sont absents. Au sud-est de la fosse quinze tessons sont répartis sur une surface de $55 \mathrm{~cm}$ sur $20 \mathrm{~cm}$ selon un axe NE-SO. Ces éléments, qui ne se raccordent pas entre eux, appartiendraient à une même grande jarre incomplète, dont on trouve des morceaux sur le squelette et près du vase. Ils ne reposent pas sur le sol de la fosse mais $8 \mathrm{~cm}$ à $15 \mathrm{~cm}$ au-dessus de celui-ci, ou directement sur les os, et suivent le pendage présenté par le sol, des bords vers le centre. Par ailleurs, leur mode de dispersion dessine un effet de délimitation net sur le côté nord-ouest, en direction du pendage.

Bien que la jarre soit largement incomplète, ses éléments peuvent avoir été déposés intentionnellement ; les arguments sont apportés par l'absence de terre entre 
les tessons et le squelette, et par le fait qu'aucun tesson de ce vase n'ait été retrouvé dans le comblement de la fosse. Ainsi, l'hypothèse selon laquelle il s'agit de fragments résiduels d'origine fortuite n'est pas démontrée. Dans ce cas, le caractère très lacunaire de la jarre signifierait qu'elle a été fracturée à l'extérieur de la fosse et qu'une partie seulement des fragments a fait l'objet d'un dépôt.

On s'interrogera alors sur l'origine des tessons qui se trouvent sur le squelette ; ont-ils été placés ainsi ou sontils en situation secondaire ? À l'appui de la seconde proposition, on remarquera que les fragments sont répartis sur un même axe SE-NO, qui correspond au sens du pendage de la fosse. Nous pouvons alors envisager que les tessons situés à distance de ceux-ci et en l'occurrence autour de la jatte ont été charriés par l'eau; d'ailleurs certains tessons, dont celui qui est plaqué contre le bord nord-ouest de la fosse, sont situés moins profondément que les autres, comme s'ils avaient flotté. Cela supposerait que l'espace vide s'étendait à toute la fosse, et qu'il ne concernait pas uniquement la périphérie du cadavre.

Reste la question de l'effet de délimitation ; traduit-il une limite réelle? Les objets peuvent avoir été placés sur un support, ce qui expliquerait à la fois la position du vase, la situation des tessons de la jarre au-dessus du sol d'inhumation et l'effet de délimitation; le pendage observé sous ces derniers serait le résultat d'un effondrement en sape de la paroi ou du foisonnement de l'argile lessivée près du bord. Néanmoins, si l'on restitue une couverture au-dessus de toute la fosse, l'hypothèse d'un effondrement du mobilier à l'origine placé sur la toiture est encore envisageable. Elle n'explique cependant pas l'effet de délimitation observé sur les fragments de la jarre, à moins que celui-ci ne soit le résultat de la manière dont ce couvercle s'est fracturé ; mais elle est en contradiction avec le mode de dispersion des fragments, qui n'est possible qu'au sein d'un espace totalement vide. Or, si le couvercle s'effondrc, l'espace vide n'est bien entendu pas maintenu.

Nous retiendrons le scénario suivant. Le corps a été déposé dans l'attitude présentée par le squelette, directement sur le sol de la fosse. En avant de ses jambes, des morceaux d'une grande jarre, brisée en un autre lieu, ont été déposés probablement sur un support en matière périssable. En avant de ses genoux, fut placé un vase complet qui reposait peut-être également sur un support puisqu'il a été retrouvé couché. La fosse fut recouverte d'un élément aménageant un espace vide. De l'eau a manifestement pénétré dans la fosse alors qu'elle était encore vide, et que le corps était en cours de décomposition ; cette eau, en drainant des particules d'argile et en favorisant leur foisonnement, serait à l'origine de la migration de certaines petites pièces et du maintien d'ossements placés en situation instable. Durant l'évolution de la structure, les éléments en matière périssable se sont effondrés, précipitant le vase au sol et entraînant un effondrement de la paroi sous le support du mobilier, puis la dispersion des tessons dans le sens de la pente.

\section{LA FOSSE 152}

Le squelette repose sur le fond d'une fosse circulaire d'un diamètre de $2 \mathrm{~m}$, conservée sur une profondeur de 0,59 m depuis le niveau de décapage (fig. 4). Le sol d'inhumation est plat. Les os sont inclus dans un sédiment brun compact et argileux, homogène, de même nature que celui qui comblait la totalité de la fosse, depuis son niveau conservé. Cependant, des plaques de loess plus claires ont été dégagées sur le membre supérieur droit et une partie du crâne, puis sur les genoux et les pieds. Du remblaiement proviennent 6 fragments de faune indéterminés vraisemblablement chauffés (17 g), ainsi qu'une dizaine de tessons de céramique non tournée (49 g), qui ne peuvent être attribués à un contexte chrono-culturel précis. À environ $20 \mathrm{~cm}$ au-dessus du crâne, dans le comblement, se trouve le squelette d'un suidé immature exhumé lors des sondages d'évaluation du site; on ne dispose d'aucune information sur sa position. Ce dernier a été examiné par D. Lalaï (AFAN Rhône-Alpes) ; bien qu'il ne soit pas possible anatomiquement de distinguer ici s'il s'agit de l'espèce sauvage ou domestique, le jeune âge de cet animal, présent dans un tel contexte archéologique, nous ferait pencher plutôt pour la seconde hypothèse, mais l'argument reste faible. Les éléments osseux de cet individu sont pour la plupart bien conservés mais quelques-uns présentent des stigmates d'attaques de radicelles de végétaux. La conservation des connexions dénote un enfouissement rapide. Aucune trace de mise à mort n'est visible. L'observation des stades d'éruption dentaire et d'épiphysation des os indique un âge voisin de 2 mois. Le dépôt de cet animal dans la fosse 152 pourrait être concomitant de l'inhumation ; aucun remaniement du remplissage, qui pourrait suggérer un enfouissement ultérieur d'un individu mort 


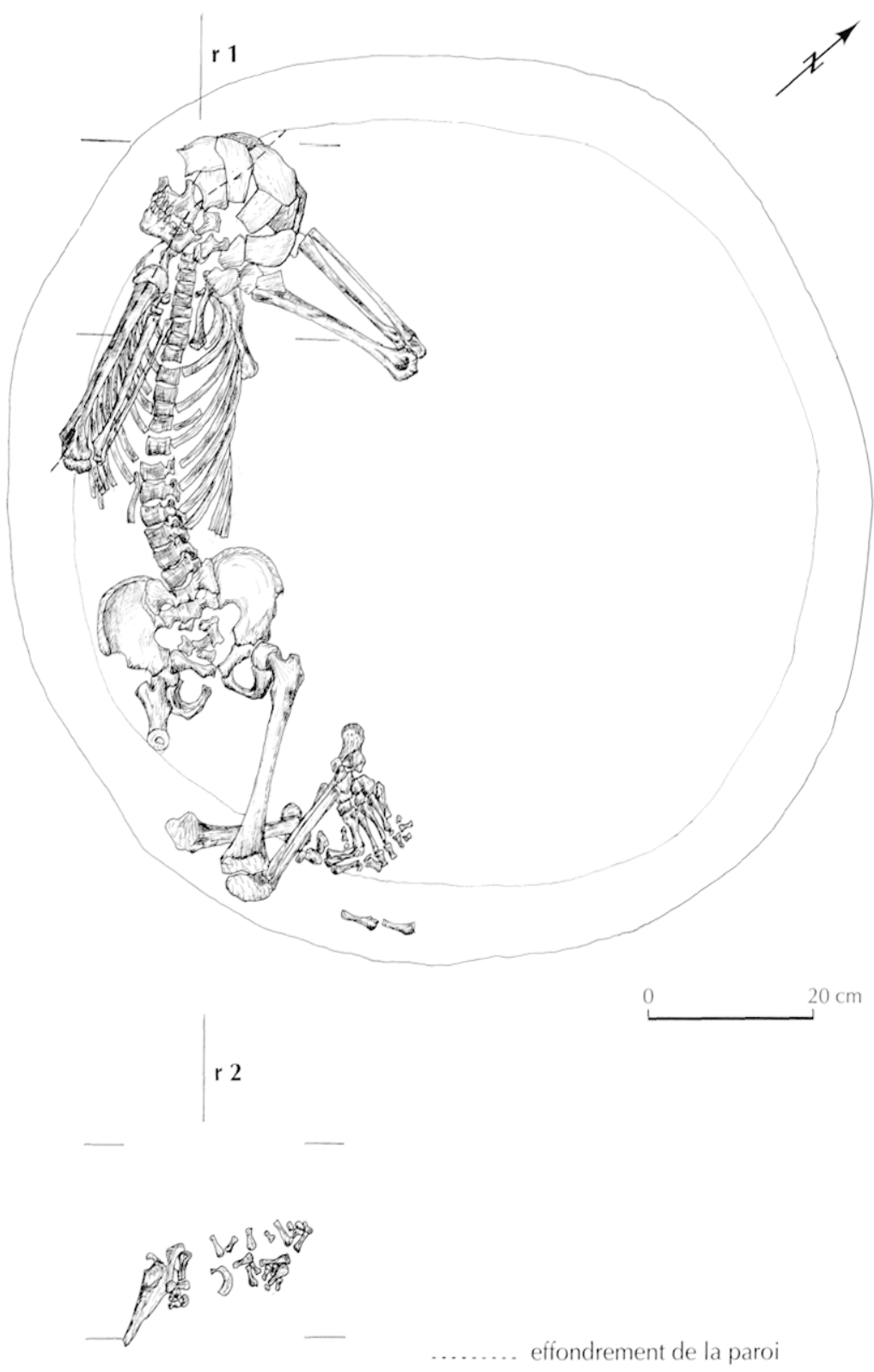

Fig. 4 - Fosse 152, squelette in situ (dessin I: Blaizot). situation des deux premières cervicales indique que cette position est proche de celle du dépôt initial. Ses avant-bras sont ramenés en amont, avec les mains situées dans la région du cou. Le coude gauche, fléchi de $20^{\circ}$, est écarté du corps, puisque le

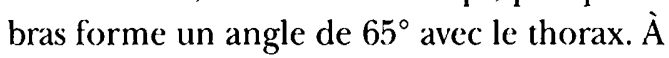
droite, le membre supérieur repose sur la face antéro-latérale des côtes, et la flexion du coude est extrême, avec un angle inférieur à $10^{\circ}$. À ce niveau, la paroi s'est effondrée sur les os (mélange de lœess pur et de loess altéré). Les côtes sont fermées, et le rachis présente une convexité thoraco-lombaire induitc par l'attitude du corps plaqué contre la paroi de la fosse. Les genoux sont fléchis et surélevés, appuyés contre le bord sud-est de la fosse, l'angle formé par le genou gauche est de $28^{\circ}$ et celui du genou droit, restitué, de $90^{\circ}$.

Globalement, les articulations sont bien préservées. Le squelette se caractérise par une forte constriction au niveau des épaules, qui se traduit par la verticalisation complète des clavicules et par la fermeture du thorax. Ce phénomène est dû à l'attitude du sujct, l'épaule droite étant en appui contre la paroi comme l'indiquent la position de la scapula, de chant, et celle du membre supérieur gauche qui se présente en abduction avec participation scapulo-humérale. L'effet de contrainte observé sur l'épaule droite est important, puisque l'humérus apparaît en vue postéro-latérale ; il est de toute évidence causé par le poids du sédiment, engendré par l'effondrement de la paroi de la fosse sur la moitié supérieure du squelette.

de causes naturelles, n'est en effet signalé, et il est également possible d'envisager a priori que l'on a affaire ici à un dépôt d'offrande.

Le squelette humain est celui d'un sujet biologiquement immature, décédé entre 11,5 et 16 ans (tabl. II). Il est placé dans la moitié sud-ouest de la fosse, plaqué contre sa paroi, et se présente en decubitus dorsal, la tête au nord-ouest et les pieds au sud-est. Il épouse la convexité du bord de la fosse et son attitude générale est la suivante: le crâne est en vue latérale gauche et la
Deux phénomènes retiennent notre attention. Le premier s'est produit au niveau de la tête et du cou ; il est d'abord illustré par la dislocation de la troisième vertèbre cervicale, qui se présente en vue caudale, tandis que l'axis est globalement en vue antérieure, comme la quatrième. D'autre part, les os des mains sont fortement dissociés sous le crâne, les épaules et le cou (cervicales et premières thoraciques). Enfin, les dernières cervicales et la première thoracique reposent $2,5 \mathrm{~cm}$ moins profondément que l'occipital. L'éparpillement des os des mains, et 
Tabl. II - Estimation de l'âge au décès des sujets biologiquement immatures.

\begin{tabular}{|c|c|c|c|c|c|}
\hline $\mathrm{N}^{\circ} \mathrm{SP}$ & \begin{tabular}{|l|}
\multicolumn{1}{|c|}{ ÂGE DENTAIRE } \\
1. Moorrees et al., 1963 a et b \\
2. Schour, Massler, 1940
\end{tabular} & $\begin{array}{l}\text { LONGUEUR DIAPHYSAIRE (en mm) } \\
\text { U : ulna / } \mathrm{R}: \text { radius / } \\
\mathrm{F}: \text { fémur } / \mathrm{T}: \text { tibia }\end{array}$ & $\begin{array}{l}\text { ÂGE DIAPHYSAIRE } \\
\text { Sundick, } 1978\end{array}$ & $\begin{array}{c}\text { MATURATION OSSEUSE } \\
\text { Birkner, } 1980\end{array}$ & $\begin{array}{l}\text { CLASSE D'ÂGE } \\
\text { en années révolues }\end{array}$ \\
\hline \multicolumn{6}{|c|}{ INHUMATIONS } \\
\hline 152 & $\begin{array}{l}1: 11,5-15 \text { ans } \\
2: 12-16 \text { ans }\end{array}$ & U:198/R:174/F:345/T:276 & $12-15$ ans & $>9-14$ ans & $10-14 / 15-19$ \\
\hline 393 & I & 1 & 1 & $<20 / 20-22$ ans & $15-19 / 20-25$ \\
\hline \multicolumn{6}{|c|}{ FOSSE 143} \\
\hline $143 \mathrm{~A}$ & $1 / 2: 1,5-2,5$ ans & / & / & $1-3$ ans & $1-4$ \\
\hline $143 B$ & $1 / 2: 1,5-2,5$ ans & 1 & 1 & $1-3$ ans & $1-4$ \\
\hline $143 \mathrm{C}$ & $1: 6$ mois-1ans & / & / & / & 0 \\
\hline $143 \mathrm{D}$ & $\begin{array}{l}1: 3-5 \text { ans } \\
2: 4-5 \text { ans }\end{array}$ & / & 1 & $>2-<6-7$ ans & $1-4 / 5-9$ \\
\hline
\end{tabular}

particulièrement la migration des phalanges de la main droite sous les vertèbres, ainsi que l'effondrement de la troisième cervicale nécessitent la présence d'un espace vide sous la tête. L'hypothèse d'un espace vide secondaire créé par la disparition d'un élément en matière périssable n'est pas recevable puisque les connexions entre le bloc crânio-facial, l'atlas, l'axis et la mandibule sont parfaitement maintenues. Compte tenu de la situation du crâne au contact du bord de la fosse, nous envisagerons plutôt que ces remaniements sont dus au fait que la tête du cadavre s'appuyait, à l'origine, contre la paroi de la fosse, ce que confirme l'aspect du crâne, qui paraît " enfoncé " entre les épaules.

Le second phénomène remarquable concerne les pieds. Les articulations sont préservées sur les deux ensembles, mais les deuxième et cinquième métatarsiens droits sont disloqués, perchés $6,5 \mathrm{~cm}$ à $9 \mathrm{~cm}$ au-dessus des autres. Le reste du pied en connexion apparaît "affaissé " puisque sa face plantaire présente une concavité exagérée, l'extrémité distale des métatarsiens étant orientée de manière oblique par rapport à l'axe donné par le tarse ; sur le même pied, on remarque que le tibia est passé sur la face médiale du tarse, et qu'une phalange est tombée en aval (les autres ont été déplacées à la fouille). Là encore, un effondrement de la paroi a été mis en évidence, les os des pieds étant pris dans un sédiment mixte composé de lœess pur et de lœess altéré. Il apparaît probable, au vu de ces différentes informations, que le pied droit s'appuyait à l'origine quasi verticale- ment contre la paroi de la fosse, et qu'il s'est progressivement affaissé sur le sol; seuls les deux métatarsiens latéraux, plaqués contre le bord de la fosse, sont restés piégés à ce niveau. Par ce dernier point, et par le fait que les deux os reposent exactement à la même cote, cette hypothèse paraît plus envisageable que celle de l'action d'un fouisseur.

Comme pour le squelette de la fosse 102, les arguments de l'interprétation du milieu de décomposition ne sont pas tous convergents. Le maintien en connexion anatomique d'éléments en situation instable tels que l'occlusion dentaire, l'épaule et le coude droit et les genoux implique un recouvrement quasi immédiat du corps; en revanche, les remaniements décrits ci-dessus, qui rendent compte de mouvements (limités) hors du volume initial du cadavre, signifient que le corps évoluait à l'air libre. Cette deuxième proposition sera retenue puisque nous avons vu que la paroi de la fosse s'était effondrée directement sur les os, ce qui nécessite un espace vide ; on précisera enfin à cet égard que les équilibres instables préservés concernent justement les ossements situés contre la paroi.

Le squelette ne présente pas de distorsion majeure par rapport à l'attitude initiale du cadavre. Il a été placé ainsi, le corps épousant étroitement le bord de la fosse. L'ensemble a peut-être été recouvert d'un élément en matière périssable ménageant un espace totalement vide, aucun effet de paroi n'indiquant la présence initiale d'un contenant limité au corps. L'examen du côté gauche du 


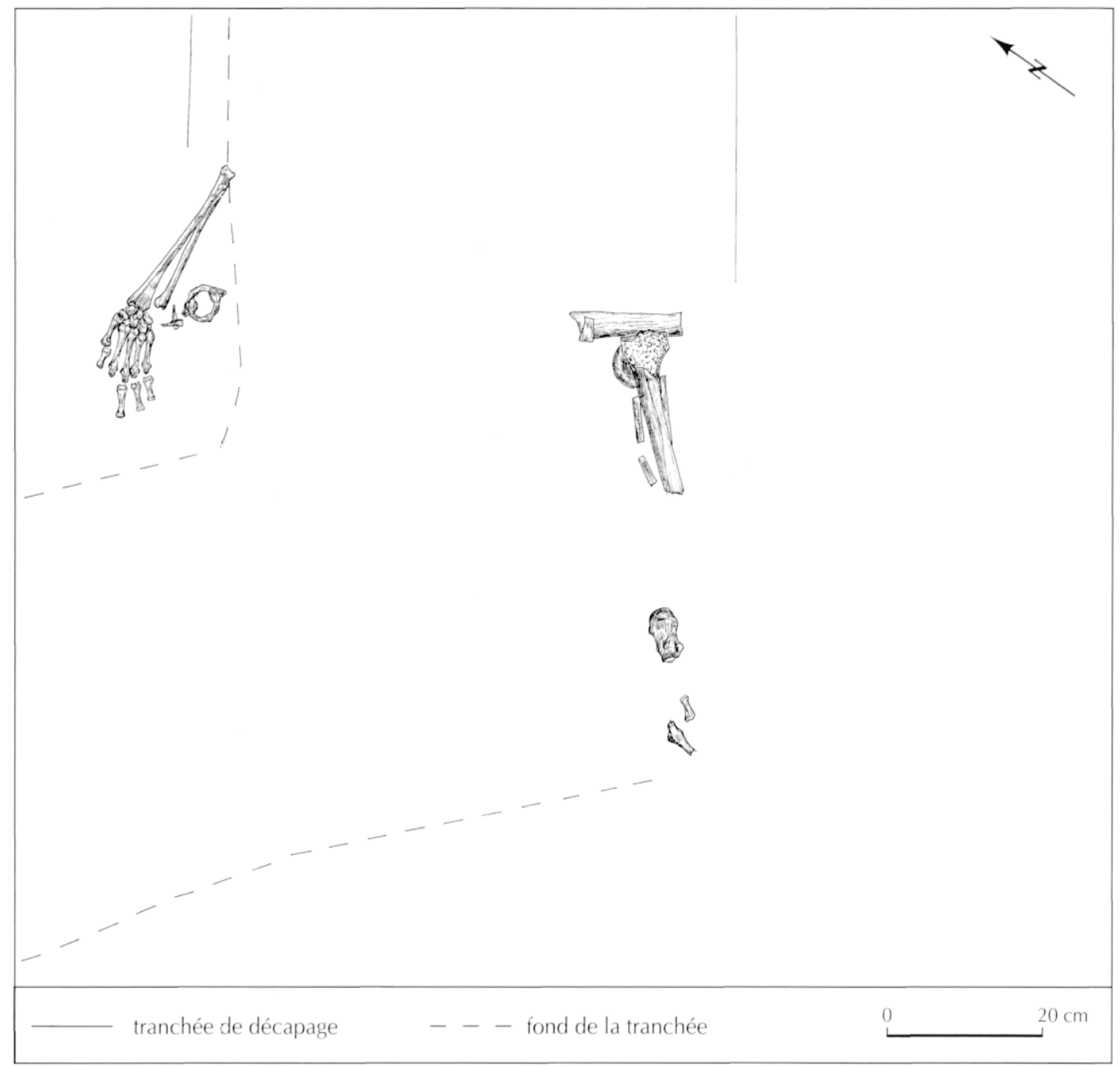

Fig. 5 - Fosse 393, squelette in situ (dessin F. Blaizot).

squelette montre que le coude et les phalanges du pied s'arrêtent sur une même limite, parfaitement parallèle au corps. L'hypothèse d'un aménagement plus complexe de la fosse, réservant un tiers à l'inhumation et les deux tiers à un autre usage, ne peut toutefois pas être démontrée sur cette seule base, en l'absence d'effet de paroi sur les os concernés. En tout cas, aucun objet ne se trouvait dans la partie non occupée par le squelette.

Comme dans tous les cas de dépôts humains en fosses de type domestique, se pose la question du caractère rituel ou non de celui du suidé. Si l'on considère que la fosse n'a pas été remblayée au-dessus de l'hypothétique couvercle, l'absence de vestiges typiques de rejets volontaires indiquerait que le colmatage s'est produit naturellement, par érosion ; il est alors permis d'envisager que l'on a profité de cette cavité durant le temps où elle se comblait partiellement, pour se débarrasser d'un animal mort. Mais la présence d'un espace vide dans le tiers inférieur de la fosse nous invite à considérer la situation archéologique du suidé sous un autre angle. En admettant qu'il ait été déposé sur le couvercle de la fosse, le fait qu'il ne se soit pas effondré sur le squelette de l'enfant peut s'expliquer par le mode de colmatage de l'espace dans lequel le corps évoluait ; on a vu que dans les fosses 102 et 152, ce colmatage s'est tout d'abord produit par l'eau, par des ruissellements le long des parois et par un foisonnement de l'argile sur le fond, puis par l'effondrement en sape des parois. Or, le suidé se trouvait $20 \mathrm{~cm}$ au-dessus du crâne, c'est-à-dire tout près de la paroi est de la fosse, à un endroit où celle-ci s'est 
incontestablement effondrée; ainsi, le suidé pourrait bien avoir été placé à l'origine sur le couvercle, et ne pas être tombé sur le squelette sous-jacent, parce qu'à ce niveau ce dernier était déjà en partie colmaté par l'effondrement de la paroi. Le résultat donne l'impression que le suidé fut déposé ultérieurement dans le comblement de la fosse.

Bien entendu, il s'agit là d'une possibilité d'interprétation, dont l'argumentation n'est pas irréfutable.

\section{LA FOSSE 393}

La fosse est largement entaillée par une tranchée militaire pratiquée au cours de la Seconde Guerre mondiale. Ses bords sont toutefois conservés au nord-est et au sud-ouest, permettant de restituer un diamètre de $0,95 \mathrm{~m}$. Du fait de ces destructions, le squelette est largement lacunaire (fig. 5). Les os, apparus au décapage mécanique, sont inclus dans un sédiment argilolimoneux brun qui ne comporte aucun matériel résiduel. Ils reposent à environ $50 \mathrm{~cm}$ au-dessus du fond de la fosse, conservée sur une profondeur de $0,68 \mathrm{~m}$.

Le squelette est celui d'un jeune adulte (tabl. II) dont il ne reste que la main et l'avant-bras droits, l'atlas, deux dents monoradiculées supérieures, et des éléments appartenant à la jambe et au pied gauches.

Les os relevant de la moitié supérieure du corps se trouvent dans la moitié ouest de la fosse, tandis que ceux qui proviennent de la moitié inférieure sont à l'opposé. L'avant-bras et la main se présentent par leur face antérieure, plaqués contre la paroi. Sur le sol d'inhumation et en situation médiale par rapport à ces derniers, reposent l'atlas en vue crânio-latérale gauche et les dents, indiquant de toute évidence l'attitude initiale de la tête. La situation respective des éléments des membres inférieurs ne permet pas de restituer leur attitude primitive parce qu'ils se trouvent en situation paradoxale, tant dans leur position les uns par rapport aux autres, que dans leur orientation. Seule leur localisation rend compte de certaines caractéristiques originelles du dépôt ; considérée par rapport à l'emplacement des os de la moitié supérieure, elle indique que le corps a été placé dans une position fléchie, la distance entre ces différents segments étant courte.

Le corps a été déposé dans une attitude fléchie ou contractée à l'intérieur d'une fosse circulaire d'un diamètre relativement faible, les membres plaqués contre

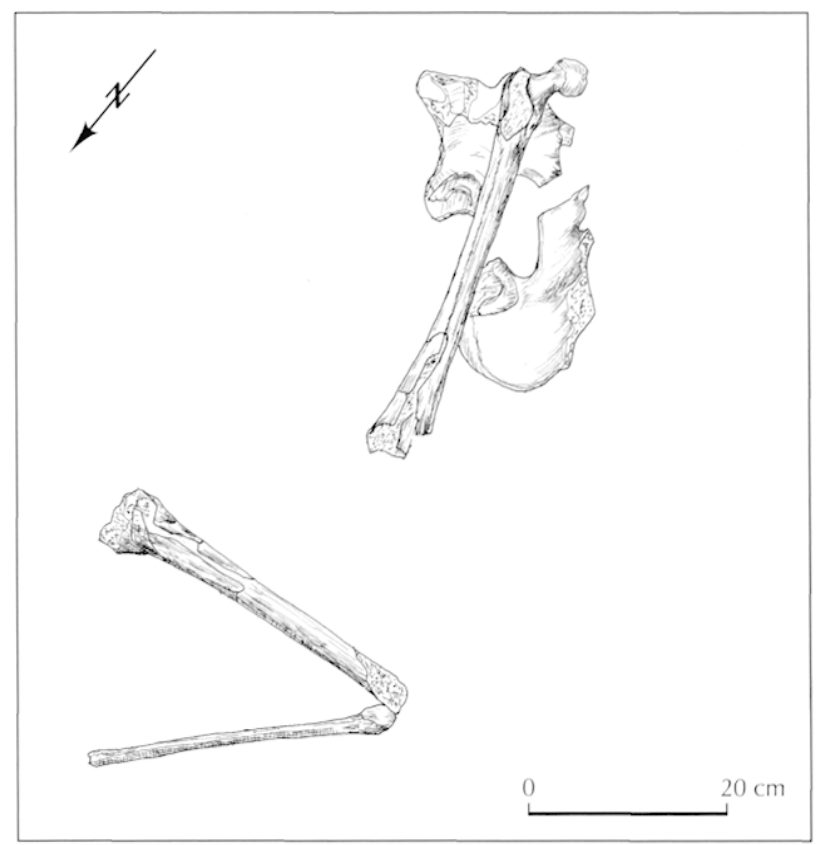

Fig. 6 - Fosse 481, squeletle in situ (dessin F: Blaizot).

les parois, la tête reposant dans le creux de l'avant-bras droit. Les os de la main reposent contre le bord de la fosse; le maintien de leurs connexions anatomiques, malgré cette situation instable, n'est toutefois pas l'indice indiscutable d'une inhumation en pleine terre, les ruissellements de l'eau chargée en particules argileuses pouvant suffire à colmater instantanément les espaces libérés par la décomposition des chairs, peu volumineuses sur les extrémités. Ainsi, les éléments dont on dispose ne permettent pas de discuter le milieu de décomposition du cadavre, et donc de discuter le mode de fonctionnement de la fosse.

\section{LA FOSSE 481}

La fosse n'est conservée que sur une hauteur de $10 \mathrm{~cm}$ et sur une surface de $1,80 \mathrm{~m}$. Sa forme reste incertaine. Elle est recoupée par une fosse qui comporte de la céramique datée de l'Âge du Bronze final IIIb. Les ossements sont inclus dans un limon brun clair homogène, qui comporte quelques tessons de céramique non tournée.

Le dépôt se compose des deux os coxaux et du membre inférieur gauche (fig. 6). Il s'agit des restes d'un sujet adulte (tabl. I). 

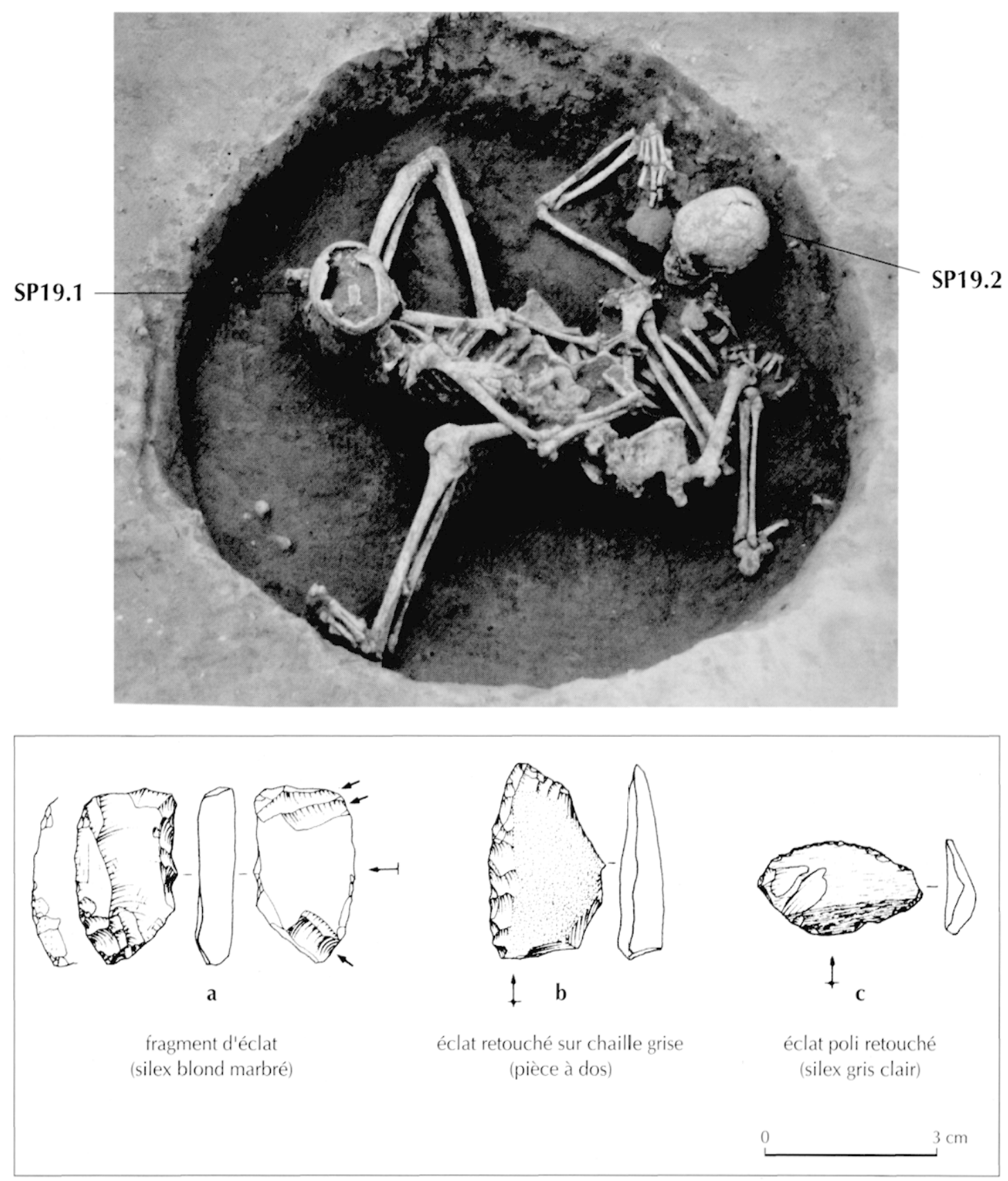

Fig. 7 - Fosse 19, squelettes 19.1 et 19.2 in situ, el matériel lithique (photo A. Vignaud, dessins S. I.ancelot).

Les os coxaux se présentent en situation respective de logique anatomique. Ils sont orientés au nord par leur bord supérieur. Le gauche n'est pas en connexion avec son fémur, qui repose en avant de cet ensemble et est orienté perpendiculairement à l'axe longitudinal du corps défini par les os coxaux. En aval et au nord de l'extrémité distale du fémur, se trouvent les deux os de la jambe gauche, dont l'extrémité proximale est dissociée.
Ces pièces reposent globalement au même niveau, les variations n'excèdent pas $4 \mathrm{~cm}$.

Seule la situation des os coxaux laisse envisager qu'il s'agit d'une sépulture primaire, argument qui reste bien faible; toutefois, malgré la disjonction de leur partie proximale, les os de la jambe ont également une position respective cohérente. L'hypothèse d'une sépulture primaire peut alors être retenue, les os ayant peut-être 
été bouleversés par le creusement de la fosse, repéré au ras du coxal et du fémur gauches. Le remaniement complet du membre inférieur droit, comme l'absence du gauche indiqueraient que l'intervention a touché l'ensemble des vestiges au-delà même de la limite ouest reconnue de la fosse protohistorique; de ce fait, on peut envisager que cette dernière a une emprise plus large dans sa partie supéricure, et donc que sa paroi est très oblique à ce niveau.

Seule la situation respective des deux coxaux pourrait être compatible avec ce qu'elle devrait être sur le cadavre. En revanche, les os longs ont été déplacés, et il n'est pas possible de restituer l'attitude originelle du corps, ni le milieu de décomposition.

\section{LA FOSSE 19}

Cette sépulture a été fouillée durant la phase de diagnostic conduite par A. Vignaud au printemps 1997 (Vignaud el al., 1997, p. 23-27). Nous disposons de quelques photographies non verticales (fig. 7), de la description et de l'interprétation qu'il a réalisées de la structure et du mode d'inhumation.

La fosse, conservée sur une profondeur de $0,87 \mathrm{~m}$, a un diamètre de $1 \mathrm{~m}$ et son profil est en cuvette. Elle est remplie d'un sédiment brun argileux caractérisé comme un loess altéré légèrement organique, qui comprend du matériel résiduel du Néolithique récent (céramiques et outils du Michelsberg). Ce remplissage est homogène de bas en haut. À environ $40 \mathrm{~cm}$ en dessous du niveau d'ouverture conservé, inclus dans cette couche unique, reposent deux squelettes adultes placés l'un sur l'autre sans sédiment intermédiaire. Le fond de la fosse est situé à peu près $47 \mathrm{~cm}$ plus bas et livre un outil sur lame appointée, portant des retouches marginales unilatérales, ainsi qu'un éclat de quartzite marqué de traces de débitage.

Le niveau d'inhumation affecte un plan incliné en direction du nord et du nord-est.

Le squelette d'un adulte masculin (tabl. I) repose sur ce niveau, en decubitus, la tête au nord-est et les pieds au sud-est (SP19.2). Son crâne apparaît en vue supérieure, l'occipital plaqué contre le bord de la fosse. Le membre supérieur droit est fléchi de $45^{\circ}$, l'extrémité distale de l'avant-bras s'appuyant contre la paroi de la fosse. La main, fléchie en dedans, est en connexion stricte. À gauche, le coude est en hyperflexion, la main venant au contact de l'épaule homolatérale sur laquelle elle s'est effondrée. Le membre inférieur gauche est en légère flexion, qui se traduit principalement par une surélévation du genou, tandis que le droit forme un angle inférieur à $25^{\circ}$. Il n'existe aucune mise à plat des volumes, tant sur le thorax que sur le bassin.

Le second squelette est celui d'un adulte féminin (tabl. I), placé tête-bêche et directement sur le précédent (SP19.1). Il repose sur son côté gauche, la main droite posée en avant de l'abdomen et la gauche refermée sur sa cuisse homolatérale. Les membres inférieurs sont fléchis, le gauche en situation proximale par rapport au droit.

Les connexions anatomiques sont bien maintenues sur les deux squelettes. On notera tout particulièrement la préservation d'éléments placés en équilibre instable, tels que le rachis cervical du squelette SP19.1, sa main droite, sa patella droite, ou encore les mains de l'autre squelette placées sur sa cuisse, dont l'une est de chant, et enfin son épaule et son coxal droits verticalisés. Aucune pièce osseuse n'a non plus roulé au nord-est, en direction du pendage. La main gauche du squelette SP19.2 constitue les seuls éléments disloqués.

Par ailleurs, les parties respectives des deux sujets qui se trouvent en contact ne présentent aucun remaniement, à l'exception justement de la main gauche de SP19.2. L'examen détaillé de ce secteur montre que les os se sont effondrés contre le genou droit du squelette SP19.1. Le fait que ces os dissociés reposent tous au même niveau, et qu'ils ne sont pas éparpillés sur le sol ou à travers le remblaiement, indique que le remaniement est le résultat de la décomposition du genou de SP19.1, qui a créé un espace vide secondaire, et non pas la conséquence de l'installation différée de l'autre cadavre.

L'ensemble de ces informations nous conduit à interpréter ces dépôts comme étant simultanés, l'installation de l'individu SP19.1 n'ayant pas bouleversé le squelette de SP19.2, et les deux corps s'étant manifestement décomposés à la même vitesse comme l'indiquent les dislocations enregistrées sur la main gauche de 19.2.

Les événements taphonomiques ont été interprétés par A. Vignaud comme significatifs d'une décomposition en milieu colmaté, en argumentant que les connexions anatomiques sont maintenues sur les pièces labiles placées en équilibre instable. Le phénomène est en effet particulièrement remarquable sur la main droite du squelette 19.2, sur le côté droit du premier, et sur toutes 
Tabl. III - Le traitement des corps humains en Europe de l'Est au Néolithique récent et au Néolithique final (réalisation F. Blaizot).

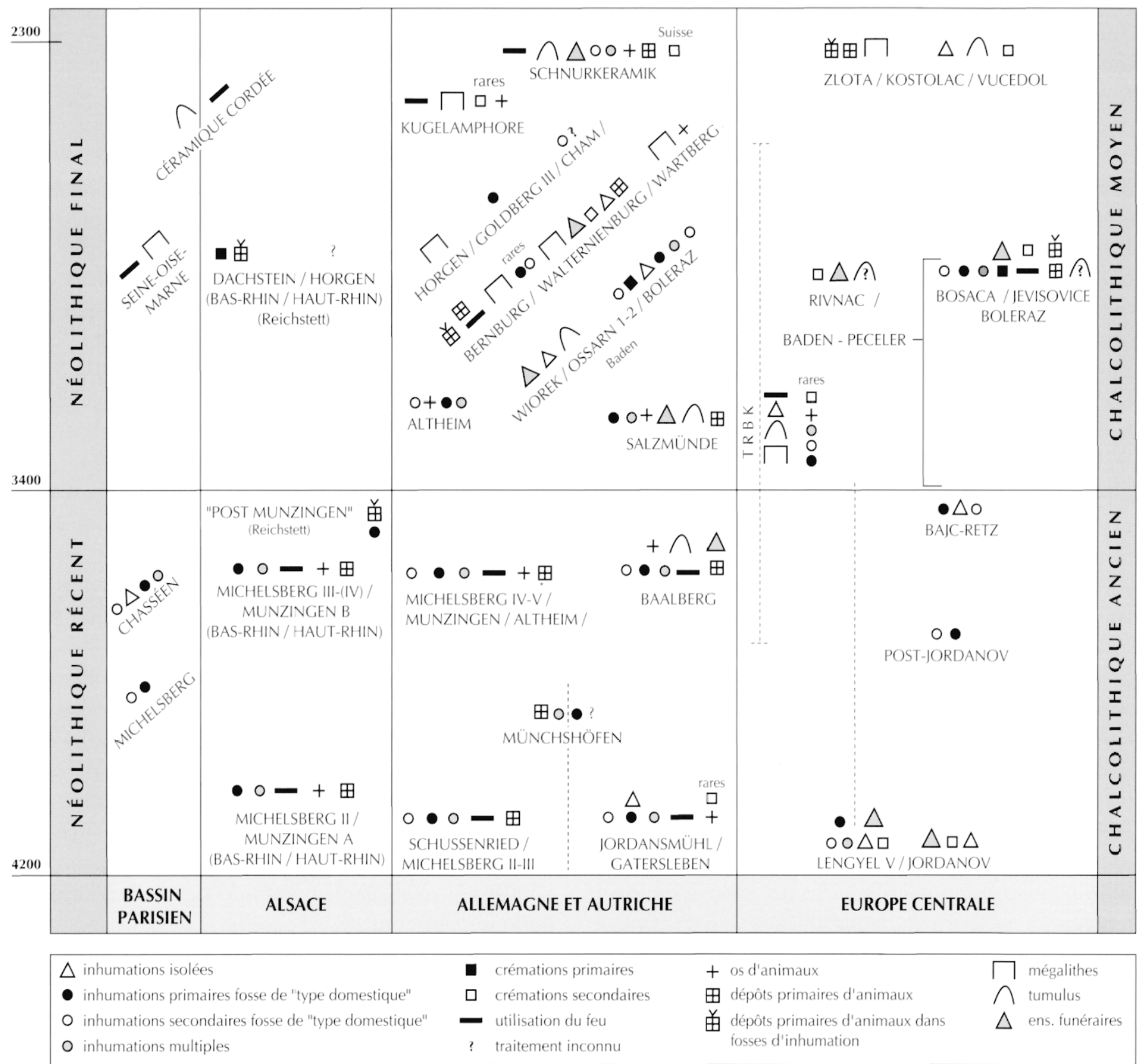

les parties labiles qui auraient dû se trouver déstabilisées par la décomposition du corps sous-jacent. Dans l'hypothèse d'un espace vide, la masse de chairs constituée par les deux sujets paraît trop importante là où ils se trouvent en contact pour estimer que des ruissellements d'une eau chargée en particules argileuses aient été suffisants pour colmater les espaces libérés par leur décomposition. L'hypothèse, acceptable pour les os des extrémités situés contre les parois, est plus difficile à démontrer pour le centre de la fosse, même si l'on envisage un colmatage par la base. Nous n'avons donc pas d'arguments à opposer à l'interprétation qu'a donnée A. Vignaud d'une décomposition en espace colmaté.

A. Vignaud s'est également interrogé sur la destination primaire de la fosse. Dans la mesure où les squelettes ne reposent pas sur le fond, et où le remplissage est exac- 
tement de même nature sous et sur ces derniers, il a émis l'hypothèse de la réutilisation d'une fosse dont le comblement aurait été recreusé pour installer ces deux sujets. Aucun argument ne vient réfuter cette interprétation, mais aucun élément ne peut, non plus, l'argumenter.

\section{ATTRIBUTION CHRONOCULTURELLE}

Dans la série, le squelette de la fosse 102 est le seul à avoir fait l'objet d'une datation par la méthode du radiocarbone ${ }^{2}$. La date obtenue est Ly-9 198, 4825 \pm 35 BP, soit cal. 3682-3531 avant J.-C., le maximum de probabilité se situant autour de 3637 et de 3549 avant J.-C. L'appartenance chronoculturelle est donc, pour l'Alsace, la fin du Néolithique récent II.

Les deux céramiques qui accompagnent le squelette posent des problèmes d'identification (fig. 3) ; la jarre n'est pas particulièrement spécifique et pourrait appartenir aux cultures Michelsberg et Munzingen, tandis que la jatte ne rencontre aucun parallèle dans ces deux cultures. Cette dernière, de couleur noire, possède un fond quasi plat et un col plutôt ouvert; une rupture, plutôt qu'une véritable carène, marque le col, flanqué à sa base de deux boutons appariés. La plupart des récipients que présente $\mathrm{J}$. Lüning pour la culture de Michelsberg ${ }^{3}$ montrent un col moins haut et souvent plus ouvert que le vase de Reichstett; ils offrent une carène plutôt qu'un épaulement (Lüning, 1967). On note une quasi-absence de mamelons sur ce type de forme dans les productions michelsberg, et, dans les rares profils proches de celui de Reichstett, les fonds sont concaves (Lüning, 1967, fig. 23 et 75). Dans le Néolithique moyen bourguignon, les épaulements sont beaucoup plus marqués, le col est droit ou légèrement rentrant et les mamelons sont situés sous l'épaulement (Pétrequin, 1989, p. 275) ; ils diffèrent notamment par l'absence du petit " cordon » qui marque l'épaulement dans notre exemplaire.

Les séries les plus représentatives de la culture de Pfyn, offrent en revanche des comparaisons positives

2. Centre de datation par le radiocarbone, université Claude Bernard, L.yon 1 .

3. Je remercie P. Pétrequin pour l'analyse qu'il a effectuée de notre céramique, et pour les comparaisons qu'il a discutées avec les cultures de Michelsberg, du NMB et de Pfyn. avec la jatte de Reichstett (Winiger, 1971, fig. 22 et 24 ; Gross, Bleuer, 1992, fig. 49). Dans la série de Zürich, on remarque un récipient à fond plat sans décor plastique (Gross, Bleuer, 1992, fig. 49) et un autre, à épaulement, qui possède comme celui de Reichstett un effet de cordon horizontal (op. cit., fig. 49.13). Ils appartiennent au niveau 4, dans un ensemble céramique qui évoque le Pfyn récent, soit le deuxième quart du $\mathrm{IV}^{\mathrm{c}}$ millénaire. La série de Thayngen-Weier possède plusieurs vases proches de celui de Reichstett, sans décor plastique, à fond plat ou aplati, avec un effet de cordon horizontal (Winiger, 1971, fig. 24) ; ces vases ont des mamelons perforés verticalement placés sous l'épaulement, mais aussi parfois des mamelons non perforés. Les fonds aplatis sont les plus fréquents, comme dans la jatte de Reichstett; ils sont datés du Pfyn classique, autour de 3800-3600 avant J.-C.

Nous avons enfin trouvé une forme vraiment semblable à celle de Reichstett dans des productions de la culture d'Altheim, en Bavière méridionale, culture absente en Alsace (fig. 3 ; Petrasch, 1985-1986, p. 61, n 1 et p. 69, fig. 15). On y rencontre ces jattes de couleur noire montées avec des colombins; elles ont des parois légèrement obliques, sont munies de boutons sous le col et leur plus grand diamètre se situe sur le bord (Petrasch, 1985-1986, p. 70). Cette culture, en partie contemporaine du Michelsberg (phases IV et V) et du Néolithique final (tabl. III), présente des liens à la fois stylistiques et structurels avec la fin du Pfyn suisse (moment de cette culture où l'on rencontre une poterie assez grossière pourvue de mamelons placés sous le rebord) et avec les cultures de Salzmünde et de Boleràz.. Sur les sites bavarois d'Alkofen et d'Altheim, ce type de vase représente $10 \%$ à $12 \%$ de la production céramique (Petrasch, 1985-1986, p. 72).

Les objets lithiques retrouvés dans le fond de la fosse 19 sont indatables (fig. 7) ; d'après N. Le Meur (1999-2000), ils représentent une industrie peu caractéristique, sur des matériaux utilisés dans tout le Néolithique. Néanmoins, il semblerait que l'utilisation d'éclats, voire d'éclats récupérés, est assez fréquente au Néolithique récent ; le fragment de silex poli, tout particulièrement, proviendrait éventuellement d'une hache ${ }^{4}$.

Les inhumations SP102, SP152, SP393 et SP19 peuvent faire partie d'un même ensemble, caractérisé

4. Information $\mathrm{N}$. Le Meur : il reste toutefois difficile de le démontrer. Les haches de silex sont caractéristiques du Néolithique récent-final. 
par des dépôts primaires pratiqués dans des fosses circulaires. Il est possible de leur rattacher la sépulture 481 , si l'on admet que l'argument de la relation de logique anatomique, entre les deux coxaux d'une part et entre les os de la jambe d'autre part, est suffisant pour estimer qu'il s'agit d'un dépôt primaire ; sa situation stratigraphique est compatible avec l'hypothèse de sa contemporanéité avec les inhumations du Néolithique. Toutefois, son emplacement, à l'écart des autres et dans un secteur vierge de tout autre vestige du Néolithique récent, minimise les probabilités de son appartenance à l'ensemble des inhumations issues de la partie sud-ouest de l'emprise décapée.

\section{SYNTHÈSE}

\section{LES MODES DE DÉPÔT}

Les fosses utilisées pour pratiquer les inhumations sont comparables à celles qui définissent les aires domestiques de l'occupation Michelsberg III-IV sur le site. Elles sont de forme circulaire, à parois droites. Aucune ne comporte de matériel attribuable à des rejets domestiques.

Mise à part la fosse SP19 où deux sujets ont fait l'objet d'un dépôt simultané, les structures ne contiennent qu'un seul squelette.

La taille des fosses qui renferment des inhumations entre dans la moyenne des structures " domestiques » du site, leur diamètre variant entre $0,95 \mathrm{~m}$ et $1,30 \mathrm{~m}$; celle qui contient l'inhumation double est la plus petite.

Nous n'avons pas d'argument pour démontrer que ces fosses ont eu à l'origine une fonction domestique ; aucune trace d'utilisation antérieure, ni de recreusement lié aux dépôts des individus n'ont en effet été relevées.

Trois individus ont été inhumés sur le fond des fosses $(102,152,481)$, tandis que les trois autres furent placés $50 \mathrm{~cm}$ au-dessus $(19.1,19.2,393)$; dans ces dernières, le remblaiement de la moitié supérieure est exactement de même nature que celui de la moitié inférieure, à savoir un loess altéré homogène. L'hypothèse du comblement d'une fosse vide réalisé en une fois, accompagné du dépôt d'un individu à mi-hauteur, peut être proposée sur la base de cette homogénéité, puisque l'on n'observe aucune pellicule différenciée sur le fond; néanmoins, l'altération des lœess est très rapide et un dépôt en grande quantité peut se produire d'un bloc, de ce fait l'hypothèse de la réutilisation d'une fosse abandonnée ne peut être exclue.

Le comblement des fosses ne produit ni foyers ni couches brûlées, contrairement à ce que l'on observe fréquemment (mais pas toujours) au Néolithique récent et final dans ce type de contexte. De même, on relève uniquement la présence de quelques tessons de céramique et seules deux fosses livrent quelques rares os de faune disloqués (152 et 19) alors que ces éléments sont souvent rencontrés en grand nombre dans ces contextes. La céramique des remblaiements est ici constituée de tessons manifestement erratiques, puisqu'ils appartiennent à des vases différents, représentés par très peu de fragments : fragments de pansc pour la plupart, dont lc poids total varie entre $49 \mathrm{~g}$ (SP152) et $230 \mathrm{~g}$ (SP102); il s'agit vraisemblablement de matériel résiduel, qui ne peut être comparé à ces riches amas qui caractérisent souvent les fosses sépulcrales du Michelsberg comme celles du Néolithique final.

Le fond de la fosse 19 livre une lame et un bloc de quartzite débité ; il s'agit des seuls objets non céramiques de la série, mais il reste difficile d'affirmer qu'ils sont intentionnellement associés au dépôt des deux individus, placés $50 \mathrm{~cm}$ au-dessus. En revanche, le squelette de la fosse 102 est accompagné de récipients posés à l'origine sur des supports en matière périssable ; l'un est complet, à l'exception d'une partie du bord, l'autre a été brisé et les fragments placés dans la fosse ne représentent pas la totalité du vase. Il s'agit de récipients volumineux, supposés avoir eu une fonction de stockage. Enfin, un suidé nouveau-né se trouve quelques centimètres audessus du crâne du squelette de la fosse 152 ; l'hypothèse que son dépôt et celui de l'enfant soient simultanés ne peut être affirmée dans la mesure où ils ne sont pas en contact. Si cette fosse a été réutilisée pour inhumer le cadavre d'un suidé mort naturellement, le remplissage n'a manifestement livré aucun indice de recreusement. On envisage en revanche difficilement que la fosse soit restée ouverte en partie après l'inhumation de l'enfant, et qu'elle ait servi de dépotoir par la suite, compte tenu de l'homogénéité du comblement et de l'absence d'autres artefacts.

Tous les squelettes ne livrent pas suffisamment d'informations pour restituer toutes les modalités de leur dépôt. Trois sont placés sur le côté, le droit pour 102 et 393 (la position de ce dernier pouvant être restituée à 
partir de la situation respective des éléments restés en place), le gauche pour 19.2, et ont les membres inférieurs fléchis. Les squelettes 152 et 19.1 se présentent en decubitus dorsal. La position des membres supérieurs et inférieurs varie d'un individu à l'autre, même chez ceux dont l'attitude générale est la même.

Les squelettes issus des structures 102 et 152 n'occupent qu'une moitié de la fosse et, dans le second cas, le corps a été déposé de manière à épouser sa paroi interne; les squelettes 19.1 et 19.2 sont, quant à eux, situés au centre de la fosse. La moitié inoccupée de la fosse 102 a manifestement été consacrée au dépôt du mobilier; en revanche, aucun objet n'est conservé dans la seconde partie de la fosse 152 .

Les squelettes ne présentent pas d'effet de paroi, de délimitation ou de constriction pouvant avoir été provoqués par les limites d'un contenant restreint au volume du corps. Néanmoins, les anomalies relevées sur les squelettes des fosses 102 et 152, comme les migrations d'ossements ou les mouvements qui se sont produits hors de l'espace initial du cadavre, témoignent d'une décomposition en espace vide. Dans la fosse 102, le déplacement des fragments de jarre sur une grande amplitude qui a pu être attribué à une action de l'eau, et leur situation, directement au contact des ossements, indiquent que l'espace vide peut occuper l'ensemble de la structure; une couverture de la fosse en matière organique peut être alors restituée.

En revanche, les deux individus de la fosse 19 semblent s'être décomposés en espace colmaté, comme le montre le maintien des connexions en équilibre instable, et ont donc probablement été couverts de terre immédiatement après leur dépôt.

Si l'on compare les inhumations dont l'état de conservation permet de restituer une grande partie des modalités de dépôt (fosses 19, 102 et 152), la structure 19 apparaît différente à divers ègards; il s'agit de la plus petite fosse, deux individus ont été inhumés au même moment, ils se situent au centre, ne reposent pas sur le fond de la fosse et les corps ont été ensevelis et recouverts directement de terre. De leur côté, les squelettes 102 et 152 présentent des points communs et diffèrent des deux derniers, tant par leur situation dans la fosse (les dépôts sont individuels, les squelettes reposent sur le fond et sont placés dans une moitié), que par le milieu dans lequel ils ont évolué (les corps se sont décomposés en espace vide). La nature du mobilier funéraire est hétéro- gène, l'un étant accompagné de céramiques brisées ou mutilées, l'autre éventuellement d'un suidé complet.

\section{LES INHUMATIONS EN FOSSES DE REICHSTETT DANS LEUR CONTEXTE CHRONOLOGIQUE ET CULTUREL}

Les dépôts humains en fosses de type domestique dispersées parmi des structures d'habitat sont particulièrement bien représentés au Néolithique récent (tabl. III), dans les horizons de Michelsberg, de Munzingen, de Baalberg, et depuis peu dans celui de Münchshöfen (Kreiner, 1995). Des sites de la culture de Gatersleben, comme Zauschwitz, Allemagne (Coblenz, Fritzsche, 1976), ou de la culture post-Jordanov, comme à PragNeubusice, République tchèque (Kostka, Šmolíková, 1997), en livrent également quelques exemples. Les manifestations de cette pratique présentent diverses formes dans les cultures néolithiques nommées ci-dessus. Dans la plupart d'entre elles, elles coexistent avec un ou plusieurs modes funéraires "réguliers". Seule la culture de Michelsberg apparaît comme un cas particulier, puisqu'on ne connaît aucun ensemble funéraire, ni aucun exemple de dépôt qui soit pratiqué dans une structure dont la forme serait réservée au traitement funéraire. En Allemagne, comme dans le Bassin parisien, les pratiques tunéraires sont diversifiées au sein d'un même groupe (tabl. III) ; on rencontre des dépôts secondaires, effectués non seulement dans des fosses « de type silo " (Lichardus, 1986; Nickel, 1998), mais également dans des fossés (Behrens, 1988; Debut, Masset, 1991) dont la fonction n'est pas toujours très bien élucidée (Matuschik, 1991, p. 48-49). Ces dépôts secondaires coexistent souvent avec des inhumations primaires, pratiquées dans des fosses adjacentes (Behrens, 1988 ; Seidel, 1998).

Malgré cette diversité, les inhumations primaires en fosses de type domestique représentent, dans toutes les régions, le mode funéraire le plus fréquent dans les cultures de Michelsberg et de Munzingen puisqu'elles constituent les deux tiers des traitements rencontrés (Nickel, 1998, p. 156). Mais les sépultures michelsberg et munzingen d'Alsace se caractérisent par la pratique quasi exclusive de ce type de dépôt ${ }^{5}$ (Lambach, 1986). En cela,

5. Une fosse exhumée sur le site Munzingen de Holtzheim (Bas-Rhin) comporte les restes incomplets d'un squelette disloqué (phase moyenne de la culture de Michelsberg) ; l'hypothèse d'un dépôt réalisé alors que la décomposition du cadavre était avancée peut être proposée (Kühnle-Aubry, 1994). 
les inhumations découvertes à Reichstett entrent dans la norme des sépultures régionales.

Les productions céramiques rencontrées pour l'instant dans le Bas-Rhin au Néolithique récent se rapportent aux phases II, III et IV de Lüning, et à la culture de Munzingen, qui remplace celle de Michelsberg autour de 3700 avant J.-C. (Jeunesse, 1989). D'après la datation obtenue sur le squelette 102 , l'ensemble des inhumations de Reichstett correspondrait donc à la fin du Munzingen B, période pour laquelle les sépultures sont inconnues en Alsace ; parmi la trentaine de fosses sépulcrales recensées dans le Bas-Rhin et le Haut-Rhin, les rares inhumations datées ${ }^{6}$ appartiennent en effet aux stades III et IV du Michelsberg, ou à la phase A de Munzingen : sites de Riedisheim "Beau-Site " et Riedisheim "Les Violettes " (Schweitzer, Fulleringer, 1973, p. 32), sites de Rosheim "Sablière Maetz " et Rosheim "Sainte-Odile " (Thévenin et al., 1977, p. 621 ; Jeunesse, 1992, p. 64), site d'Eschentzwiller "Brandstätte » (Wolf, 1979), site d'Entzheim “Aéroport " (Lambach, 1986, p. 23) et site d'Holtzheim (Kühnle-Aubry, 1994). Or, aucune fosse domestique du site de Reichstett ne livre de matériel postérieur à 3700 avant J.-C., et la jatte qui accompagne l'inhumation SP102 n'est pas particulièrement représentative des productions du Munzingen récent d'Alsace, ni de celles du Michelsberg V, connues en Allemagne. On a pu remarquer, de plus, la parenté typologique entre cette céramique et une production des cultures de Pfyn et d'Altheim, sachant que le nombre de ces récipients est plus important dans la dernière que dans la première. Ainsi, malgré la date absolue, il est difficile de rattacher les inhumations de Reichstett à un contexte culturel précis, en cette fin du Néolithique récent; d'ailleurs, si l'on sait que l'Alsace est occupée par les cultures de Horgen et de Dachstein à partir de 3500 avant J.-C., les modalités de la transition entre l'horizon Munzingen ct ces dernières restent obscures, en termes de processus et de datation (Jeunesse, Schneider, 1985, p. 125). Il n'est

6. Aucun squelette alsacien, en dehors de ceux d'Holztheim et de Reichstett, n'a été daté par le radiocarbone. La séquence chronologique fournie par les auteurs est soit imprécise (Michelsberg), soit déterminée par des récipients en céramique complets placés sur le sol d'inhumation (Eschentzwiller, Fntzheim, Hohatzenheim, DidenheimLerchenberg ?), ou par leur contexte archéologique général, ou encore, dans le pire des cas, par le matériel fragmentaire issu du comblement de la fosse, probablement le plus souvent résiduel. pas exclu que du matériel non identifié, appartenant à cette phase récente, soit déjà présent dans le matériel du Munzingen (Lichardus, 1986, p. 344), et la découverte isolée que constitue cette céramique de type Pfyn et Altheim ne peut pas être interprétée. Les comparaisons effectuées indiquent en tout cas toutes la même direction : d'une part la haute vallée du Rhin entre Bâle et le lac de Constance et d'autre part la Bavière méridionale, qui constituent respectivement à ce jour les expansions les plus occidentales des cultures de Pfyn et d'Altheim (fig. 8).

La datation basse fournie par le squelette 102 et la présence d'une céramique originale justifient de rechercher si, en matière de traitement funéraire, les sépultures de Reichstett se distinguent ou correspondent, au contraire, à celles dont l'attribution culturelle est la phase moyenne du Néolithique récent.

A Reichstett, les fosses utilisées pour inhumer ne diffèrent pas, ni par leur morphologie ni par leur taille, des fosses domestiques. Il s'agit de grandes fosses circulaires à parois droites, beutelförmigen Gruben, typiques des cultures de Michelsberg et de Munzingen; en contexte d'habitat, elles servent de structure de stockage puis de rejet (Jeunesse, Sainty, 1986).

La diversité observée à Reichstett, tant dans l'attitude des corps que dans leur situation dans la fosse, constitue un trait caractéristique des inhumations primaires en fosses de type domestique, dans le Michelsberg comme dans les autres cultures, contemporaines ou postérieures (Jeunesse, 1982, p. 95-96 ; Veit, 1996). Dans ces contextes, certains squelettes se caractérisent par des attitudes désordonnées, semblant indiquer que la position du corps n'a pas été rectifiée au moment du dépôt, tandis que d'autres présentent des postures qui témoignent d'un arrangement du corps dans la fosse. Les inhumations de Reichstett illustrent bien ce phénomène, les attitudes des squelettes 102, 152 et 19.1 correspondant à des positions non naturelles (corps arrangés) alors que le squelette 19.2 paraît déposé sans avoir été apprêté. L'idée, fréquemment émise, que certains corps ont été jetés sans ménagement dans les fosses, implique une péjoration a priori de certaines sépultures ; en réalité, ces différences de traitement ne peuvent être pour l'instant interprétées, compte tenu du faible effectif exhumé sur chaque site.

La fosse SP19 contient une véritable sépulture double, mode fréquemment rencontré dans les inhumations en fosses de type domestique; en Alsace, quatre 


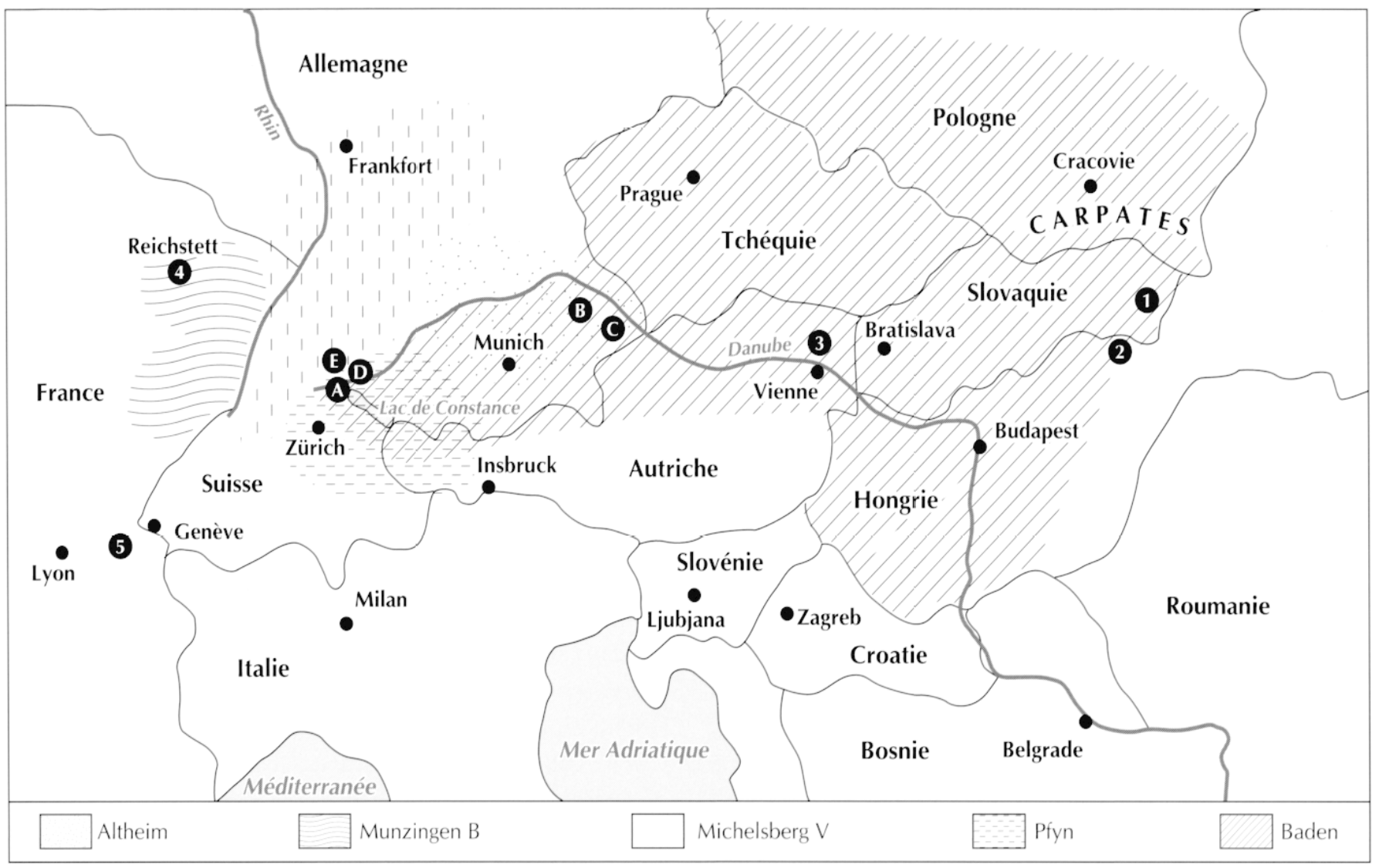

Fig. 8 - Situation des cultures de Michelsberg, de Munzingen, de Pfyn et d'Altheim à la fin du Néolithique récent. Expansion de la culture de Baden au début du Néolithique final et situation des sites mentionnés: 1, Nitriansky Hràdok; 2, Budakalàsz; 3, Sitzenberg et Au am Leilhaberge ; 4, Reichstelt ; 5, Le Gardon ; A, Sipplingen et Bodman ; B, Mamming ; C, Eichendorf-Aufhausen ; I), Thayngen-Weier ; L, ArbonBleiche (réalisation F. Blaizot).

" sépultures doubles " sont mentionnées dans le Michelsberg (Jeunesse, 1982 ; Lambach, 1986), bien que le terme mériterait d'être précisé dans chacun de ces exemples ${ }^{7}$.

Seule la fosse 102 comporte du mobilier céramique siricto sensu, c'est-à-dire des récipients expressément déposés sur le sol d'inhumation avec le corps. Le reste provient du comblement, et se résume à de faibles "poignées » de tessons de toutes périodes, dont l'aspect roulé, la mauvaise représentation des individus et la situation (en suspension dans le sédiment à diverses profondeurs) laissent envisager qu'il s'agit de matériel

7. L.e terme de sépulture double sous-entend que les dépôts sont simultanés. Dans le cas où les squelettes sont séparés par une couche de terre (Riedisheim “ Les Violettes", Rosheim “ Sablière Maetz "...), la simultanéité ne peut être démontrée. résiduel issu des couches initiales du site. Les outils lithiques trouvés dans la fosse 19 ne peuvent être non plus considérés comme du mobilier funéraire, en raison de leur emplacement, $50 \mathrm{~cm}$ au-dessous des squelettes. Le petit suidé de la fosse 152 pose le même problème ; l'absence d'autres artefacts et l'homogénéité du comblement ne permettent pas de démontrer l'hypothèse d'un dépotoir, mais l'emplacement de l'animal quelque $20 \mathrm{~cm}$ au-dessus du squelette nous prive également d'arguments immédiats dans l'autre sens. Or, en contexte Michelsberg, si les dépôts d'animaux complets sont fréquents dans des fosses utilisées comme dépotoir (Thévenin et al., 1977, p. 613 ; Arbogast, 1993), ils sont en revanche totalement inexistants dans les fosses qui renferment les corps humains, puisque partout on n'y relève que des os disloqués, ou des parties anatomiques en connexion (Teilbestattung: Lichardus, 1986 ; Seidel, 1998, 
notamment) ${ }^{8}$. Ainsi, la proposition d'un enfouissement concomitant de l'inhumation ne peut être ici discutée, ni par l'organisation archéologique de la fosse SP152, ni par comparaison, les dépôts d'animaux complets dans les fosses qui comportent un individu humain n'apparaissant dans l'Est qu'au Néolithique final ${ }^{9}$ (Korek, 1951, p. 43 ; Behrens, 1964 ; Nevizánsky, 1985, p. 264 ; Häusler, 1994, p. 46-47) (tabl. III).

La rareté du mobilier funéraire correspond à ce qui est généralement mentionné dans la culture Michelsberg; il n'en existe que 5 cas en Alsace, représentés par des céramiques, des outils et une meule (Jeunesse, 1982, 1992, p. 64).

Dans la fosse 102, le vase de stockage est brisé et incomplet, tandis que la jatte présente une lacune au niveau du bord. Le caractère intentionnel de ce dépôt implique-t-il que les vases ont expressément été cassés et mutilés avant d'être placés dans la fosse ? De tels dépôts sont souvent mentionnés; le site de Didenheim, en Alsace, livre des vases de stockage lacunaires (Lambach, 1986 ; Schweitzer, 1987). On rencontre des récipients incomplets dans toutes les cultures qui pratiquent l'inhumation en fosse de type domestique, tant dans le Néolithique récent que dans le Néolithique final, et les vases de stockage sont fréquents (Novotný, 1958, p. 56 ; Němejcová-Pavúková, 1963, p. 674 ; Nevizánsky, 1985, p. 265 et 268 ; Kaufmann, 1995 ; Kreiner, 1995, p. 74). Il est souvent difficile d'être certain qu'ils se rapportent à une pratique funéraire; des éléments représentant un vase très incomplet peuvent appartenir à une phase d'utilisation plus antérieure de la fosse ou faire partie du comblement au même titre que le sédiment, d'autant plus si l'on se trouve en contexte d'habitat. Pour ce qui est des récipients ébréchés, le choix de ne réserver aux morts que des vases usagés est encore une hypothèse plausible, leur présence n'étant que symbolique.

8. À Soultz SP2 (Haut-Rhin), "les éléments d'un squelette d'un lapin" sont mentionnés "sur la poitrine d'un squelette "(Lambach, 1986, p. 24). La représentation réelle de l'animal, ses éventuelles connexions et sa situation précise (sur, au-dessus) ne sont pas claires.

9. On ne connaît que de rares exemples antérieurs à cette période, comme celui de Jordanov en Pologne (un enfant et un cerf: Behrens, 1964 , p. 65), celui de Künzing-Bruck en Basse Bavière (Mittelneolithikum) qui livre un dépôt simultané d'un homme et d'un très jeune suidé (cas unique: Schmotz, 1993, p. 18-23), ou de Gehofen (culture de Baalberg) où l'on a des chiens entiers (Veit, 1996, p. 300). Nous n'avons trouvé aucun exemple dans le Michelsberg.
Aucune des fosses sépulcrales de Reichstett ne présente de stratigraphie complexe, définie par différents niveaux de remplissage ponctués de couches de charbons ou de rubéfaction ou encore de terre tassée; au contraire, les comblements sont totalement homogènes, qu'il s'agisse du remblaiement de la fosse au-dessus du squelette ou de celui qui se trouve au-dessous, dans les deux cas où le corps n'a pas été déposé sur le fond de la fosse (SP19 et SP393). En cela, ces fosses se distinguent d'un certain nombre d'entre celles qui ont été pour l'instant exhumées en Alsace (Jeunesse, 1982), notamment sur les sites de Riedisheim (Schweitzer, Fulleringer, 1973), et de Didenheim (Schweitzer, 1987) ${ }^{10}$.

En l'état actuel des connaissances, la valeur d'une telle observation est discutable; pour certains, les amas de tessons, les os et parties de squelettes d'animaux, et les niveaux brûlés observés dans les comblements sont considérés comme les témoins de la cérémonie funéraire (Schaeffer, 1925-1926 ; Lichardus, 1986 ; Schweitzer, 1987), alors que pour d'autres, ces vestiges sont liés à la fonction primaire ou tertiaire de ces fosses, dont l'histoire est longue et complexe (Jeunesse, 1982, p. 97; Jeunesse, Sainty, 1986). Chacune de ces deux propositions est plausible, bien que la première ne repose pas sur une démonstration évidente; mais que ce soit chez les auteurs qui la défendent ou chez. ceux qui la réfutent, aucune étude précise du matériel (typologie, représentation, type de fragmentation, situation exacte dans la fosse, etc.) n'entre en ligne de compte. L'argument fondé sur une identité entre ce matériel et celui que l'on trouve en contexte domestique stricto sensu (Forrer, 1912) doit être pondéré, puisqu'il n'existe pas de modèle universel de ce que doivent être les vestiges de l'appareil funéraire ". Pour l'instant, l'hypothèse de C. Jeunesse (1982), émise à partir de la parenté des modes de comblement entre les fosses dont les différentes utilisations ont été de nature "domestique " et celles qui comportent une inhumation, reste la plus argumentée. Une

10. Il est impossible de connaître la provenance du matériel des fosses fouillées en dehors de celles-ci. I a description précise des comblements fait également défaut.

11. L'utilisation d'un mobilier non spécifique pendant le rituel funéraire (qui ne se distinguerait pas de celui utilisé quotidiennement) est parfaitement envisageable, d'autant plus que les rares céramiques qui semblent accompagner les corps appartiennent au cortège typologique courant. 
seule observation irait néanmoins dans l'autre sens : dans la fosse 2 de Didenheim, le comblement de la fosse audessous et au-dessus du squelette était non seulement homogène, mais comportait des tessons qui se raccordaient entre eux, ce qui est en faveur d'un remblaiement de l'ensemble de la fosse réalisé en une seule fois (Schweitzer, 1987) ; mais on peut également supposer qu'on ait recreusé dans une fosse comblée de rejets domestiques pour enfouir le corps, puis recomblé avec le même sédiment.

L'hypothèse d'une utilisation continue de ces fosses, où le dépôt d'un cadavre ne représenterait qu'un événement ponctuel de son histoire, implique d'une part que l'inhumation ne fait pas l'objet d'une structure fabriquée pour la circonstance et, d'autre part, que les dépots sont contemporains du fonctionnement de l'habitat. Les fosses de Reichstett ne témoignent d'aucune trace indiscutable d'une utilisation antérieure (rubéfaction du fond liée à la conservation des grains par exemple) ou postérieure au dépôt des corps (déchets en masse). Cependant, lorsque les squelettes reposent audessus du fond de la fosse, comme ici en 19.1-2 et 393, l'idée de la réutilisation d'une fosse en partie abandonnée peut être avancée (Jeunesse, 1982 ; Nickel, 1998, p. 156), et l'absence d'artefacts et l'homogénéité du sédiment correspondraient alors à un comblement naturel par ruissellement (Jeunesse, Sainty, 1986, p. 57). Dans cette optique, le dépôt sur le fond de la fosse des squelettes 102 et 152 ne réfute pas l'hypothèse d'une réutilisation : la fonction sépulcrale pourrait avoir suivi immédiatement l'abandon de la structure en tant que silo (Jeunesse, Sainty, 1986, p. 69).

Dans nos exemples, cette discussion tourne rapidement court, si l'on considère la seule argumentation développée ci-dessus ; nous ne disposons pas d'éléments tangibles pour étayer chacune de ces propositions (déchets domestiques, préparation du fond de la fosse, etc.) et, en contre partie, l'absence de critères d'identification peut trouver d'autres explications et ne saurait remettre en cause l'hypothèse d'une réutilisation.

La restitution des modes d'inhumation, qui n'a été possible que dans trois cas $(19.1-2,102,152)$, renouvelle d'une certaine manière l'argumentation en faveur de l'une ou de l'autre interprétation. L'analyse taphonomique des squelettes 102 et 152 montre que les corps ont évolué en espace vide, et que celui-ci concerne la totalité de la fosse ; clle devait alors être munie d'une espèce de couvercle, à défaut d'une architecture plus complexe, qu'aucun argument ne permet d'envisager. Nous n'en avons pas non plus pour supposer que la fosse est restée totalement ouverte.

Se pose alors de nouveau la question du suidé découvert quelque vingt centimètres au-dessus du crâne du squelette 152. Si la proposition du dépôt du suidé sur le couvercle de la fosse peut être retenue comme plausible, l'animal ferait partie de la sépulture. On mentionnera la présence de trois squelettes de suidés nouveau-nés reposant les uns sur les autres, dans une même fosse (F101) située au nord/nord-est de la sépulture 102 (fig. 1) ; mais ils se placent à mi-hauteur dans le remblaiement, et de ce fait ne peuvent être alors considérés comme significatifs d'un rituel, contrairement aux trois petits cochons de Geispolsheim, en Alsace, interprétés comme un dépôt de fondation (Jeunesse, 1993, p. 123). Il n'existe pas d'élément pour envisager que les trois suidés de la fosse 101 ont un lien quelconque avec les sépultures et aucun matériel ne permet d'attribuer la structure à un état chronologique précis du site.

La démonstration d'une fosse " architecturée " est un élément nouveau, tant dans le contexte du Néolithique récent que dans celui, plus large, de ces dépôts en fosses de type domestique ${ }^{12}$. Que signifie alors, dans le contexte de ce que les auteurs allemands nomment des inhumations en "fosses poubelles" (abfallgrube), la mise en ouvre d'une architecture, aussi sommaire soit-elle? Doit-on considérer que l'on se trouve tout d'un coup dans une autre logique, où l'inhumation ne s'apparente plus à la gestion des déchets, mais fait l'objet d'un traitement plus spécifique, du fait de cet aménagement, même si la structure d'accueil elle-même reste non spécifique? S'agit-il de donner une dimension véritablement funéraire, de marquer la fosse en tant que sépulture? L'abscnce de détritus dans lc comblement supéricur des fosses, qui prouve que l'inhumation appartient au

12. Nous n'avons trouvé, à travers la littérature, qu'un seul exemple possible d'une décomposition en espace vide : sur le site de Munzingen, un squelette présente un certain nombre de dislocations interprétées par le fouilleur comme le résultat d'un effondrement du corps placé assis à l'origine (Veit, 1996, p. 283). Néanmoins, il est précisé que le crâne est resté " en connexion " (avec l'atlas ? entre le bloc crânio-facial et la mandibule ?) ; or si ce corps s'était décomposé en espace vide alors qu'il était assis, le crâne aurait inévitablement roulé. L'absence d'information plus précise ne permet donc pas de retenir cette hypothèse. 
dernier état de leur utilisation, témoigne en tout cas qu'une distinction est opérée entre le dépôt du cadavre et le rejet des déchets domestiques.

Pour résumer, nous dirons que lcs fosscs à inhumation de Reichstett, attribuées, par la datation de l'une d'entre elles, à la fin du Néolithique récent, sont regroupées dans un secteur vierge de toute occupation contemporaine. Le regroupement apparait assez rare dans le Néolithique récent, puisqu'on ne le rencontre en Alsace qu'à Soultz-Haut-Rhin. Mais sur les sites, les investigations n'ont été menées généralement que sur de faibles surfaces, ce qui peut être à l'origine de cette impression de dispersion. Il n'est pas impossible que les dépôts de Reichstett prennent place dans des structures ruinées préexistantes, qui appartiennent à l'occupation Michelsberg III et IV, en tout cas pour ce qui concerne les sépultures 393 et 19. Mais il semble exclu d'envisager une utilisation postérieure de ces fosses; l'habitat qui correspond à la fin du Néolithique récent paraît se trouver ailleurs, qu'il s'agisse des énigmatiques maisons ou des aires spécialisées de stockage ou de rejet. Le terme de "sépulture en habitat " (Siedlungsbestattung), qui qualifie généralement ce type de dépôt, ne serait donc pas adapté à notre série, et il conviendrait plutôt de privilégier celui de "sépulture en fosse de type domestique ". Cependant, l'hypothèse selon laquelle ces dépôts funéraires auraient été pratiqués à distance des zones domestiques ne repose que sur l'absence de matériel postérieur à la phase moyenne du Michelsberg ; or, sur les habitats néolithiques, les rejets de détritus sont plus nombreux dans les fosses abandonnées, qui se situent à proximité des maisons, que dans celles qui se trouvent en périphérie. Il n'est donc pas impossible que les fosses qui présentent un comblement stérile appartiennent à une zone très périphérique de l'habitat contemporain des sépultures, dont le cœur aurait échappé à l'emprise des fouilles, d'autant que les fosses à inhumation sont localisées en limite du décapage.

L'utilisation d'une fosse de type domestique pour inhumer, les attitudes variées des corps, et la présence d'un dépôt simultané constituent des caractères présents dans le Michelsberg et le Munzingen ; mais les pratiques funéraires mises en évidence dans les fosses 102 et 152 sont des aspects nouveaux pour ces contextes puisque, pour l'instant, ne sont connus que des dépôts en pleine terre pratiqués dans les aires de fosses de détritus d'un habitat, qui continuent à fonctionner comme dépotoir par la suite. Devons-nous alors proposer qu'avec les fosses de Reichstett nous soyons passés, en cette fin du Néolithique récent, à un autre type de traitement, voire à unc autrc conccption de la sćpulture ? On ne peut l'affirmer, sachant d'une part que l'ensemble des rejets domestiques peut s'être effectué dans des fosses situées plus près des maisons, et d'autre part que des fosses architecturées ont peut-être existé au Michelsberg moyen mais qu'elles ne furent pas reconnues comme telles à la fouille ${ }^{13}$. La documentation disponible provient d'investigations relativement anciennes et les informations restent lacunaires et imprécises tandis que les squelettes sont mal datés. Ces approximations peuvent occulter d'éventuels aspects particuliers et ne permettent pas de discuter pour l'instant les différences mises ici en évidence dans une perspective chronoculturelle. Si le groupe qui est à l'origine de ces sépultures est " apparenté "à la culture d'Altheim, du fait de la ressemblance qui existe entre le vase de la sépulture 102 et ceux de la production de cette culture, il n'est malheureusement pas possible de reconnaître le mode sćpulcral en tant que tel, les tombes de la culture d'Altheim étant mal distinguées, en l'absence de mobilier, de celles du Michelsberg (Veit, 1996, p. 274). Quant aux rites funéraires de la culture de Pfyn, ils restent à ce jour mal connus, en dehors des squelettes "isolés " dans les couches de destruction des sites lacustres (Gross et al., 1987 ; Wyss, 1988), et de la station IV de Chalain : fouilles de l'été 1998 P. Pétrequin, étude F. Blaizot, publication en préparation dans Chalain $I V$ ). Aucun site mégalithique n'a en tout cas pu être mis en relation avec ce groupe jusqu'à ce jour.

\section{LA CRÉMATION MULTIPLE EN FOSSE DU NÉOLITHIQUE FINAL (SP143)}

\section{LES DONNÉES ARCHÉOLOGIQUES}

\section{STRATIGRAPHIE INTERNE}

La fosse 143 est grossièrement circulaire à tendance elliptique, d'une largeur de $2 \mathrm{~m}$ du nord au sud et de

13. Aucun des squelettes fouillés jusqu’à présent n’a fait l'objet d'un enregistrement adapté à l'interprétation du mode d'inhumation (Lambach, 1986). 
2,30 m d'est en ouest. Son contour a été détruit au sud au moment de la découverte. Elle est conservée sur une hauteur maximale de $75 \mathrm{~cm}$ et possède un fond concave. La succession des couches de haut en bas est la suivante (fig. 9).

Une couche constituée de lœss altéré d'une épaisseur de $40 \mathrm{~cm}$ contient quelques tessons fragmentaires (319 g) situés plus particulièrement dans les quinze premiers centimètres qui appartiennent aux horizons du Néolithique moyen et du Néolithique récent. De ce niveau proviennent quelques rares os de faune.

Une couche hétérogène composée de loess rubéfié, d'une épaisseur qui varie de $8 \mathrm{~cm}$ à $14 \mathrm{~cm}$ (près des bords de la fosse), correspond à l'effondrement de la partie rubéfiée des parois. Au centre de la fosse, elle est d'une faible épaisseur (environ $2 \mathrm{~cm}$ ) et se caractérise par des inclusions charbonneuses. Cette couche repose directement sur les os. Aux abords des parois, elle est constituée horizontalement d'une juxtaposition de loess jaune et de loss rubéfié, puis de nouveau de loess jaune, traduisant un effondrement des parois en deux temps.

La couche d'ossements humains apparaît $50 \mathrm{~cm}$ sous le niveau de décapage et sa plus grande épaisseur est de $12 \mathrm{~cm}$. Les os sont brûlés et inclus dans une matrice hétérogène charbonneuse de couleur brune, dans laquelle sont mélangés du loess chauffé, des charbons et du loess rubéfié. Quelques os de faune, dont certains sont brûlés, sont présents.

Les ossements situés en périphérie de l'amas se trouvent sous la couche de loess provenant de l'effondrement des parois.

Près de la paroi dans l'angle nord-est, on relève un petit nombre de fragments d'os humains sur la couche d'effondrement de la paroi, $10 \mathrm{~cm}$ à $15 \mathrm{~cm}$ au-dessus de l'amas d'ossements.

À la base des os se trouve une couche noire très charbonneuse d'une épaisseur moyenne de $5 \mathrm{~cm}$. Cette couche est localisće au centre de la fosse sur une aire de $1,30 \mathrm{~m}^{2}$ et elle comporte des ossements en moins grand nombre que la précédente. Elle est circonscrite par du lœess rubéfié sur une épaisseur de $7 \mathrm{~cm}$, qui se raréfie en se rapprochant du centre.

Directement sous ce sédiment on a le squelette complet d'un suidé en connexion, placé sur le côté droit la tête à l'ouest et la queue à l'est. Son crâne, son coxal et ses côtes gauches sont noircis, indiquant que ces parties ont chauffé à une température proche de $200-400^{\circ}$
(Doklàdal, 1963 ; Bonucci, Graziani, 1975). Il repose un peu au-dessus du fond de la fosse et est inclus dans une couche de loess remanié chauffé.

La succession des couches qui correspond à une logique fonctionnelle et l'effondrement des parois témoignent d'une crémation in situ.

\section{LES OS HUMAINS}

Le poids total des os humains est de $9257,59 \mathrm{~g}$.

Ce poids élevé et la reconnaissance in situ de doublets indiquent que plusieurs individus sont représentés. Ia crémation est très hétérogène, puisque la couleur des os varie du brun foncé au blanc craycux. Ceci montre que la température de certains os a été portée au moins jusqu'à $650^{\circ}$, mais que pour d'autres elle n'a pas dépassé $300^{\circ}$ (Bonucci, Graziani, 1975). Il arrive qu'un même os présente toute la gamme chromatique potentielle : brun, noir, gris et blanc. On citera à cet égard l'exemple d'un humérus droit dont les divers fragments dispersés sur une amplitude de $50 \mathrm{~cm}$ offrent cette caractéristique. Les éléments d'un même squelette sont également brûlés de manière hétérogène. Dans tous les cas, le changement de couleur n'est pas graduel mais aléatoire. L'hétérogénéité du degré d'ustion des différents os est un phénomène relativement fréquent, tant en contexte archéologique (Herrmann, 1972) qu'en contexte moderne où la couleur des os est considérablement diversifiée che\% un même sujet (MacKinley, 1989, p. 66, 72).

Ia fragmentation est très diversifiéc, les morceaux variant de $0,5 \mathrm{~cm}$ à $20 \mathrm{~cm}$. Les os qui se trouvent sur le fond de la fosse sont beaucoup plus fragmentés que ceux qui proviennent de la surface. Il est possible que ce phénomène soit corrélé avec le type de crémation ou avec des actions postcrématoires plutôt qu'avec le poids des terres puisque le niveau supérieur de la couche d'ossements est surmonté d'une importante masse de sédiment qui aurait dû les fragmenter également. À l'examen, les os les plus brûlés apparaissent fragiles, cassant facilement. Leur surface comporte des fendillements transversaux marqués, quelques fissures concentriques toujours profondes ou des craquelures. Ponctuellement, il existe des fragments cristallins très fortement déformés. Les pièces brunes ou noires ont une surface brillante et sont colorées dans la masse. Ces caractéristiques témoignent d'une crémation de cadavres ou en tout cas d'os frais (Buikstra, Swegle, 1989). On 


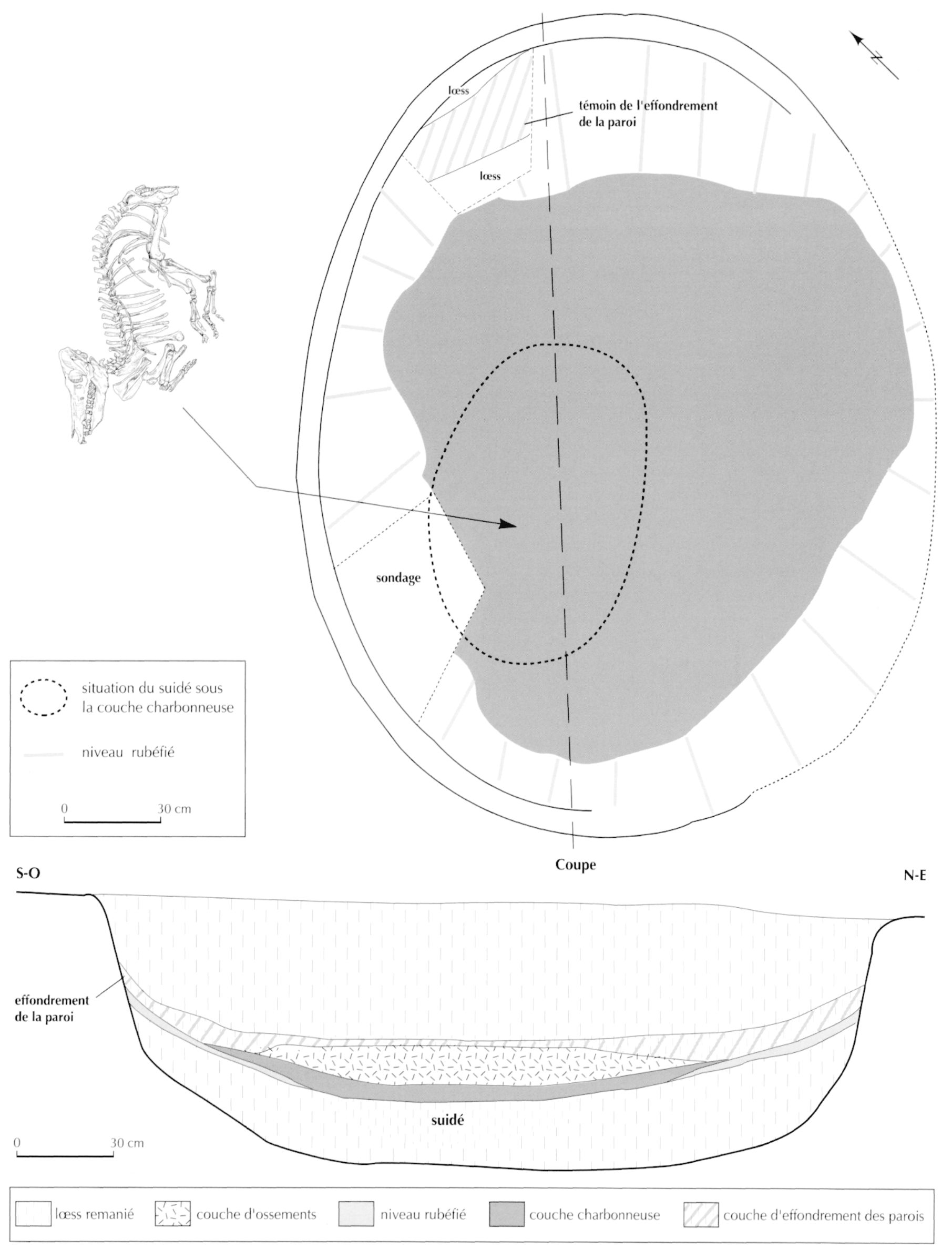

Fig. 9 - Plan et coupe de la fosse 143 (dessin, DAO F: Blaizot). 
remarque aussi que les crânes sont globalement plus brûlés que les os longs, eux-mêmes plus brûlés que les vertèbres; ceci serait en faveur d'une crémation de cadavres, les masses musculaires et les viscères jouant un rôle protecteur (Buikstra, Swegle, 1989, p. 252 ; Méniel, 1994, p. 283).

Certaines pièces, particulièrement celles qui se trouvent en surface ( $\mathrm{rl}$ ) et contre les parois ou dans la moitié ouest (fig. 11), sont couvertes de plaques de calcite indurée d'une épaisseur atteignant parfois $5 \mathrm{~mm}$. Bien que la structure de l'encroûtement ne soit pas cristalline, on ne peut exclure l'hypothèse d'une percolation des eaux à travers la terre, d'autant plus que l'encaissant comme le comblement sont constitués de loess ou de sédiment lehmique qui produisent de fréquentes concrètions naturelles : " poupées de lœess".

\section{LA FAUNE}

La masse totale des os de faune est de 40,57 g.

Ils nous ont été livrés en deux lots ; l'un provient de la surface de l'amas d'ossements humains brûlés dans l'angle nord-est de la fosse, tandis que l'origine exacte du second est inconnue (sont notés " niveau supérieur"). L'examen de ces ossements, effectué par D. Lalaï, donne les résultats suivants.

Le lot supérieur : sur les sept restes présents dans ce lot d'un poids total de $14,57 \mathrm{~g}$, quatre ont pu être déterminés. Ainsi, une extrémité distale de métacarpien, une partie proximale de première phalange et un fragment d'os coxal sont attribuables au bouf adulte, tandis qu'une première phalange appartient à un suidé juvénile sans que l'on puisse se prononcer pour l'espèce sauvage ou domestique. Aucune trace de découpe n'est visible sur ces éléments osseux et les quelques marques qu'ils présentent résultent de l'activité de divers prédateurs domestiques et/ou sauvages (chien, porc/sanglier?, rongeurs, etc.). Un fragment (indéterminé) est brûlé.

Le lot inférieur: celui-ci comprend trois restes osseux dont deux fragments indéterminés, et une seconde phalange d'un bouf adulte, d'un poids total de $26 \mathrm{~g}$. Ils ne montrent aucune trace de découpe. Les deux pièces indéterminées sont brûlées. D'après leur couleur, elles ne semblent pas avoir subi une cuisson supérieure à $350^{\circ}$.

Ces petits lots de restes fauniques ne livrent que peu d'informations. Toutefois, on peut constater que les os ou fragments d'os qui ont été reconnus (à l'exception peut-être du coxal) correspondent aux parties qui sont éliminées dans les premières phases de la découpe bouchère. La carbonisation de certains pourrait résulter de leur rejet dans des foyers, mais il n'est pas exclu, pour les trois restes du lot inférieur, que cet état découle de la crémation des corps dans la fosse. Néanmoins, les données sont trop faibles pour voir dans ces vestiges des témoignages de dépôts d'offrandes. Il est plus probable qu'ils ont été rapportés dans la fosse lors de son comblement.

Le squelette d'un suidé complet, d'un poids total de $3,10 \mathrm{~kg}$, est situé sur le fond de la fosse (fig. 9). Il ne porte aucune trace de découpe. Ce squelette présente tous les signes d'une décomposition en espace colmaté. En effet, les volumes du corps (thorax et bassin) sont globalement préservés, les articulations labiles sont maintenues et les seuls mouvements observés restent d'une amplitude limitée à l'intérieur du volume des chairs (épaules). Si cet animal a été déposé dans la fosse au moment où le bûcher fut construit, il a été succinctement couvert de terre au préalable, puisqu'il n'existe aucun fragment d'os humain parmi les os de son squelette. De plus, seul a chauffé le côté opposé à celui sur lequel il reposait. Si le suidé avait été simplement déposé à même le sol sous le bûcher pendant la crémation, il n'aurait pas forcément été brûlé de manière plus intensive compte tenu du milieu réducteur du fond de la fosse mais, en revanche, il aurait été colmaté par la couche charbonneuse, ce qui n'est pas le cas. Cet animal appartient-il à une phase antérieure de l'utilisation de la fosse, ou a-t-il une fonction funéraire? Si l'on considère la première hypothèse, les datations obtenues par le radiocarbone indiqueraient que les deux fonctions, dépotoir domestique/dépôt funéraire, sont contemporaines. Or, il n'y a pas la moindre trace d'une occupation domestique du Néolithique final dans l'emprise décapée du site et aucun artefact dans le comblement des $20 \mathrm{~cm}$ inférieurs de la fosse. Peut-on réellement admettre qu'au Néolithique final on ait transporté un cochon mort, qui représente un certain poids, à distance des aires de rejets habituelles pour s'en débarrasser? Il apparaît pour cette raison peu probable que ce dépôt corresponde à un rejet de nature domestique. Le corps s'est décomposé en espace colmaté, prouvant qu'il fut recouvert de terre rapidement après son dépôt, mais, d'autre part, ce colmatage est succinct, puisque son côté exposé a brûlé ; il est donc probable qu'un temps relativement court s'est écoulé entre le 
moment où fut déposé le suidé et celui où le bûcher funéraire fut installé au-dessus. Bien que l'on ne puisse pas totalement éliminer celle d'un acte rituel d'une autre nature (fondation, abandon) n'ayant aucun lien avec le bûcher sous-jacent, l'hypothèse d'un dépôt en relation avec la crémation nous paraît pouvoir être privilégiée.

D. L., F. B.

\section{LE MOBILIER}

Dans le tiers sud-est de la fosse, se trouvent 4 fragments d'un objet façonné sur bois de cerf. Ces pièces sont réparties parmi les os humains. Elles sont brûlées et témoignent d'un degré de chauffe relativement important (couleur grise).

\section{Description}

Il s'agit d'un outil fabriqué à partir d'une baguette prélevée sur une ramure de bois de cerf (fig. 10a). Il présente à son extrémité proximale une encoche et à sa partie distale, une partie active " mousse ».

\section{Origine anatomique}

L'origine exacte de la zone prélevée ne peut malheureusement pas être déterminée. Il s'agit vraisemblablement d'un segment droit tel qu'un merrain (A, B ou C).

\section{Traces techniques}

La crémation a effacé de nombreuses traces. Toutefois, nous pouvons définir avec une relative précision le mode de fabrication de cette pièce :

- la partie proximale de la baguette présente quelques copeaux émoussés qui indiquent un débitage du segment en percussion lancée à l'aide d'un tranchant (hache ou herminette ?) ; la légère irrégularité du fût de la baguette indique également un prélèvement en percussion lancée ;

- l'encoche de la baguette a été elle aussi façonnée par percussion lancée ;

- le fût de l'objet a été régularisé par abrasion longitudinale ; les stries liées à cette abrasion sont très nettes et circonscrites aux côtés latéraux de la pièce ;

Selon J.-L. Voruz (comm. pers.), il semblerait que nous devrions rattacher l'absence de perlure du bois de cerf à l'état brut de la lamelle; de nombreux merrains de bois jeunes ne portent pas, ou très peu, de perlures : la perlure et les gorges-négatifs de canaux d'irrigation sanguine, qui existent pendant la pousse du printemps, deviennent de plus en plus marqués avec l'âge des cerfs.

\section{Traces d'utilisation}

La surface de l'objet observée à la loupe binoculaire apparaît très altérée, c'est pourquoi nous nous limiterons à quelques observations. Les stries liées au façonnage et observées latéralement tendent à disparaitre au fur et à mesure que l'on se rapproche de sa partie distale. L'extrémité distale (partie travaillante) semble tassée et piquetée, comme si elle avait été utilisée par pression sur un matériau dur. Quelques zones luisantes attestent la présence d'un micropoli, mais l'altération due à la crémation ne nous permet aucune conclusion.

\section{Attribution culturelle}

Les outils mousses sur baguette encochée sont rencontrés dans les cultures de tradition Horgen notamment en Allemagne et en Suisse (Itten, 1970, Ramseyer, 1982, Winiger, 1981, 1985). La technique de fabrication mise en ouvre pour l'objet de Reichstett, c'est-à-dire prélèvements par percussion lancée, est également commune au Horgen.

\section{Interprétation}

Plusieurs interprétations fonctionnelles peuvent ĉtre proposées pour cet objet ${ }^{14}$; a priori, les traces d'utilisation mises en évidence par Y. Maigrot feraient songer à un retouchoir de silex, malgré son apparente fragilité ; en effet, cette fonction, expérimentée avec succès, s'accorde bien avec la retouche plate couvrante, fine, du Néolithique final (J.-L. Voruz, comm. pers.). Il semblerait même que les outils mousses sur bois de cervidés représentent le seul type d'outil, pour le Néolithique final, pouvant être associé au travail du silex. Il pourrait s'agir également d'une navette à ravauder les filets, du type de celles que l'on rencontre dans la culture de Horgen et que l'on voit encore chez les pêcheurs du lac de

14. Je remercie J.-L.. Voruz pour son aide ; les remarques qui suivent s'appuient sur des informations qu'il nous a livrées. 
Neuchâtel (J.-L. Voruz, comm. pers.). Mais l'hypothèse d'un objet de parure, ou reconverti en parure, doit encore être évoquée. La fonction de parure n'est d'ailleurs pas incompatible avec celle de l'outil. D'ailleurs, un article récent, qui porte sur la représenta-

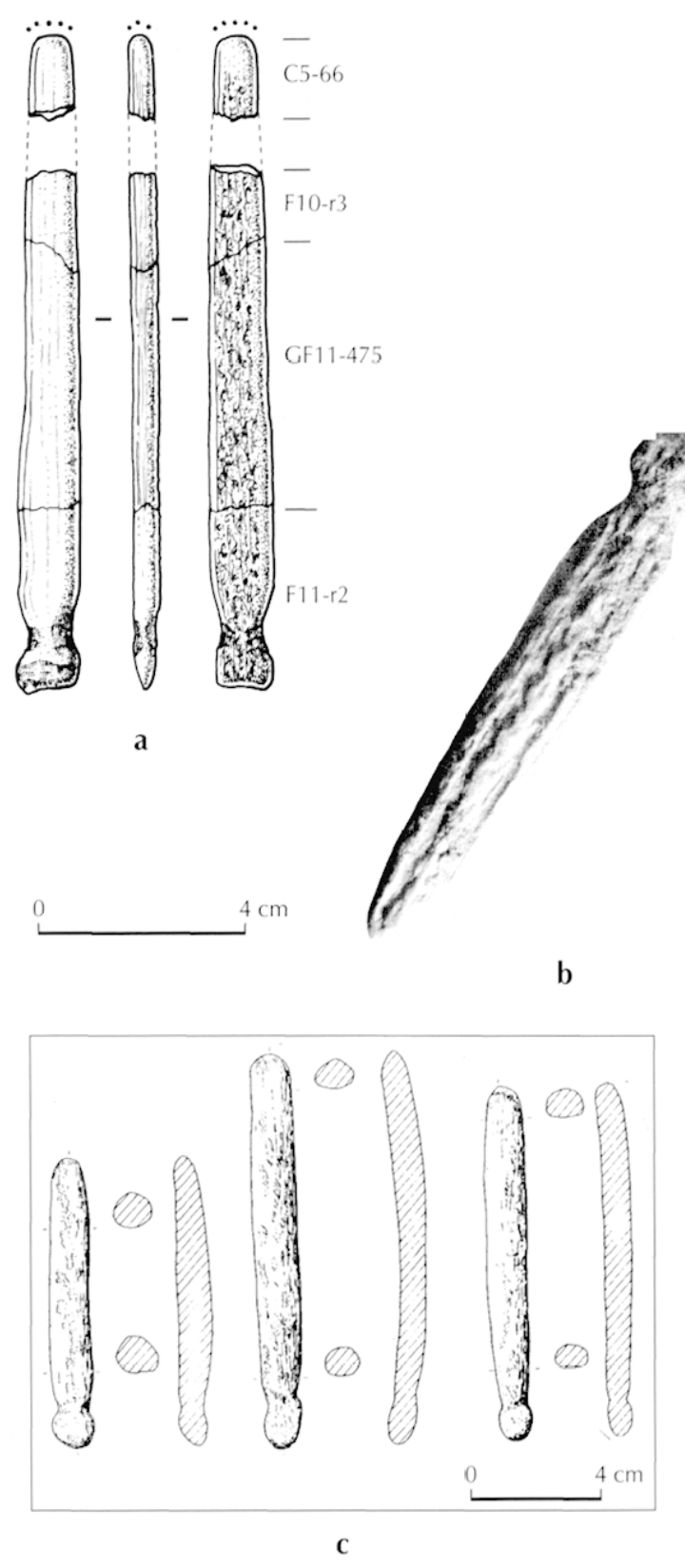

Fig. 10 - Outil en bois de cerf, et éléments de comparaison (dessin Y. Maigrol) : a, Reichstett ; b, objet fusiforme à gorge en bois de cerf, du niveau IV de la grotte Tournié ( $\approx$ 350 BC); partie basale de l'objet en $Y$ des statues-menhirs du Rouergue et du Saint-Ponais (photo H. Barge in Ambert, 1998) ; c, outils Horgen, d'après Voruz, 1984, fig. 39. tion des objets réels sur les statues-menhirs, considère que ces " objets fusiformes à gorge ", rencontrés entre 3300 et 2800 avant J.-C., sont ceux que l'on voit représentés autour du cou des statues-menhirs féminines (Ambert, 1998, p. 187). Par cela, il ne s'agit pas d'attribuer une valeur symbolique, à partir d'un aspect pseudoanthropomorphe, à ces objets, mais de proposer qu'ils puissent avoir été portés ainsi dans la vie courante. Des objets identiques apparaîtraient en Suisse, dans les groupes de Pfyn et de Horgen, aux mêmes dates (Ambert, 1998, p. 188, Voru\%, 1984). On ne manquera pas de souligner l'analogie entre l'objet de Reichstett et ces derniers (fig. 10b et c). Ils diffèrent toutefois dans les détails de leur facture: celui qui est présenté par P. Ambert comporte une extrémité distale appointée et une extrémité proximale discoïde, ce qui n'est pas le cas de l'objet de Reichstett. Si malgré cela ces deux types d'objets peuvent être rapprochés, la présence de celui de Reichstett parmi les os humains pourrait être expliquée par le fait qu'il était porté en sautoir par l'un des individus. Quoi qu'il en soit, l'hypothèse d'un retouchoir à silex doit être privilégiée, et il convient d'insister sur le parallélisme avec ceux de la culture de Horgen (J-L. Voruz, comm. pers.), en soulignant que cette culture n'a jusque-là pas été reconnue en basse Alsace (Jeunesse, Schneider, 1985). Ce type d'objet est particulièrement fréquent dans ce contexte, comme le montrent les découvertes faites à Yverdon et à Yvonand (Voruz, 1984, fig. 39, p. 327) (fig. 10). On notera enfin que c'est la première fois que l'on trouve cet objet en contexte sépulcral.

Y. M., F. B.

\section{Datation absolue}

La présence d'un unique objet datant associé à la crémation nous a conduite à effectuer deux datations par le radiocarbone. L'une porte sur des charbons de bois recueillis au milieu de l'amas d'ossements et donc supposés provenir des matériaux du bûcher, et l'autre porte sur le squelette du suidé ${ }^{15}$. La première (AMS ETH-19 073) nous donne un résultat de 3140 cal. avant J.C. à 2915 cal. avant J.-C. (72,4\%), et la seconde (ARC 1814) de 3375 cal. avant J.-C. à 3035 cal. avant J.-C.

15. Laboratoire Archéolabs, résultats donnés avec une probabilité de 2 sigma. 
$(93,3 \%)$. Ces résultats sont compatibles avec les indications fournies par l'outil, et la structure peut ainsi sans ambiguïté être attribuée à la première moitié du Néolithique final. Il s'agit de la seule trace d'occupation du site pour cette période.

\section{RESTITUTION DU BÛCHER FUNÉRAIRE}

\section{L'INSTALLATION DU BÛCHER}

La crémation sur place est attestée par les données archéo-anthropologiques et géoarchéologiques. Mais il ne reste aucun élément du bûcher funéraire, et les conditions de la crémation ne peuvent être que très partiellement approchées par l'examen des témoins indirects conservés. Plusieurs indices s'offrent à nous :

- la rubéfaction s'est produite sur les parois, comme l'indique la couleur de la couche qui correspond à leur effondrement, composée de lœess rubéfié et, sur le sol autour, d'une masse de terre charbonneuse située au centre de la fosse ; les limites de cette dernière n'atteignent pas les bords de la fosse ;

- le mode de répartition des os brûlés affecte une forme globalement rectangulaire orientée ouest-est (fig. 11) ; bien que la limite ouest soit toutefois irrégulière, les os se répartissent, comme à l'est, sur une ligne située à distance de la paroi ; aucune de ses limites ne coïncident avec l'aire de répartition de la couche charbonneuse : au nord et au sud elles se situent en dedans; à l'est et à l'ouest elles outrepassent à la fois cette couche et les traces de rubéfaction au sol.

La rubéfaction du sol est un phénomène a priori étonnant. En effet, elle est très rarement attestée ; dans les tombes-bûchers romaines, qui offrent un parallèle avec notre structure dans la mesure où elles sont excavées, seules les parois sont brûlées (Gaitzsch, Werner, 1993; Bel, 1996). Les observations réalisées par J.P. Pautreau en Thailande dans le cadre du " projet combustion » (CNRS, UPR 403), et par A. Marshall et J. MacKinley en Angleterre, ont cependant montré que de telles traces pouvaient être parfois préservées, et cela uniquement dans des structures en creux, sinon la pluie et le vent les faisaient disparaître (Pautreau, 1994, p. 313 ; MacKinley, 1997, p. 132-136). Dans le bûcher expérimental d'Acy-Romance (Lambot, 1994) installé dans une excavation de $30 \mathrm{~cm}$ de profondeur seulement, le sol était rubéfié sur une épaisseur de $2 \mathrm{~cm}$, uniquement là où le bois se trouvait à son contact. Dans ce cas, le bûcher était construit à l'aide de bûches disposées en croisillons formant des cheminées qui ont immédiatement aspiré les flammes vers le haut et fait baisser la température au sol (Lambot, 1994, p. 258). Faut-il imaginer à Reichstett une construction très différente qui aurait réussi à maintenir une température élevée au sol au début de la crémation malgré le milieu réducteur?

On connaît des cas actuels où les corps sont brûlés " en meule " à l'intérieur d'une caisse de bois posée à même le sol et couverte par une superstructure qui constitue le bûcher, comme chez les Jaba à Bali (Charras, 1979 , p. 156) ; or, les effets de délimitation observés à Reichstett dans le mode de répartition des os pourraient rendre compte de parois qui ont disparu. Mais si l'hypothèse d'une crémation dans une caisse peut être a priori envisagée sur cette base, la caisse ne pouvait en aucun cas être posée directement sur le sol, du fait qu'à l'ouest comme à l'est la limite de répartition des os outrepasse celle de la rubéfaction et que, sous les os, le sol est chauffé.

On doit alors concevoir une architecture élevée; le caractère hétérogène de la crémation et les grands écarts d'ustion observés entre les os ne sauraient traduire une ventilation insuffisante ayant empêché une crémation correcte. Au contraire, la rubéfaction du sol indique que l'appel d'air s'est produit et a même été important ; l'agencement des bûches est donc probablement responsable en grande partie de cette coloration.

Néanmoins, la combustion doit s'être effectuée très près du sol pour pouvoir le chauffer à ce point et c'est pourquoi il faut s'interroger sur le mode de mise à feu qui joue un rôle non négligeable; en effet, plus il se fait en hauteur, plus les résidus qui retombent jouent le rôle d'isolant du sol (Pautreau, 1994, p. 314). Il est ainsi très probable que le feu est parti du sol à Reichstett. On rappellera, à l'appui de cette hypothèse, la présence de cette aire charbonneuse de forme vaguement circulaire très localisée au centre de la fosse, dont les limites se situent à distance de ses parois (fig. 9) ; il s'agit là très probablement de l'emplacement du foyer. Bien que le bûcher s'enflamme rapidement en hauteur et qu'au bout d'un moment les corps entrent en autocombustion, il a suffi à produire la rubéfaction du sol autour. Le bûcher a donc été installé dans la fosse, et non pas directement audessus, contrairement à ce que l'on restitue par exemple 


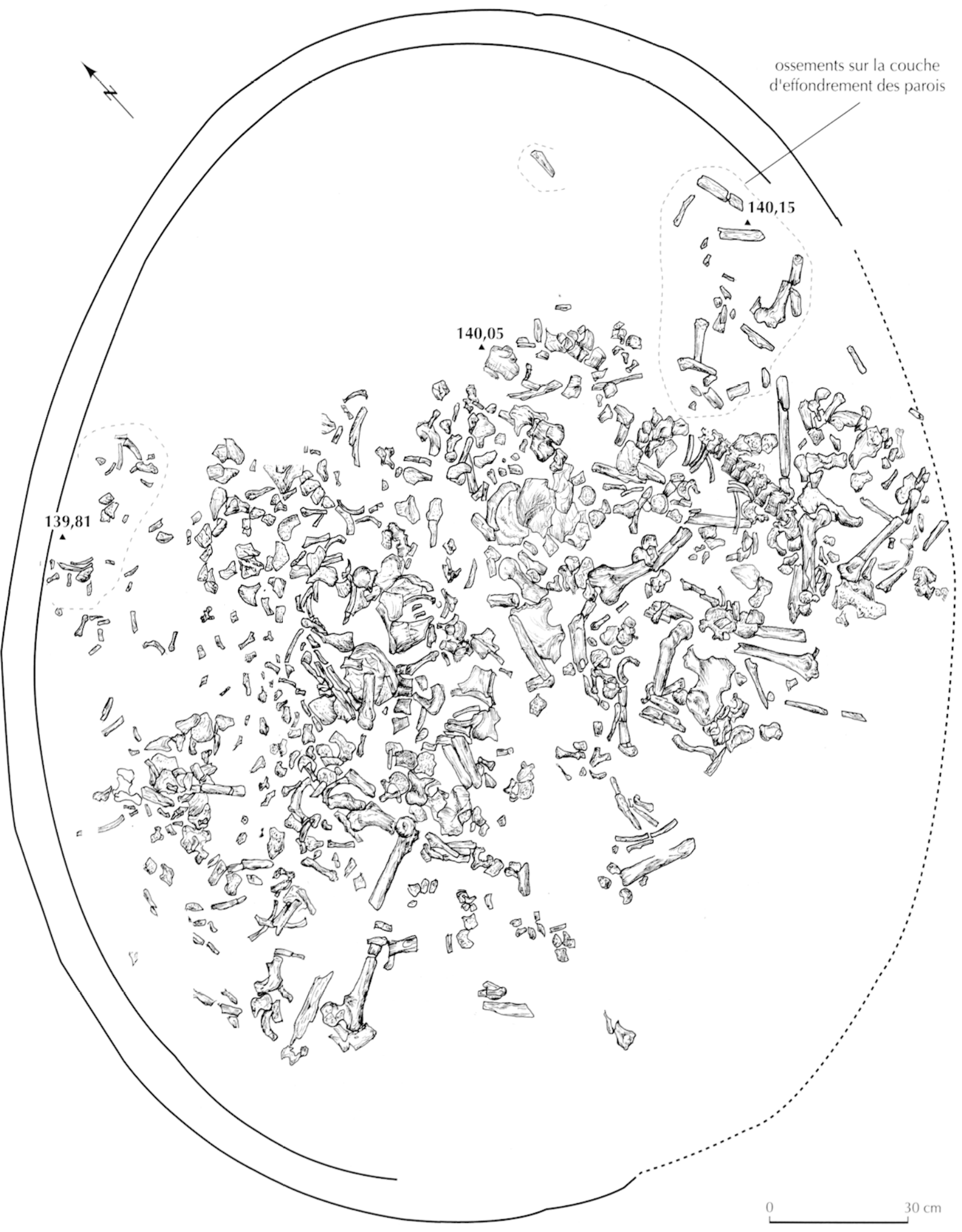

Fig. 11 - Surface de l'amas d'ossements, décapage 1 (dessin F. Blaizot). 
des tombes-bûchers romaines (Gaitzsch, Werner, 1993, p. 61 et 64$)$.

\section{TAPHONOMIE DE L'AIRE DE COMBUSTION}

L'évolution taphonomique de l'aire de combustion est abordée à présent à travers les sédiments. Une phase de sédimentation serait intervenue peu de temps après la combustion. La genèse de l'accumulation permet de préciser les principales étapes de la crémation. L'accent est mis sur l'importance des transformations subies par les sédiments au cours de la combustion. Le contact entre un dépôt obtenu en milieu réducteur et un dépôt obtenu en milieu oxydant est le fail des phénomènes de désagrégation chimique et des processus dynamiques.

\section{Orientations, description}

La calcination d'un sédiment en domaine carbonaté provoque, à des températures voisines ou supérieures à $500^{\circ}$, la transformation progressive des carbonates en un oxyde de calcium qui est à la base de toutes les formations superficielles calcaires, la chaux. Par calcination, on obtient de la chaux vive qui par addition avec l'eau donne le lait de chaux: $\mathrm{CaO}+\mathrm{H}_{2} \mathrm{O} \rightarrow \mathrm{Ca}(\mathrm{OH})_{2}$. $\mathrm{Au}$ contact de l'atmosphère, la chaux produite s'hydrate et se dissout rapidement. Mais lorsque le gaz carbonique $\left(\mathrm{CO}_{2}\right)$ est en quantité suffisante lors de la combustion, la chaux se précipite sous forme de carbonate de calcium (forme stable). Les sols meubles plus poreux améliorent la diffusion des gaz $\left(\mathrm{CO}_{2}\right)$, ce qui faciliterait également cette altération lors de la combustion. Ce processus est à l'origine de la formation de couches de cendres blanches observées sur des foyers en contexte archéologique (Brochier, 1984; Courty, 1984). La comparaison de lames minces de dépôts carbonatés chauffés a montré trois évolutions (Courty, 1984) :

- disparition des lits sparitiques ;

- augmentation de la porosité fissurale ;

- opacification des lits micritiques (coloration en gris).

Dans certains cas, le feu peut provoquer une production de limons : certains limons fins carbonatés des aires de combustion sont d'origine végétale et résultent de la transformation des oxalates de calcium contenus dans les plantes brûlées (Brochier, 1984). Ce phénomène expliquerait la présence de grains de calcite dans les sédiments de foyers (masse carbonatée micritique à rhomboèdres) (Courty, 1984).

Or, à Reichstett, si l'aire de combustion est établie sur un matériel parental carbonaté (loess), celle-ci ne présente pas de dépôts carbonatés, ce que l'on devrait alors théoriquement imputer à un manque de $\mathrm{CO}_{2}$ et à une dissolution postcrémation. Le faciès de combustion est ici défini par une aire d'accumulation charbonneuse grise à noirâtre, faite de matériaux pulvérulents associés aux lœess micacés du fond de fosse. L'accumulation ne présente pas de cimentation carbonatée charbonneuse, le sédiment est riche en limons fins agrégés; les niveaux reposent sur un sédiment non altéré et compact. Un sédiment rougeâtre recouvre le pourtour de la crémation et se différencie nettement du matériel sédimentaire encaissant. On note l'absence de stratification à l'intérieur du dépôt rubéfié, celui-ci semble sceller en partie la structure ; au centre, le fond de la fosse n'est pas affecté par la rubéfaction. L'horizon supérieur est caractérisé par un dépôt brunifié homogène qui indiquerait l'absence de perturbations postérieures.

On observe successivement :

- un lœess décarbonaté ;

- une zone noircie avec une fraction organique carbonisée ;

- un sćdiment coloré en rouge par les oxydes de fer et de titane sur le pourtour de la fosse ;

- un horizon supérieur brunifié.

La genèse du faciès décrit ci-dessus a été déclenchée par le comportement de la combustion (intensité, durée, chaleur produite, flammes). Des observations sur des dépôts carbonisés expérimentaux (Courty, 1984) montrent qu'au cours de la dégradation d'un foyer à l'air libre, l'épaisseur de sol carbonisé peut se réduire de moitié en quelques semaines seulement du fait de l'activité biologique; dans ces cas-là, on observe également un tassement et une évolution des teintes vers le gris et, en quelques mois seulement, l'aire carbonisée passe sensiblement à une aire panachée, tant verticalement qu'horizontalement. Or, nos observations sur l'aire de combustion de Reichstett montrent que le dépôt charbonneux est au contraire très mélanisé et peu perturbé, et que la stratigraphie est proche de celle de l'origine (faible diminution de la couche de charbons); on n'observe pas de processus de transformation chimique à ce niveau, tandis qu'un sédiment altéré se surimpose au niveau de la crémation. Ces obser- 
vations iraient dans le sens d'un colmatage rapide de la fosse.

\section{Transformation des minéraux argileux et type de combustion}

Les transformations induites par la chaleur ne se concentrent pas seulement sur le combustible, mais elles se produisent également sur le matériel parental, support du foyer. Il faut notamment une combustion entretenue et prolongée pour faire évoluer le combustible en dépôt carbonisé. Par ailleurs, la rubéfaction ne s'effectue pas au centre du foyer, mais autour de celui-ci. Au cours d'une combustion, plusicurs phénomènes affectent les minéraux argileux :

- changements structuraux de la kaolinite à $350^{\circ}$;

- destruction de la kaolinite à $500^{\circ}$;

- déshydratation des argiles gonflantes à $500^{\circ}$;

- destruction des matériaux argileux à $800^{\circ}$; à cette température, seuls les feldspaths et les quartz résistent ainsi que les oxydes de fer ( $\mathrm{Fe} \mathrm{+++,} \mathrm{coloration} \mathrm{rouge)}$ (Mathieu, Stoops, 1972). Le degré et la rapidité de destruction des minéraux argileux dépendraient donc de l'intensité de la combustion, mais on sait également qu'une atmosphère réductrice entraine une destruction plus rapide des minéraux qu'une atmosphère oxydante. Selon M.-A. Courty (1984), la combustion totale de la matière organique utilisée dans la combustion (bois, végétaux) est réalisée lorsque tout le carbone présent est désagrégé sous forme de $\mathrm{CO}_{2}$, ce qui nécessite des températures constantes de l'ordre de $950^{\circ}$ à $1000^{\circ}$ que seule l'utilisation d'un four permet d'atteindre. En revanche, la calcination et l'apparition des oxydes ferriques sont réalisées autour de $800^{\circ}$.

Ces informations permettent d'arriver à deux conclusions dans le cas qui nous occupe :

- la température maximale obtenue lors de la crémation n'a pas pu dépasser $800^{\circ}$ (conservation des oxydes de fer) ;

- le lit charbonneux de la crémation serait dû à une combustion en atmosphère réductrice (dans laquelle le matériel inflammable ne s'est pas consumé normalement) présente en fond de fosse. Le charbon de bois s'obtient en effet lorsque la combustion est incomplète, le produit de combustion étant étroitement lié aux conditions de calcination. Par ailleurs, on considère que dans un feu de courte durée l'essentiel des produits de

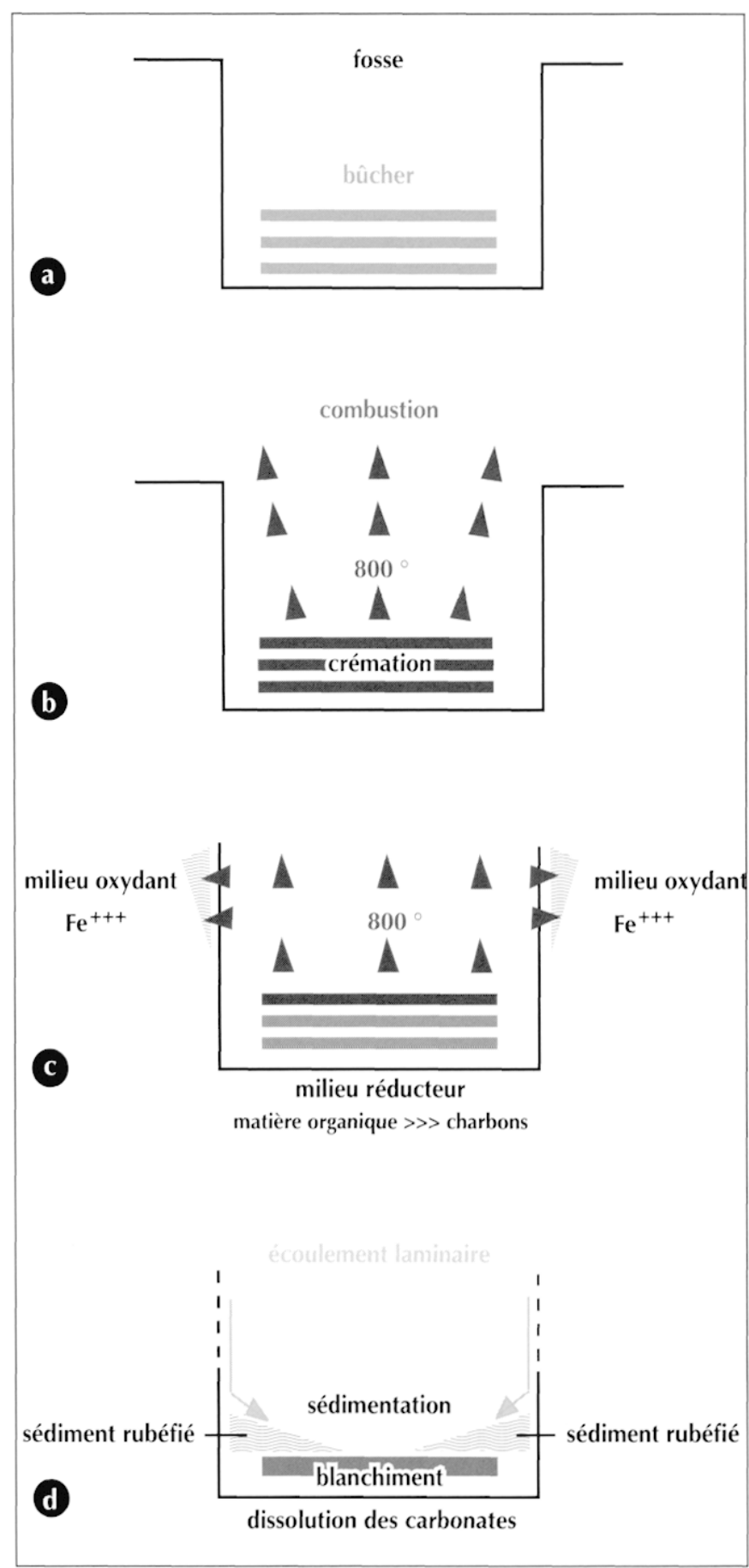

Fig. 12 - Processus dynamiques de la crémation (réalisation X. Boës).

combustion est ćgalement constitué de charbons ; un feu entretenu (température élevée de longue durée) produit en revanche des carbonates de calcium, ce qui n'a pas été observé dans la fosse. Cependant, il reste difficile d'affirmer que le feu a été de courte durée sur la seule présence des charbons, les carbonates ayant pu être dissous rapi- 
dement par l'eau atmosphérique, d'autant que l'on constate à Reichstett une sédimentation due à un écoulement laminaire (fig. 12).

Cette analyse permet donc de restituer deux genèses différentes au sein de la fosse :

L'action du feu sur le sédiment argileux s'est produite dans la zone des hautes températures, là où le milieu est oxydant, c'est-à-dire vers le haut des parois de la fosse (destruction des minéraux argileux, libération des oxydes de fer). Par contre, vers le foyer, le milieu réducteur (fond de fosse) a provoqué à la surface du sol une couche noircie (charbons). C'est par cette différence entre le milieu réducteur et le milicu oxydant que l'on peut expliquer la présence d'os incomplètement brûlés (combustion incomplète) et également l'aspect contradictoire des données sédimentaires (sol rubéfié au contact du sol noirci). Le caractère oxydant ou réducteur du milieu de combustion est ćgalement lié à l'épaisseur de la couche carbonisée : plus la couche est mince plus la rubéfaction est marquéc, car les dégazages sont plus intenses (maximum atteint en haut des parois de la fosse). Vers le lit de cendres, les températures diminuent rapidement, la couche carbonisée est plus épaisse, on constate un blanchiment sous le sol cendreux. Le contact entre les deux sédiments s'explique par des processus dynamiques postcrémation, en ambiancc humidc (ćcoulement laminaire, fig. 12). Si les conditions de calcination ont donc pu être appréhendées par le matériel sédimentaire, il n'est toutefois pas possible, en l'absence d'une analyse micromorphologique, d'établir une relation simple entre la quantité de sédiment noirci et la quantité de combustible utilisé, car trop d'éléments entrent en jeu (types de végétaux, parties végétales utilisées).

X. B.

\section{L'ARCIITECTURE DU BÛCHER}

Les corps n'ont certainement pas reposé directement sur les bûches puisque l'aire de dispersion des os diffère de celles de la répartition des résidus et de la rubéfaction. On restituera donc un bûcher surmonté d'une plate-forme sur laquelle furent entassés les cadavres ; audessous de cette plate-forme, fut pratiqué " un foyer " (le bûcher stricto sensu) d'allure plutôt arrondie; de tels bûchers sont connus à l'heure actuelle en Tasmanie (Wahl, Wahl, 1983, p. 517). Nous ne disposons d'aucun élément pour définir son mode de construction ni la façon dont elle était maintenue sur le foyer; aucun trou de poteau n'a été retrouvé sur le fond, et le sol contemporain à l'extérieur de la fosse n'est pas conservé. Rien ne permet de dire non plus si des bûches ont été placées au-dessus du corps, bien que cet aménagement soit probable dans la mesure où il garantit une crémation intensive (Wahl, 1981, p. 275). L'hypothèse d'une plateforme est en tout cas compatible avec la rubéfaction des parois de la fosse, attestée par la structure de la couche qui résulte de leur effondrement. En effet, cette plateforme aurait provoqué un retour des flammes qui seraient venues lécher les parois.

Reste la question des effets de délimitation linéaire observés dans la répartition des os. Si l'on considère l'hypothèse de parois, on imagine difficilement que ces dernières aient constitué les montants verticaux de l'ensemble du bûcher; en effet, ses limites ouest et est venaient au contact des bords de la fosse, ainsi que l'indique l'absence d'effet de délimitation sur ces deux côtés. La fermeture continue des quatre côtés du bûcher aurait alors empêché l'air de circuler. Il est ainsi plus plausible d'interpréter ces délimitations comme les indices d'un contenant des corps, c'est-à-dire restreintes à l'architecture de la seule superstructure, à l'image des constructions utilisćes pour certains moines bouddhistes (Wahl, Wahl, 1983, p. 517), plutôt que comme un élément constitutif de l'élévation du bûcher. La masse de cadavres exclut l'éventualité du transport du contenant, qui ne peut donc être assimilé à un cercueil. On doit alors imaginer une véritable architecture crématoire. Toujours dans cette perspective, il peut paraittre étonnant que la destruction par le feu des parois, qui contraignaient l'ensemble des corps à l'origine, n'ait pas modifié l'aspect final du dépôt, alors qu'il est fort probable que le bois ait brûlé arant les os. Le mode d'effondrement du bûcher expliquerait ce phénomène, expérimentalement observé sur une crémation d'animaux, au cours de laquelle le bûcher s'est effondré sur lui-même, en ne produisant que de rares dispersions des pièces osseuses au-delà de ses limites (MacKinley, 1997, p. 134).

Cependant, ces effets de délimitation peuvent également être attribués à une architecture postérieure à la crémation. Les os auraient été repoussés à distance des parois sud et nord, et on peut même imaginer que deux planches, placées l'une au sud et l'autre au nord, 


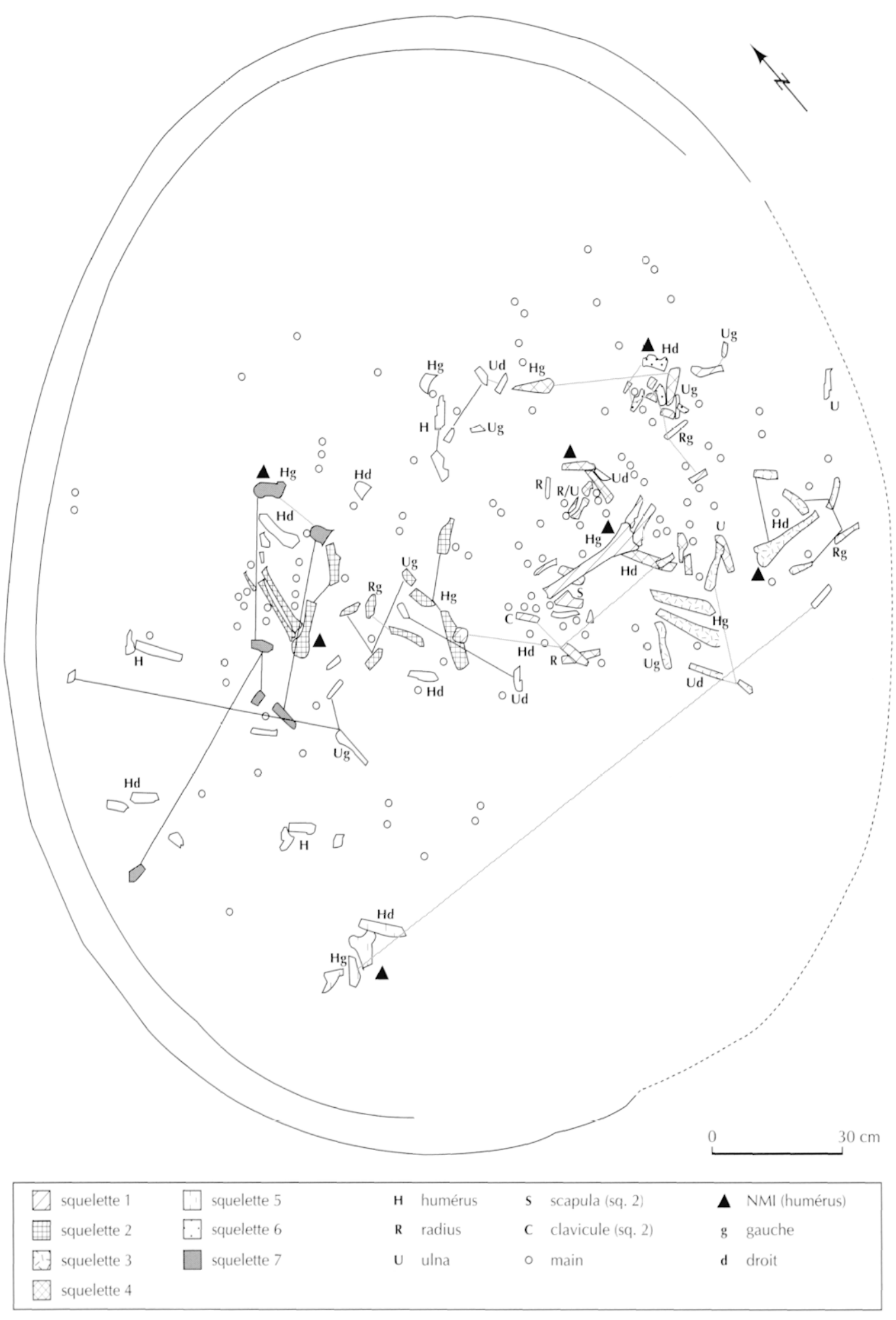

Fig. 13 - Répartition des membres supérieurs identifiés des sujets adultes el liaisons anatomiques dans la fosse 143 (dessin, DAO F: Blaizot). 


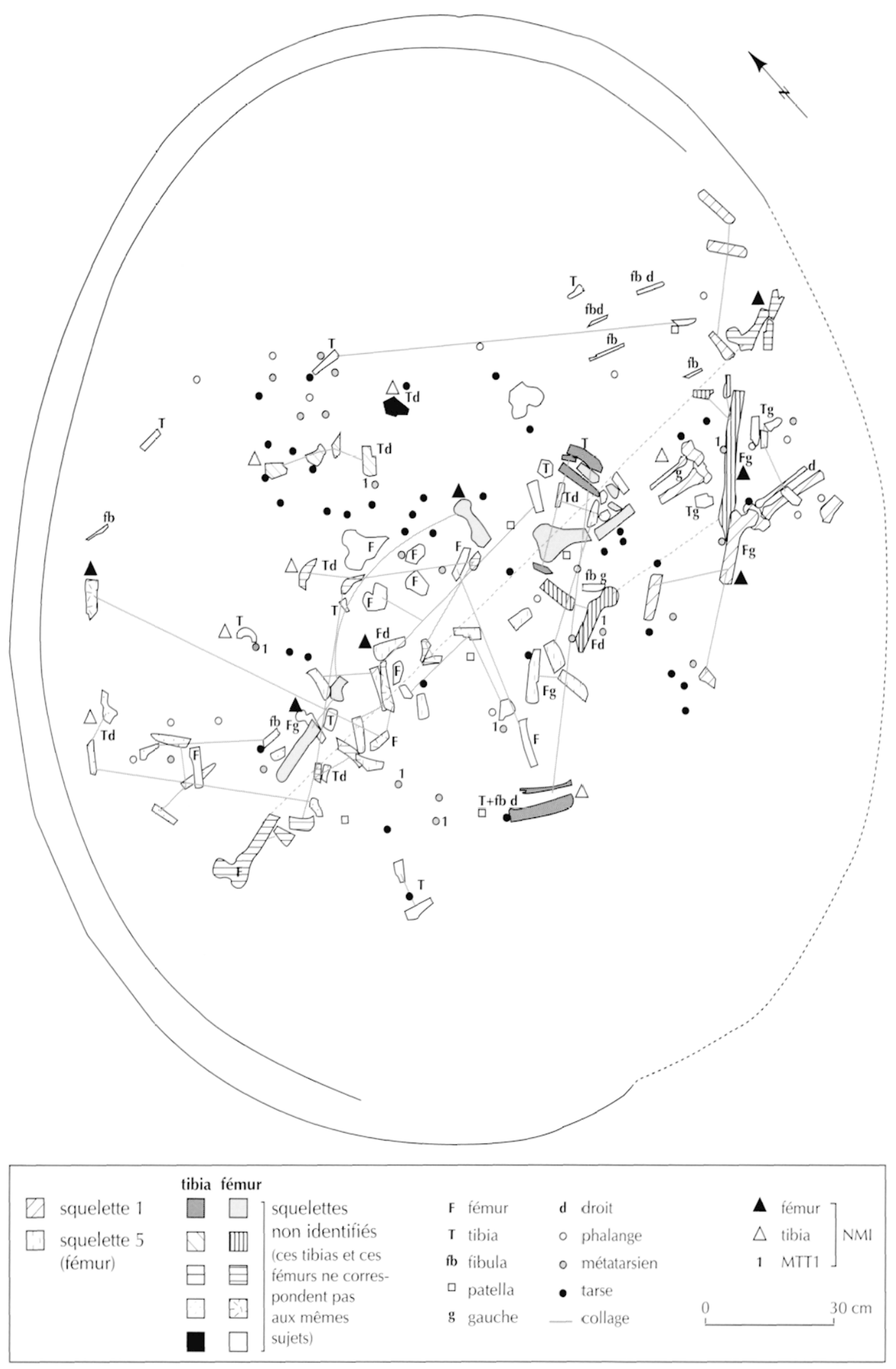

Fig. 14 - Répartition des membres inférieurs identifiés des sujets adultes et liaisons anatomiques dans la fosse 143 (dessin, DAO I: Blaizot). 
auraient contraint la masse osseuse sur ces deux côtés, aménageant une espèce de " coffrage " à l'intérieur de la fosse. Si c'est le cas, cette construction fut réalisée après l'effondrement des parois rubéfiées de la fosse, puisque la couche qui lui correspond repose sur les os situés en périphérie. Il n'existe cependant pas de véritables arguments pour étayer cette hypothèse. En effet, l'amplitude des liaisons ne semble guère plus importante au nord et au sud qu'ailleurs (fig. 13 et 14), et seule la présence de quelques os sur la couche d'effondrement de la paroi au nord-est pourrait résulter d'un balayage.

Nous estimons ne pas être en mesure de privilégier une interprétation plutôt qu'une autre à partir des témoins archéologiques qui nous restent.

L'architecture du bûcher peut également expliquer l'hétérogénéité du degré d'ustion des différents os. En effet, dans le cas de Reichstett, elle ne peut être mise sur le compte d'une faiblesse du bûcher comme en témoigne la rubéfaction du sol et la couleur crayeuse d'un grand nombre d'ossements. L'expérimentation d'Acy-Romance a montré par ailleurs que la température d'un bûcher peut rapidement monter et on sait que de simples rondins empilés produisent des pointes de température proches de $1400^{\circ}$ (Shipman et al., 1984, p. 308). De même, l'entassement des corps ne peut être tenu responsable de ces variations, la forte proportion de cadavres, et donc de graisses, ayant au contraire probablement favorisé la combustion des chairs; d'autre part, tout ne se consume pas en même temps, les os ne brûlant qu'une fois que les chairs et les tendons sont détruits, et $800^{\circ}$ y suffisent (Wells, 1960, p. 35 ; Buikstra, Swegle, 1989, p. 251). Dans la mesure où les corps se situaient en hauteur par rapport au bûcher, et où l'atmosphère était réductrice dans le fond et oxydante en hauteur, il est beaucoup plus plausible d'envisager que lorsque les os se sont disloqués certains sont tombés dans les résidus de bois sous-jacents et ont cessé de brûler.

\section{NATURE DU DÉPÔT}

Ponctuellement et à tous les niveaux de décapage, on observe des ossements en connexion anatomique (fig. 15). Il s'agit principalement de segments vertébraux des étages thoracique et lombaire et de parties d'hémithorax comprenant ou non la clavicule. Les ensembles en connexion, qui se rapportent à des régions anato- miques différentes, ne sont pas en relation logique les uns avec les autres. À trois reprises les liaisons anatomiques sont conservées entre un tibia et une fibula et dans deux cas entre ces os et ceux du tarse (tarse postérieur ou tarse postérieur et antérieur). Des rapports de logique anatomique sont conservés deux fois entre une scapula et une clavicule. Deux membres supérieurs appartenant à deux sujets différents sont maintenus en connexion ou en situation de logique anatomique. Enfin, la connexion coxo-fémorale est préservée dans deux cas. En dehors de ces liaisons primaires, il existe un certain nombre de "données latentes " (Leroi-Gourhan, 1986) plus difficiles à interpréter compte tenu du nombre d'individus. Il s'agit d'éléments qui se trouvent dans une situation de proximité par rapport à d'autres régions anatomiques pouvant indiquer une attitude plausible du corps; on songe tout particulièrement à la présence d'os des mains parmi des côtes en connexion. De même, il existe des os relevant d'un même ensemble anatomique qui se trouvent disloqués dans un même secteur, et dont l'état de conservation ne permet pas de dire s'ils appartiennent à un même individu; on mentionnera la présence d'un fragment d'os coxal droit en connexion avec un sacrum à proximité desquels se trouve le segment proximal d'un fémur droit, ou encore des os des mains, vu des pieds, qui se trouvent en relation spatiale correcte avec les os auxquels ils se rapportent en théorie.

La préservation d'un grand nombre de connexions anatomiques entre des pièces labiles nous conduit à envisager que ce sont des cadavres et pas des ossements disloqués qui ont été brûlés dans cette fosse. On retrouve certaines caractéristiques observées dans des contextes de crémations traditionnelles et expérimentales, comme le détachement systématique des membres et le maintien du tronc (Pautreau, 1994), ou la résistance de la hanche et des vertèbres inférieures (Wahl, 1981, p. 272 ; Méniel, 1994, p. 283, 286). Néanmoins, cette interprétation ne peut être totalement argumentée dans la mesure où le maintien de connexions sur des régions anatomiques est un phénomène ponctuel dans cet ensemble, la plupart des ossements offrant un brouillage apparent qui occulte l'identification spontanée des différents squelettes. Il est de ce fait possible de lui opposer l'hypothèse que ce sont à la fois des os frais et des parties de corps " débitées " qui furent déposés et brûlés dans cette fosse, plutôt que des cadavres entiers. Or, avant d'examiner la distribution 
spatiale des ossements reconnus comme appartenant à un même sujet par l'étude des liaisons anatomiques secondaires (Duday, 1987a), cette proposition ne peut être entièrement réfutée; on remarquera seulement qu'il n'existe aucun argument pour l'étayer a priori, telles que la reconnaissance de fractures qui ne relèveraient

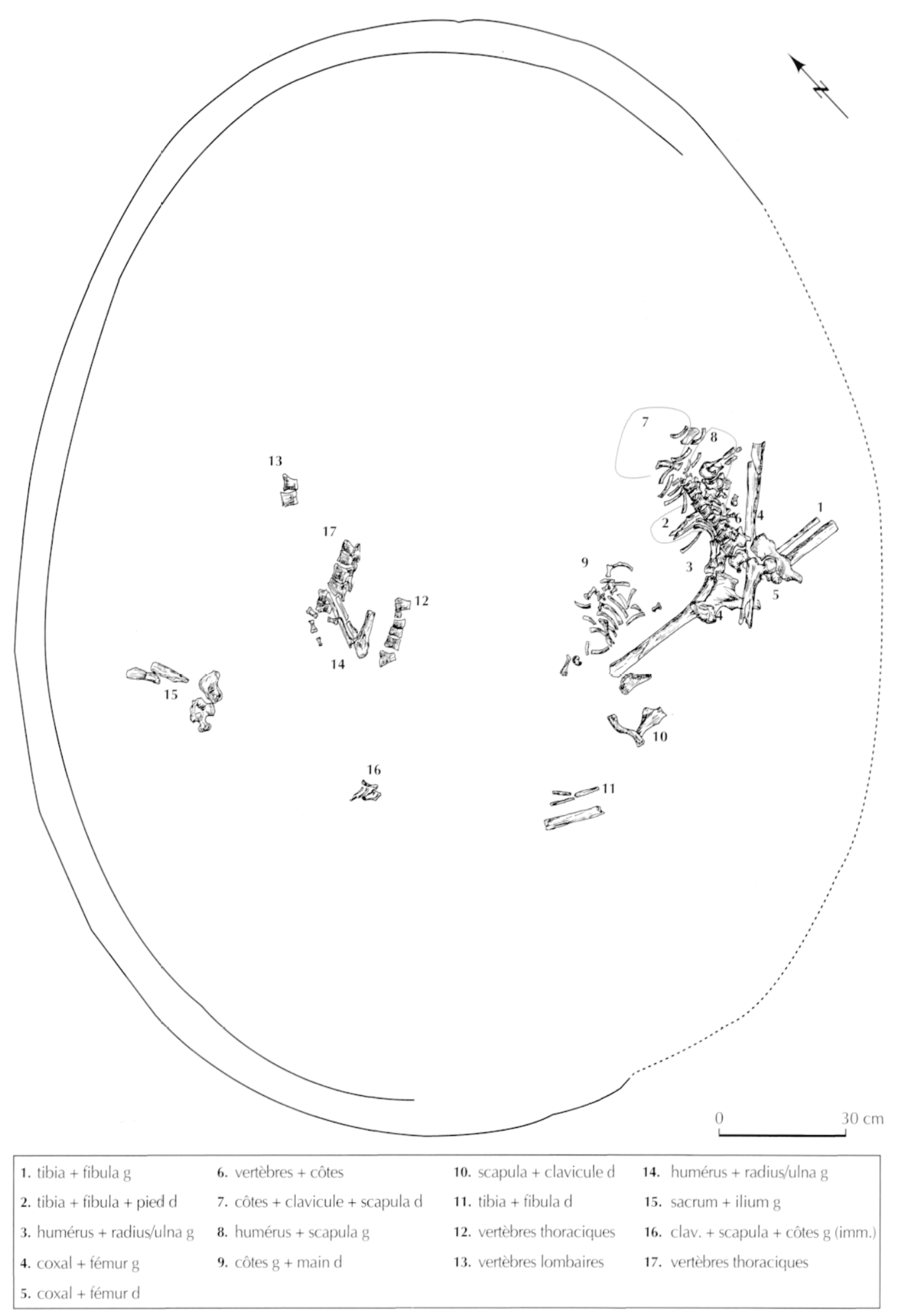

Fig. 15 - Connexions anatomiques dans la fosse 143 (dessin F. Blaizot). 
pas d'une thermofraction ou celle de traces de découpe. Cependant, il reste encore la solution que les ossements aient été décharnés naturellement par décomposition puis brûlés dans un second temps, puisque le temps nécessaire au séchage complet d'un os est bien supérieur à celui que demande la décomposition d'un corps. Ainsi, la proposition d'une crémation d'os frais n'est pas incompatible avec l'hypothèse d'une décarnisation naturelle, mais il est impossible sur son seul aspect de distinguer un os qui a brûlé avec la chair d'un os frais décharné (Buikstra, Swegle, 1989). En effet, seules des microradiographies susceptibles de révéler des attaques bactériennes post-mortem permettent de prouver que la crémation a été réalisée sur un corps décharné (Grévin et al., 1990).

La dynamique de constitution de cet ensemble est donc une question qui doit se poser dès cette étape de notre raisonnement, et plusieurs éventualités s'offrent à nous :

- des corps, ou des parties de corps et des os, ont été déposés successivement dans cette fosse, puis l'ensemble fut brûlé en une seule fois ;

- il s'agit d'un lieu de crémation ayant fait l'objet de plusieurs utilisations successives ;

- les dépôts et la crémation se sont faits en une seule fois.

Nous ne possédons pas d'éléments pour argumenter la première hypothèse. Le fait qu'il n'en existe aucun indice probant, tels que des rangements, ne prouve rien, des dépôts successifs n'impliquant pas obligatoirement un remaniement systématique des restes des sujets précédents. L'organisation de la couche, qui présente des segments en connexion et des zones de quasi totales dislocations (qui seront étudiées en détail plus loin), ne témoigne pas d'une gestion de l'espace de type collectif. On dira toutefois que s'il s'agit de dépôts et de crémations successifs, ils ne peuvent pas avoir été pratiqués sur une longue durée puisque, dans le secteur sud-ouest de la fosse où l'on observe le plus grand nombre de segments anatomiques en connexion, les os se chevauchent sans sédiment intermédiaire et n'offrent aucune démonstration évidente d'un remaniement des uns par l'arrivée des autres.

Aucune couche de terre ni de charbon ne sépare la couche d'ossements en plusieurs niveaux, ce qui $a$ priori est incompatible avec l'hypothèse de réutilisations successives du même bûcher. Cependant, des études de bûchers, expérimentaux ou traditionnels, montrent que la présence de charbons n'est pas systématique après une crémation, soit parce que le bois utilisé ne produit pas de résidus, soit parce que le combustible s'est réduit à une cendre pulvérulente qui s'est dispersée au vent (Lambot, 1994). Seul le fait que tous les ossements reposent sur la même couche charbonneuse, et que les os des couches inférieures ne sont pas plus brûlés que ceux qui se trouvent en surface, nous conduit à réfuter cette hypothèse.

Nous n'avons, par les seules données archéologiques et d'anthropologie descriptive, aucun argument à objecter à la troisième hypothèse ; au contraire, les observations semblent converger en son sens. Celle-ci sera donc discutée à l'aide d'autres données relatives à la représentation et à la chorologie des pièces osseuses.

\section{RÉPARTITION DES INDIVIDUS SELON LE SEXE ET L'ÂGE AU DÉCÈS}

\section{ESTIMATION DU NOMBRE MINIMUM D'INDIVIDUS}

Le Nombre minimum d'individus (NMI) a été estimé à partir de tous les paramètres possibles pour chaque unité osseuse individualisable. Il s'agit dans un premier temps d'obtenir un nombre correspondant à la fréquence d'un fragment déterminé, puis d'augmenter si possible cet effectif par la recherche des appariements. Dans un troisième temps seulement, la recherche d'éventuelles liaisons de contiguité ou de compatibilité permet de discuter la représentation de chaque sujet et sa distribution dans l'espace (Duday, 1987a). Compte tenu des modifications parfois importantes qui se produisent sur les os brûlés (déformation, réduction de la taille et du diamètre, forte fragmentation) les deux derniers exercices sont excessivement compliqués dans un tel contexte ; les probabilités que l'on a d'établir des liaisons secondaires y sont extrêmement réduites.

Le NMI est de 11 sujets qui se divisent en 7 adultes et en 4 jeunes enfants.

Les pièces sur lesquelles ce nombre a été établi sont les suivantes: la région pétreuse du temporal $(\mathrm{N}=11$ sans distinction possible d'âge), les restes dentaires (maxillaire $=7$ adultes, dents $=4$ enfants), le fémur, l'humérus et les os de l'avant-bras. Le nombre de sept adultes est également donné par l'atlas (qui n'a été retrouvé que pour trois immatures), par la scapula, 
le talus, le premier métacarpien et le premier métatarsien. En revanche, la clavicule offre un score de cinq adultes seulement (tandis qu'elle représente bien les quatre enfants), comme les os des jambes (tibia et fibula), la mandibule et la patella, tandis que le carpe en donne quatre. Les dix os coxaux adultes identifiés déterminent cinq sujets sûrs, mais deux pièces s'excluent mutuellement et sont incompatibles avec les autres ce qui permet d'évaluer un NMI de 7 individus. Cette région ne représente en revanche que deux sujets immatures.

\section{ESTIMATION DU SEXE DES ADULTES ET DE L'ÂGE AU DÉCÈS DES SUJETS ADULTES ET IMMATURES}

Quatre os coxaux fournissent suffisamment d'éléments pour estimer le sexe. Ils correspondent à quatre sujets différents. Bien entendu, chacun des critères préconisés dans les deux méthodes de J. Bruzek (Bruzek, 1991 ; Bruzek et al., 1996) n'a pu être systématiquement vérifié, les os étant très lacunaires. Les résultats nous donnent deux hommes et deux femmes (tabl. I).

Compte tenu de la fragmentation des os et du temps qu'il nous a été possible de consacrer à cette étude, l'âge au décès des adultes n'a pas été recherché à partir des sutures crâniennes. Il a été estimé sur la base de l'évolution de la face sacro-pelvienne pour les quatre individus dont le sexe a pu être identifié par les os coxaux (Lovejoy et al., 1985). Les résultats doivent cependant être considérés à leur juste valeur. En effet, non seulement la définition que les auteurs donnent des caractères est subjective, ce qui entraîne des erreurs intra-observateurs importantes, mais de plus les différences liées au sexe (processus différentiels de vieillissement, contraintes biomécaniques spécifiques aux femmes) ne sont pas prises en considération (Broqua, 1998). Cette méthode reste donc imprécise et les erreurs d'estimation se révèlent importantes.

L'âge au décès des immatures n'a pu être estimé, dans la série de Reichstett, qu à partir du degré de maturation des dents conservées (Moorrees et al., 1963a, 1963b) et de la croissance osseuse des pièces présentes (Birkner, 1980), aucun os long n'étant complet pour utiliser la longueur diaphysaire. Les résultats sont les suivants : un sujet est décédé entre 6 mois et un an, deux autres autour de 1,5 à 2,5 ans, et le quatrième vers 3 à 5 ans (tabl. II).

\section{LE PROCESSUS CRÉMATOIRE}

\section{REPRÉSENTATIVITÉ DES DIFFÉRENTES RÉGIONS ANATOMIQUES}

La masse totale en ossements qui atteint $9257,59 \mathrm{~g}$ pour 11 individus est relativement faible par rapport aux références théoriques. Bien que ces dernières présentent de grandes différences selon les auteurs (Herrmann, 1976 ; Krogman, 1978; Kunter, 1989 ; Murray, Rose, 1993 ; MacKinley, 1994a ; Warren, Maples, 1997) le poids total obtenu à Reichstett n'est compatible qu'avec les valeurs minimales des données comparatives de référence les moins élevées (Herrmann, 1976; MacKinley, 1994a). En effet, celles-ci donneraient $10676 \mathrm{~g}$ (Herrmann, 1976) et 11016,5 g (MacKinley, 1994a) pour 11 sujets. Ces valeurs peuvent toutefois être considérées comme acceptables pour trois raisons. Ia première est qu'elles correspondent au poids théorique minimum de 11 adultes alors que nous avons 4 enfants et 7 adultes. La deuxième est que le mode crématoire (conduction ou crémation passive) peut modifier le poids osseux (MacKinley, 1994b) et que certains os résistent plus mal que d'autres au feu (Doklàdal, 1967, p. 81, 1970; Duday, 1996; Taffanel et al., 1998). Enfin, l'évolution des os dans la terre et leur traitement archéologique peuvent également être à l'origine d'un déficit osseux (Blaizot, à paraître). Cependant, si la présence d'enfants et les problèmes de conservation paraissent a priori constituer des raisons probables à l'insuffisance du poids total des ossements, l'hypothèse d'un prélèvement postcrématoire ne peut être totalement écartée. En effet, par un certain nombre d'arguments développés cidessus, nous avons pu retenir la proposition d'une crémation de cadavres complets et de dépôts simultanés. Or, certaines pièces osseuses donnent un NMI de 5 adultes tandis que d'autres permettent d'en comptabiliser 7. De plus, même dans les cas où le NMI est de 7, nous n'obtenons des appariements dans le cas d'os pairs que pour cinq sujets, deux étant sous-représentés. Il convient alors d'analyser ce phénomène par l'évaluation des poids de chaque région anatomique. À cet égard, nous avons utilisé les indices pondéraux qui permettent d'éviter les biais induits par la conservation différentielle des ossements, en prenant en compte tous les fragments dont l'origine anatomique est identifiée et non pas uniquement ceux qui participent au calcul du NMI (Duday, 1987b). 
Tabl. IV - Comparaison des indices pondéraux par régions anatomiques (population totale, adultes et enfants) avec ceux d'une population théorique (variations minimale et maximale).

Clav. : clavicule, Scap. : scapula ; (t. Sc. : ceinture scapulaire (clavicule + scapula); Av. br. : avant-bras (radius + ulna); M. sp. : membre supérieur (humérus, radius, ulna); M. inf. : membre inférieur (fémur, tibia, fibula); Diaph. : totalité des diaphyses du squeletle; Extr. : extrémités (main et pied).

\begin{tabular}{|c|c|c|c|c|c|c|c|c|c|c|c|c|c|c|c|c|c|c|c|c|c|}
\hline & Crâne & Vertèbres & Côtes & Clav. & Scap. & Ct.Sc. & Humérus & Radius & Ulna & Av. br. & M. sp. & Main & Coxal & Fémur & Patella & Tibia & Fibula & M. inf. & Pied & Diaph. & Extr. \\
\hline \multicolumn{22}{|c|}{ Reichstett : sépulture 143} \\
\hline adultes & 22,7 & 9,8 & 3,7 & 0,5 & 2 & 2,5 & 9,96 & 2,4 & 2,8 & 5,23 & 15,2 & 1,5 & 7,1 & 20,4 & 0,5 & 6,9 & 1,4 & 29,1 & 3,1 & 47,3 & 4,2 \\
\hline immatures & 61,78 & 2,26 & 3,9 & 0,8 & 0,6 & 0,1 & 6,4 & 0 & 0 & 3,1 & 9,6 & 0,2 & 2 & 6 & 0 & 4,75 & 1,3 & 12,1 & 0,5 & 26,15 & 0,7 \\
\hline adultes/immat. & 25,2 & 9,4 & 3,7 & 0,6 & 1,9 & 2,4 & 9,7 & 2,4 & 2,8 & 5,1 & 14,8 & 1,4 & 6.8 & 19,56 & 0,5 & 6,8 & 1,4 & 28,06 & 2,96 & 46 & 4,4 \\
\hline \multicolumn{22}{|c|}{ Krogman 1978 : indices pondéraux de référence } \\
\hline moyenne & 20,23 & 10,06 & 6,42 & 1,04 & 2,8 & 3,9 & 6,38 & 2,18 & 2,66 & 4,8 & 11,27 & 2,5 & 7,83 & 17,67 & 0,57 & 10,63 & 2,47 & 30,85 & 5,79 & 43 & 8,32 \\
\hline valeur minimum & 16,8 & 9,03 & 5,48 & 0,8 & 2,42 & 3 & 5,72 & 1,9 & 2,4 & 3,9 & 9,12 & 2,2 & 7,15 & 16,5 & 0,38 & 9,5 & 2,2 & 26 & 5 & 34,8 & 6,8 \\
\hline valeur maximum & 23,7 & 11,1 & 7,4 & 1,2 & 3,26 & 4,8 & 7,04 & 2,5 & 2,9 & 5,8 & 13,4 & 2,9 & 8,5 & 18,8 & 0,69 & 11,7 & 2,8 & 36,8 & 6,5 & 49,5 & 9,8 \\
\hline
\end{tabular}

esquilles indéterminées : 3,4\% diaphyses indéterminées : 1,84\% Total indéterminés : $5,3 \% \quad \square$ déficit $\square$ norme/acceptable $\square$ surreprésentation

Les indices pondéraux, calculés pour chaque région anatomique à partir du poids total des os brûlés, sont présentés et comparés aux références théoriques (Krogman, 1978) dans le tableau IV.

Les résultats obtenus, stades de maturation réunis (tabl. IV, adultes/immatures), montrent qu'un déficit affecte les côtes, la ceinture scapulaire, les os coxaux, les os des jambes (tibia et fibula), les extrémités et dans une moindre mesure les vertèbres dont l'indice est proche de la valeur théorique minimale. En revanche, les indices de l'humérus, du crâne et du fémur sont légèrement supérieurs aux valeurs théoriques les plus hautes. Mis à part les os des jambes et les coxaux, la mauvaise représentation concerne des pièces osseuses qui possèdent une part importante d'os spongieux, ou celles de petite taille. L'examen des indices pondéraux par grand secteur anatomique (crâne, membre supérieur, membre inférieur) permet de relativiser la sur- ou la sous-représentation de certaines pièces. Il apparaît notamment que la surrepréscntation des uncs cst fonction du déficit manifesté par d'autres, et que les déséquilibres traduits par certains segments d'un membre sont gommés lorsque les os sont regroupés par grande catégorie ; en effet, d'une part les indices pondéraux enregistrés pour les membres supérieurs et inférieurs sont corrects, et d'autre part l'indice pondéral des diaphyses entre dans la variation théorique. Ce dernier point signifie donc qu'un problème d'identification des esquilles est très probablement à l'origine du déficit observé sur les jambes et sur la clavicule ; ces os sont présents, mais classés dans les diaphyses indé- terminées. En revanche, les autres régions touchées par ce déficit ne peuvent relever d'un problème d'identification, au moins pour ce qui concerne le tronc puisqu'il s'agit de fragments qu'il est facile de reconnaître. L'hypothèse évoquée plus haut d'une conservation différentielle ou d'une résistance au feu sélective suivant les régions anatomiques nous semble pouvoir alors être retenue ici. Elle est d'autant plus probable que les tests effectués dans les crématoriums modernes montrent que les vertèbres résistent mieux que les côtes (Doklàdal, 1967 , p. 81), ce qui s'accorderait bien avec nos résultats (tabl. IV).

Si l'on examine les indices pondéraux des régions anatomiques en séparant les adultes et les enfants et qu'on les compare aux valeurs théoriques (tabl. IV), on remarque que la surreprésentation du crâne est très importante chez les immatures, alors que l'indice crânien des adultes entre dans la fourchette de variation. Une autre disproportion est constatée cette fois de manière inverse sur les os déterminés des membres (membres supérieurs et inférieurs) qui n'est pas compensée par l'ajout du poids des diaphyses immatures d'origine indéterminée. Enfin, chez les enfants, le déficit général observé sur les régions fragiles est accentué. La présence de toutes les régions anatomiques pour chaque sujet immature exclut l'hypothèse d'un dépôt d'ossements décharnés et sélectionnés de certains d'entre eux. Les anomalies enregistrées relèvent donc probablement de biais induits à la fois par l'utilisation d'une population de référence adulte et par des problèmes d'identification 
(Blaizot, à paraitre). En effet, les rapports pondéraux entre les différentes régions anatomiques ne sont incontestablement pas équivalents chez les jeunes enfants et chez les adultes (Duday, 1989, p. 469) ; par ailleurs, l'os compact étant plus mince chez. l'enfant, la fragmentation sous forme d'esquilles est augmentée et plusieurs de leurs ossements ont certainement été classés dans la catégorie des "indéterminés ".

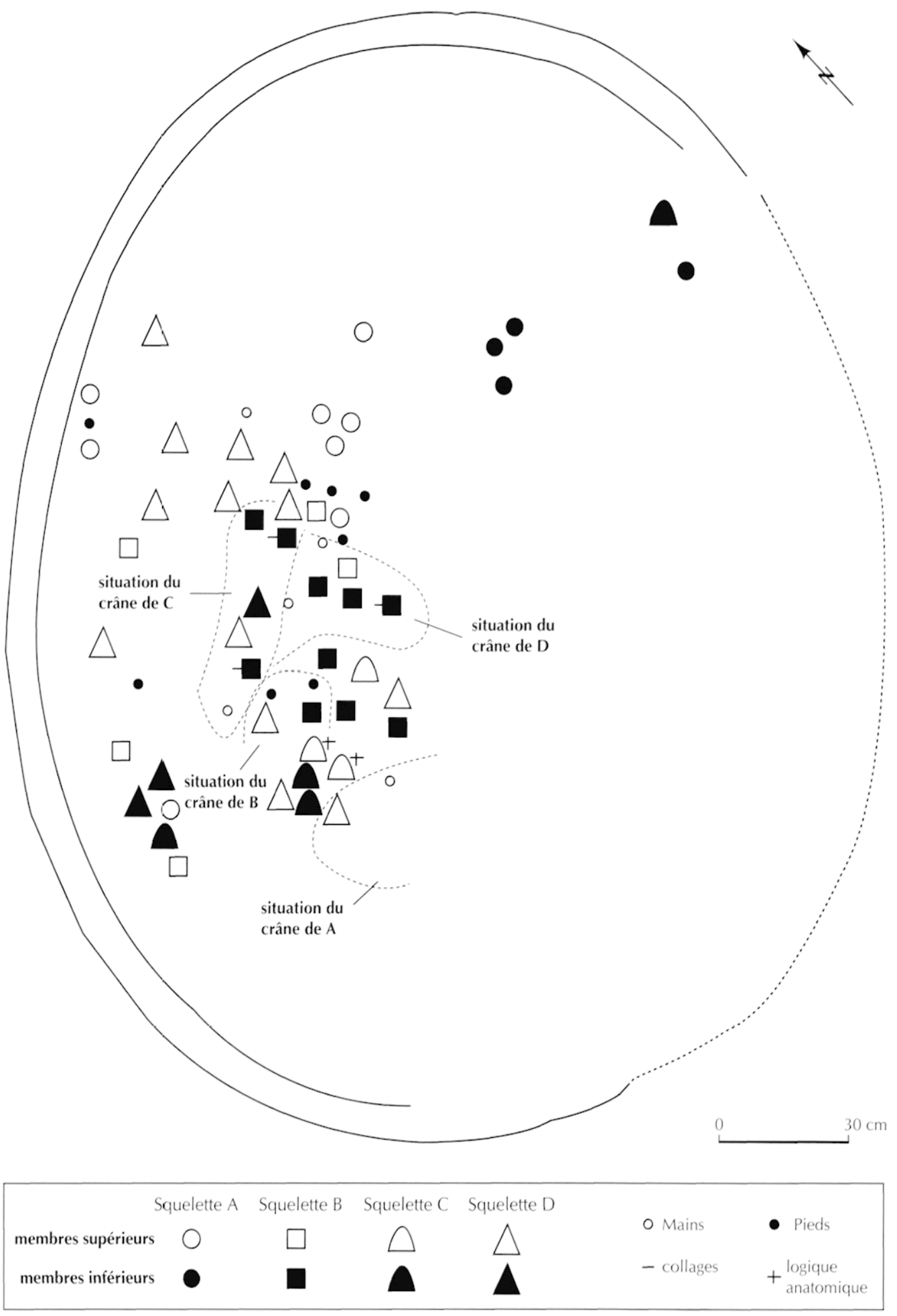

Fig. 16 -Répartition des ossements des sujels immatures dans la fosse 143 (réalisation I: Blaizot). 
Les indices pondéraux sont ainsi riches d'informations. Ils nous permettent de privilégier l'hypothèse de dépôts de cadavres complets dans la sépulture et de mettre en doute celle de mutilations de cadavres comme celle de prélèvements d'ossements choisis après la crémation.

\section{LE MODE DE DÉPÔT}

L'importante fragmentation entraîne de grandes difficultés pour attribuer les os à un même squelette. Les collages entre les petits fragments de diaphyses ou de crânes n'ont pas été recherchés systématiquement, ce qui aurait représenté un travail colossal irréalisable dans le cadre de l'archéologie préventive. En ce qui concerne les diaphyses, seuls les fragments identifiés ont fait l'objet de cette recherche. Les enfants ont été plus facilement individualisés du fait des différents stades de maturation; deux présentent le même stade de maturation (squelettes A et B) mais l'un (squelette A) possède des os plus volumineux que l'autre. Des sept adultes, cinq sont relativement bien représentés par les membres supérieurs ; l'un très gracile (squelette 1) et un autre très robuste (squelette 5) se distinguent aisément des autres. Mais dans la plupart des cas il n'a pas été possible d'associer les membres supérieurs aux membres infërieurs, et en aucun cas d'attribuer un crâne aux divers segments individualisés.

Les os qui appartiennent aux enfants se situent dans la moitié ouest de la fosse, à l'exception des membres inférieurs de l'un des deux sujets àgés de 1,5 à 2 ans et d'un fragment de fémur du plus jeune qui se trouvent dans le quart est (fig. 16). On note en revanche la présence de fragments de crânes sur toute la surface de l'amas; néanmoins, la plus grande concentration est observée à l'ouest où se trouvent également les fragments qui fournissent le NMI (dents), les os des extrémités et les éléments du tronc. L'ensemble de ces informations permet de supposer que les enfants ont été déposés dans la moitié ouest de la fosse.

Il reste difficile de restituer la position et l'orientation initiales de ces enfants avec exactitude. Une seule relation de logique anatomique est enregistrée pour les quatre squelettes, entre une scapula, une clavicule et quelques côtes gauches appartenant à l'individu le plus jeune (squelette C, fig. 16). Leur agencement se rapporte à un corps placé en decubitus dorsal et orienté la tête au sud-est. Les autres éléments de ce squelette se trouvent toutefois en situation aberrante par rapport à cette région anatomique; le tibia droit a été identifié parmi ces os en place tandis que le gauche en est distant de $30 \mathrm{~cm}$ au nord-ouest et le fémur de $1,40 \mathrm{~m}$ à l'est, les fragments du crâne sont dispersés sur $50 \mathrm{~cm}$ au nord-est et l'humérus est reconnu $20 \mathrm{~cm}$ à l'est de cet ensemble.

Les ossements du sujet le plus âgé (squelette D) présentent une organisation particulière; les os de son membre supérieur droit sont au nord-ouest et ceux du membre supérieur gauche au sud-ouest. Son crâne a été reconnu entre ces deux lots et ce qui reste de ses membres inféricurs est dispersé à l'aplomb des fragments de crâne pouvant lui être attribués et au sud-ouest de ceux-ci. L'hypothèse que le cadavre ait pu être assis à l'origine ne peut cependant être retenue compte tenu des remaniements pouvant avoir été occasionnés par l'effondrement du bûcher.

Les membres inférieurs du squelette B sont regroupés de même dans le voisinage du crâne alors que les quelques tronçons de diaphyses attribués à des membres supérieurs sont dispersés au nord, nord-est et nord-ouest de cet ensemble. Si l'ulna, la scapula et l'humérus droits sont au nord-est et l'humérus et la clavicule gauches au nord-ouest, le radius gauche se trouve avec le membre supérieur droit.

Enfin, les os du squelette A sont ceux qui présentent la plus grande amplitude de dispersion, les éléments de son crâne se trouvant au sud-ouest à une distance de $0,80 \mathrm{~m}$ des membres inféricurs. Comme on l'a vu, ses membres inférieurs sont dans le quart est de la fosse. Il n'existe aucune logique dans la situation des os gauches par rapport aux droits.

Les adultes sont retrouvés tant dans la moitié est que dans la moitié ouest de la fosse, mais les os matures restent majoritaires à l'est. L'adulte le plus gracile (squelette 1) est caractérisé par le maintien en connexion anatomique de son coude et de son épaule gauches dont la position semble indiquer que le sujet se trouvait soit placé en decubitus dorsal, soit sur le côté gauche (fig. 13). Ces os ont pu être facilement appariés sur le critère de leur gracilité. Les restes de l'avant-bras gauche sont situés plus de $60 \mathrm{~cm}$ à l'est des segments en connexion. Les os droits sont plus disloqués, puisque leurs fragments se trouvent en amont de l'épaule gauche. Toujours sur le critère de cette extrême gracilité, nous avons recherché les membres inférieurs du même sujet 
(fig. 14). Les seuls qui pourraient lui appartenir et qui s'apparient entre eux sont illustrés pour les jambes et les pieds par des segments en connexion tant à droite qu'à gauche. Toutefois, ils rendent compte d'une position incompatible avec celle qui est donnée par le membre supérieur gauche, à moins d'envisager une posture particulièrement compliquée, que ne vient confirmer aucun pendage de ces os (bien que cela ne soit pas un critère déterminant de quoi que ce soit dans le cas d'un bûcher funéraire). Les os des membres inférieurs correspondent en effet à un sujet assis regardant vers le sud-ouest, le genou droit en hyperflexion dirigé latéralement avec le pied ramené sous les fesses, et le genou gauche fléchi de la même manière mais avec le pied placé en arrière du bassin. Si l'on retient l'appartenance de ces us à un même sujet comme fortement probable, il n'est pas possible de déterminer par quels segments en connexion (épaule/coude ou cheville/pied) l'attitude initiale du corps est représentée.

Le membre supérieur droit d'un autre sujet (squelette 2) apparaît en bon rapport anatomique et traduit une orientation tête au sud-ouest (fig. 13); la connexion du coude est néanmoins détruite, l'extrémité proximale de l'avant-bras ayant glissé au nord-ouest. D'autre part, les os gauches qui leur correspondent sont situés au sud-est de ces derniers, ce qui n'est pas compatible avec la position décrite précédemment à moins que l'humérus, en vue antérieure, ait pivoté secondairement sur lui-même et que l'attitude initiale soit celle d'un procubitus.

Le squelette le plus robuste (squelette 5 , fig. 13 et 14) a pu être identifié par ses fémurs et ses humérus. Dans la fosse, le fémur droit étant situé au nord-ouest et le gauche au sud-est alors que les humérus sont décalés au sud-ouest de ces derniers, on pourrait supposer que le sujet a été placé en procubitus à l'origine; mais l'absence de crânc cn amont des humérus et ce qui vient d'être dit pour les squelettes précédents nous invitent à envisager cette hypothèse comme très incertaine.

On remarque que les fragments de crâne sont majoritairement rassemblés au centre de l'amas osseux, notamment à distance des parois nord-ouest et sud-est de la fosse, contrairement aux autres régions anatomiques (fig. 17). Cela indiquerait-il que les corps ont été placés avec la tête dirigée vers le centre de la fosse (assis ou fléchis) ? L'examen de la répartition des vertìbres irait dans ce sens (fig. 18) ; elles semblent en effet s'organiser en deux amas, l'un à l'est et l'autre à l'ouest, tandis que les fragments d'atlas sont justement situés entre ces deux groupes au milieu des crânes.

Les appariements effectués avec les os longs montrent que le côté gauche est quasi systématiquement moins bien conservé que le droit. Si certains auteurs utilisent le critère du degré d'ustion pour reconstituer la position du cadavre sur le bûcher (Wells, 1960 ; Herrmann, 1972 ; Wahl, 1981, p. 276), il nous semble hasardeux de les suivre dans cette voie, compte tenu de notre ignorance de toutes les modalités de la crémation.

Les exemples présentés ci-dessus illustrent l'impossibilité de restituer l'attitude originelle des corps à l'intérieur de la fosse. Non seulement l'extrême fragmentation des os et le grand nombre de squelettes d'adultes compliquent l'identification individuelle, mais de plus dans les cas où différentes régions anatomiques peuvent être reconnues comme appartenant à un même sujet elles fournissent des informations contradictoires. Seule la situation globale des corps peut être retrouvée, qui permet de constater le regroupement des enfants dans une moitié de la fosse. La répartition verticale des pièces osseuses, par niveau de décapage, ne permet pas non plus de reconnaître un ordre dans la succession des dépôts, les liaisons étant aussi nombreuses inter-couches qu'intra-couches, et tout aussi nombreuses entre les fragments d'un même os ou entre les os d'un même squelette.

\section{LE MODE CRÉMATOIRE}

Dans plusieurs sociétés qui pratiquent la crémation, le corps est manipulé à l'aide de perches pour activer la combustion, notamment celle des parties qui brûlent le moins bien. Toutefois, les signes d'une conduction du bûcher restent difficiles à percevoir à travers les vestiges archéologiques, parce qu'il n'existe malheureusement que très peu d'études du comportement du squelette soumis au feu et la démonstration d'une telle pratique est largement fondée sur des hypothèses heuristiques issues des contextes archéologiques, comme celle du rassemblement des os dans un seul secteur de la fosse par exemple. Ainsi, le mode de dislocation des articulations sous l'action du feu étant mal connu, il est difficile d'interpréter les remaniements observés, c'est-à-dire de déterminer s'ils se rapportent à un processus de désorganisation naturelle ou à d'éventuelles interventions prati- 
quées sur les cadavres en cours de combustion (Blaizot, à paraître). Malgré l'indigence de nos références théoriques, la question de ce que l'on pourrait appeler une " crémation active " doit être posée dans le cas de Reichstett, et discutée à partir de l'analyse des ossements en place et des rares informations dont nous disposons sur le comportement du corps pendant qu'il brûle. Il est bien entendu que notre démarche reste quelque peu empirique, puisque les remaniements qui se produisent sur les os sont en grande partic fonction du type de bûcher, et que dans ce cas précis ce dernier résulte de notre interprétation.

L'organisation des ossements mise en évidence à Reichstett est compatible avec les phénomènes décrits en contexte expérimental. Les connexions anatomiques résiduelles touchent principalement le tronc et la région du bassin, ce qui correspond à un fait fréquent dans les crémations (Wahl, 1981, p. 272 ; Eckert et al., 1988, fig. 3 ; Pautreau, 1994, p. 311 ). Le mode de répartition des côtes et des vertèbres semble témoigner d'un brassage limité de cette région ; elles dessinent deux groupes séparés par un secteur de très faible densité, l'un à l'est et l'autre à l'ouest (fig. 18); la totalité des pièces immatures se trouve dans le second, tandis que le premier comporte $59 \%$ du poids des vertèbres adultes et $58 \%$ de celui des côtes adultes. Dans la moitié est, on observe des zones de densité qui correspondent aux éléments en connexion. Lorsque les scapulas sont en relation anatomique, c'est rarement avec les côtes, mais avec l'humérus, ce qui confirme la bonne résistance de l'articulation de l'épaule pendant la crémation (Wahl, 1981, p. 272). I.es os du crâne présentent une organisation particulière avec cette densité au centre de la fosse et une importante dispersion des petits fragments (fig. 17). Ce phénomène peutil être mis en relation avec l'explosion de la boîte crânienne qui se produit parfois autour de $700^{\circ}$ (Wahl, 1981) ou avec une dispersion des fragments consécutive à sa fissuration (Günther, Schmidt, 1953) dans le cas d'une combustion longue sur un bûcher élevé? Les os gauches et droits des membres supérieurs de chaque individu paraissent spatialement bien distincts (fig. 13). Si les os des mains sont relativement dispersés, il existe toutefois des concentrations de pièces compatibles entre elles au voisinage des membres supérieurs. En revanche, les membres inférieurs semblent de manière générale beaucoup plus fragmentés et plus dispersés que les membres supérieurs (fig. 14). Il n'y a d'autre part que très peu de coïncidences entre le mode de dispersion de ces derniers et celui des os des pieds, notamment dans le quart nord de la fosse. Enfin, les liaisons par collage sur une amplitude avoisinant les $70 \mathrm{~cm}$ sont fréquentes, et il existe un appariement entre deux fémurs distants de $1,50 \mathrm{~m}$ (tiers diaphysaires proximaux avec les épiphyses, à l'est et à l'ouest). Il semblerait donc que les membres inférieurs ne se soient pas comportés de la même manière que les membres supérieurs lors de la crémation, peut-être parce que les os des jambes se disloquent rapidement et finissent par se briser (MacKinley, 1989 , p. 65).

Même si l'on ne parvient pas à restituer l'attitude originelle des corps, on voit que plusieurs éléments sont en situation de logique anatomique et que les os droits et gauches de chaque grande région sont généralement bien individualisés pour chaque sujet. Mais lorsque l'on confronte les différents segments reconnus comme appartenant à un même sujet, on constate des aberrations. Par ailleurs, l'observation de la répartition de chaque grande région anatomique montre que certaines ont une organisation spatiale qui leur est propre. Ces observations doivent être mises en relation avec certains phénomènes attestés en contexte expérimental tels que le déplacement par rotations latérales, les mouvements verticaux en bloc des segments anatomiques et la flexion des membres (Klapproth, 1954-1955; Wahl, 1981, p. 272 ; Méniel, 1994, p. 283 ; G. Depierre, comm. orale).

Les connexions résiduelles, qui touchent principalement le tronc et la région du bassin, sont localisées sur une bande qui traverse le centre de la fosse de l'est vers l'ouest. Les deux zones de concentration illustrent des recouvrements partiels sur toute l'épaisscur du dépôt et sur de faibles surfaces, entre huit segments anatomiques ; certains ensembles peuvent appartenir à un même sujet, mais il n'est pas possible de le démontrer. La préservation et la superposition de ces ensembles dans un même secteur de la fosse peuvent rendre compte de conditions particulières de la crémation, ou plus exactement de celles du mode de destruction du bûcher en divers endroits ; en effet, si le bûcher s'effondre graduellement, la destruction est plus rapide au centre qu'en périphérie (MacKinley, 1997, p. 134-135, fig. 4). De plus, l'opposition des deux milieux différents de la combustion (réducteur et oxydant) peut également avoir provoqué des réactions brutales et favorisé des dislocations ponctuelles du bûcher. Cependant, il est vrai que dans l'hypo- 


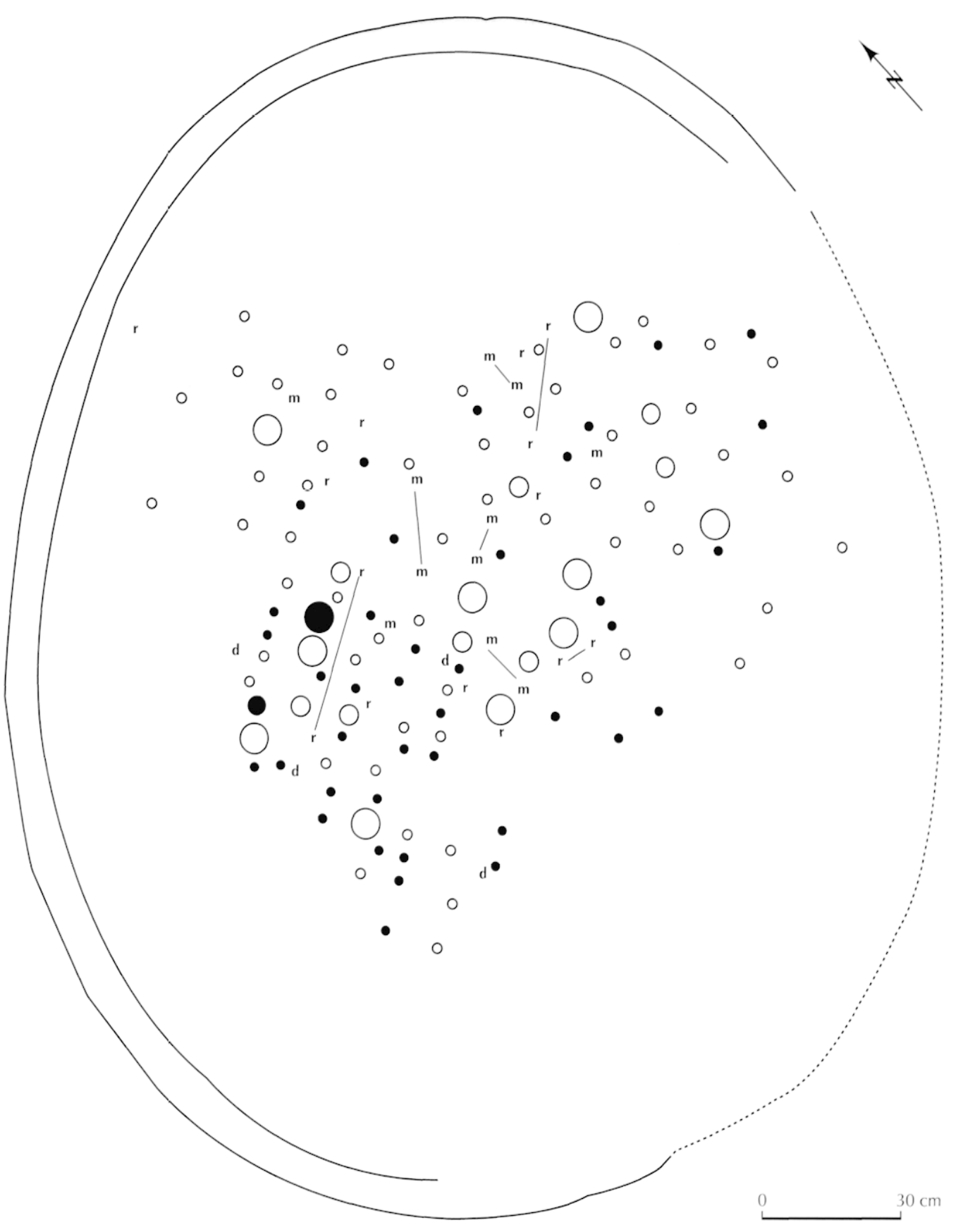

\begin{tabular}{|c|c|c|c|}
\hline Adultes (poids réels) & Immatures (poids réels) & & $\mathbf{r}$ rocher du temporal $(\mathrm{N}: 11)$ \\
\hline ○ 0,1 à $24,9 \mathrm{~g}$ & - 0,1 à $31,6 \mathrm{~g}$ & NMI & $m$ maxillaire $(\mathrm{N}: 7 \mathrm{AD})$ \\
\hline 25 à $49,8 \mathrm{~g}$ & 31,7 à $63,2 \mathrm{~g}$ & & d dents immatures $(\mathrm{N}: 4 \mathrm{IM})$ \\
\hline 49,9 à $74,7 \mathrm{~g}$ & 63,3 à $94,8 \mathrm{~g}$ & & — liaisons \\
\hline
\end{tabular}

Fig. 17 - Répartition des fragments de crânes des sujets adultes et immatures dans la fosse 143 (réalisation F: Blaizot). 


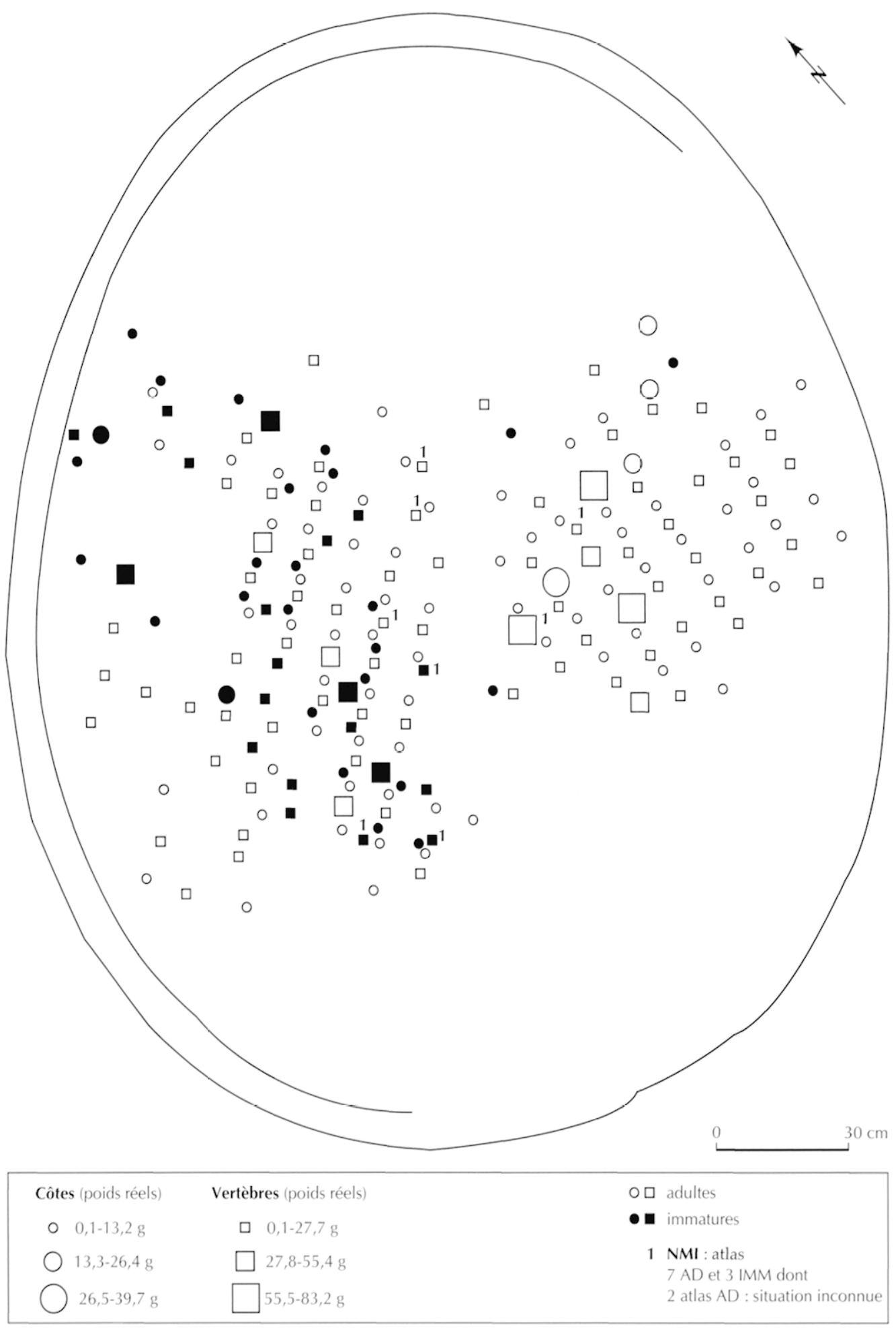

Fig. 18 - Répartition des fragments du tronc (vertèbres et côtes) dans la fosse 143 (réalisation F: Blaizot). 
thèse où les effets de délimitation, reconnus au nord et au sud, correspondraient à un arrangement de la couche d'ossements, d'éventuelles connexions préservées à l'origine dans ces secteurs pourraient avoir été détruites à cette occasion.

L'organisation des ossements de cette fosse semble a priori en contradiction avec le schéma théorique que l'on peut imaginer des résultats d'une crémation active, qui aboutirait probablement à un bien plus grand mélange des ossements.

Néanmoins, les observations réalisées en Thaillande sur des bûchers où les crématistes pratiquent la conduction montrent que cette pratique n'est pas incompatible avec la préservation de quelques connexions, bien qu'il paraisse impossible dans ces cas-là de déduire une quelconque position du corps à partir de la répartition des restes brûlés (Pautreau, 1994, p. 311, 313). En effet, les crématistes manipulent plutôt le tronc, plus long à brûler, tandis que les membres s'en détachent très vite (Pautreau, 1994, p. 311 ; G. Grévin, comm. pers.). Mais différents modes de conduction semblent exister puisqu'au Népal et en Inde G. Grévin cite des exemples où l'ensemble du squelette est manipulé, ce qui aboutit à un magma informe de fragments (Grévin, 1997, p. 431). Par ailleurs, des expérimentations menées sans conduction sur des animaux morts arrivent soit à des conclusions proches (Méniel, 1994, p. 283), soit révèlent un maintien suffisant du squelette pour que l'attitude initiale du corps soit lisible (MacKinley, 1989, p. 71). En l'absence d'analyse précise de la répartition des os au sol dans des cas de crémations humaines, il reste difficile de se référer à ces exemples dont les résultats sont en partie contradictoires. On peut considérer que trois types d'observations doivent être réunis pour envisager l'hypothèse d'une conduction en contexte archéologique. Ce sont: une extrême fragmentation des os du fait de leur manipulation à chaud (MacKinley, 1994a), le rassemblement de tous les os ou d'une quantité représentative dans un secteur de la fosse (Richier, à paraître), et une abondance de liaisons sur une très grande amplitude. Un autre argument à l'appui d'une conduction serait apporté par le mode de dispersion des ossements sur le plan vertical ; il apparaît que leur manipulation en cours de crémation conduit à les confiner dans les niveaux supéricurs des résidus du bûcher (MacKinley, 1997, p. 136). Or, à Reichstett, la fragmentation est variable et pas du tout excessive, les liaisons sur une longue distance (supérieure à $1 \mathrm{~m}$ ) ne concernent que peu d'ossements (fig. 13, 14, 16), les os sont présents sur toute la surface et sur toute la hauteur de la couche des résidus, bien que les quatre premiers centimètres de la couche charbonneuse en comportent moins ${ }^{16}$.

Lorsque les chairs ont disparu il n'y a plus d'autocombustion. Une oxygénation difficile peut être, dans certains cas, compensée par un apport de graisse supplémentaire (huiles diverses). Mais la conduction du corps constitue aussi un moyen de maintenir l'oxygénation nécessaire à une bonne combustion et ramène les os effondrés dans les résidus au cœur du foyer (Mackinley, 1989, p. 72). Dans le cas de Reichstett, si la grande variation de la gamme chromatique observée sur les os est le résultat de l'étouffement de certains d'entre eux dans les résidus du bûcher, cela signifie peut-être que les os n'ont pas été touchés durant la crémation.

Nos arguments restent faibles toutefois, et nous pouvons donc uniquement dire que nous n'avons pas à Reichstett les éléments indiscutables pour la démonstration d'une telle pratique. L'organisation des segments anatomiques ne paraît pas s'écarter fondamentalement de celle qui est observée dans des crématoriums où la conduction n'est pas pratiquée.

\section{FERMETURE DE LA FOSSE}

En périphérie, les ossements sont recouverts d'une couche hétérogène de loess pur et de plaques rubéfiées. L'étude géoarchéologique a démontré que deux effondrements des parois s'étaient produits successivement. Le feu en activité ayant tendance à renforcer les parois, elles n'ont pas pu s'effondrer pendant la crémation; le contenu de la fosse a donc forcément évolué à l'air libre pendant un certain temps, soit parce que celle-ci était à ciel ouvert, soit parce qu'elle était couverte d'un élément qui ne s'est pas conservé. D'après X. Boës, un tel effondrement a pu survenir asse\% rapidement après le refroidissement (par exemple en une semaine), puisque la fosse a été comblée volontairement en une fois, ainsi qu'en témoigne le remplissage très homogène au-dessus des os. La présence de quelques os sur la couche d'effondrement dans l'angle nord-est de la fosse (fig. II), qui

16. Mais il s'agit là cles résidus du combustible sous-jacent. 
se rapporte à un remaniement postérieur à la crémation, peut être attribuée à un animal ou à un effondrement différé de la périphérie du bûcher, ce qui serait un argument de plus à l'hypothèse selon laquelle la fosse n'a pas été comblée directement après la crémation. Mais nous avons vu également qu'elle peut résulter d'un éventuel remaniement volontaire des limites nord et sud de la couche d'ossements.

Le remplissage est vierge, mis à part quelques tessons disparates probablement résiducls proches de la surface et ces rares ossements d'animaux dont trois sont localisés au nord-est à la surface de l'amas d'os humains. Bien que l'interprétation de ces restes soit compliquée par l'incertitude qui règne sur la provenance exacte d'un lot noté " niveau supérieur ", toutes les parties représentées paraissent typiques de rejets de boucherie résiduels et ne sauraient témoigner d'une offrande. Le dépôt du suidé pourrait en revanche être associé à la crémation; en effet, l'absence totale de détritus dans le fond de la fosse, l'homogénéité et la faible épaisseur de la couche qui le colmate semblent incompatibles avec l'hypothèse d'une structure de rejet réutilisée pour la crémation. De plus, la date obtenue sur ses ossements recouvre celle fournie par les charbons de la couche de crémation. Ce suidé, qui affleurait de toute évidence sous le bûcher puisque son côté gauche est brûlé, constituerait alors peut-être l'un des éléments d'un rituel. Le mobilier funéraire stricto sensu est absent ; l'objet peut en effet difficilement être considéré comme un viatique ; s'il n'est pas intrusif (ce qui est probable étant donné qu'il est brûlé), il s'agit plus probablement d'un objet que l'un des individus portait sur lui.

\section{SYNTHÈSE}

Les différentes étapes du fonctionnement de la fosse peuvent être résumées comme suit.

Dans le quart inférieur d'une fosse légèrement surcreusée en cuvette, le corps d'un suidé adulte complet est déposé. Il est directement colmaté d'une couche de loxss remanié peu épaisse, à la surface de laquelle il affleure.

Un bûcher funéraire est construit. Bien qu'il ne soit pas possible d'en restituer l'architecture dans ses détails, il apparaît constitué d'une plate-forme surélevée, sur laquelle reposent les corps; au-dessous se trouve le bûcher proprement dit. Les effets de délimitation enre- gistrés au nord et au sud pourraient éventuellement correspondre à deux parois latérales construites sur la plateforme, mais l'hypothèse d'un aménagement postérieur à la crémation est également plausible.

Onze individus sont placés sur la plate-forme; quatre enfants sont regroupés dans une partie, tandis que les adultes semblent occuper toute la surface. On ne peut pas reconnaître l'attitude des corps, mais ils semblent avoir été orientés avec la tête en direction du centre de la fosse.

La mise à feu est effectuée sous la plate-forme. Aucune preuve de conduction ne peut être établie à partir des données dont on dispose.

La fosse reste ouverte un temps suffisant pour permettre aux parois rubéfiées de s'effondrer en deux temps sur la couche d'ossements.

Si les effets de délimitation linéaire enregistrés sur les os ne correspondent pas à l'architecture de la structure de combustion, ils rendraient compte d'un réarrangement de la masse d'ossements avant la fermeture de la fosse; sur les côtés nord et sud, les os auraient été repoussés voire peut-être contraints par des parois rigides de manière à former un coffrage rectangulaire qui traversait la fosse. La présence éventuelle d'un couvercle ne peut être argumentée.

Puis la fosse est comblée en une seule fois avec le sédiment des alentours, en témoigne la présence de quelques tessons attribués à différentes périodes préhistoriques antérieures au Néolithique final et de rares os de faune disparates.

\section{LE BÛCHER FUNÉRAIRE EN FOSSE DU NÉOLITHIQUE FINAL DANS SON CONTEXTE CHRONOLOGIQUE ET CULTUREL}

La situation de cette structure, isolée parmi les vestiges du Néolithique récent, pose de nouveau le problème de l'indigence des données relatives au Néolithique final en Alsace (Jeunesse, Schneider, 1985) puisqu'il n'existe à Reichstett aucune trace d'un habitat qui lui soit contemporain.

Doit-on envisager qu'à Reichstett l'habitat se situe en dehors de l'emprise décapée ou alors, comme le propose C. Jeunesse, que le mode d'implantation des habitats du Néolithique final est d'une nature incompatible avec leur survie archéologique (Jeunesse, Schneider, 1985) ? 
On ne connaît aucun exemple du traitement des corps humains au début du Néolithique final dans la région, et la fosse SP143 exhumée sur le site de Reichstett-Mundolsheim en est le premier. La structure peut être définie à la fois comme une tombe-bûcher, pratiquée dans une fosse circulaire de " type domestique ", et comme une tombe multiple puisque onze individus ont été brûlés simultanément. Bien que les pratiques funéraires soient très diversifiées durant le Néolithique final (tabl. III), la crémation primaire y est quasi absente ; la fosse SP143 traduit ainsi un mode de traitement des corps inhabituel au cours de cette période. En effet, si l'usage du feu est attesté au Néolithique final I en contexte funéraire, il ne s'exprime en aucun cas de cette manière. Il s'agit soit de véritables crémations qui aboutissent à une sépulture où les restes font l'objet d'un dépôt secondaire, comme dans les cultures de Baden (groupe de Boleraz) et de Rivnac en Europe centrale (Nevizánsky, 1985), ou dans le Walternienburg en Allemagne (tabl. III) (Fischer, 1956, p. 220), soit de feux pratiqués à l'occasion de la condamnation ou de la réfection d'un monument funéraire (Masset, Baratin, 1980) Häusler, 1994, p. 50). Dans ces derniers cas, l'objectif n'est pas le traitement du cadavre mais celui de la structure, comme par exemple dans les cultures SOM du Bassin parisien, de Bernburg en Allemagne, et plus tard dans le groupe des Amphores globulaires (Häusler, 1994, p. 46). En outre, lorsqu'une crémation sur os frais a été mise en évidence, il s'agit de dépôts secondaires (Billand et al., 1995, p. 127).

La crémation primaire ne peut non plus être considérée comme le prolongement, dans une région périphérique, d'une pratique ponctuelle plus ancienne. En effet, si dans les tombes en fosses, le feu joue un rôle important durant le Néolithique récent, puis dans le Néolithique final (tabl. III), il n'est jamais utilisé sur les cadavres (Nevizánsky, 1985). Seuls sont rougis les parois ou le sol des fosses (Banner, 1956, p. 206 ; Schweitzer, 1987, p. 67 ; Döhle et al. 1992), ou encore le sommet des couches du comblement (Veit, 1996, p. 304) ; les rares cas où les os sont brûlés ont été interprétés comme le résultat d'une chauffe accidentelle (Veit, 1996, p. 292). Mais on a vu que la rubéfaction des fosses pouvait provenir des restes d'une utilisation antérieure (Jeunesse, Sainty, 1986, p. 55). Ainsi, malgré certaines informations publiées (Lüning, 1967, p. 132), on ne connaît pas de crémations vraies au Michelsberg. En effet, sur les sites belges de
Boitsfort et d'Ottenbourg (De Loë, Rahir, 1924), auxquels se réfère $\mathrm{J}$. Lüning, la nature funéraire des structures n'a jamais été démontrée; nous ignorons en réalité si les os sont humains et les fameuses « levées funéraires " se rapporteraient plus probablement à des travaux défensifs (De Laët, 1967, p. 340). De même, l'hypothèse d'une crémation dans la grotte du Rudemont à Arnaville, en Meurthe-et-Moselle, (Blouet et al. 1982) ne repose pas sur une analyse des ossements, et l'attribution chronoculturelle du squelette reste douteuse, compte tenu de la complexité stratigraphique du remplissage des grottes. Nous n'avons pas retenu non plus la fosse de type domestique du site d'Ammendorf (culture de Baalberg), en Allemagne, dont les informations ne sont pas claires (Grimm, 1937, p. 166-167); les restes d'un squelette brûlé sont mentionnés, mais ils se trouvent placés $50 \mathrm{~cm}$ sous la base de la couche interprétée comme les restes d'une crémation in silu.

La simultanéité des dépôts, le nombre élevé d'individus et le caractère tout à fait particulier de cette pratique crématoire dans le Néolithique final nous invitent à nous interroger sur la nature de la structure. En effet, la sépulture étant définie comme le lieu où s'accomplissent les gestes funéraires ultimes autour du cadavre, suivant le mode le plus fréquemment utilisé par la société en question, nous ne pouvons pas a priori assimiler cet ensemble à une sépulture stricto sensu.

Dans une communauté, le décès de 11 sujets représente un événement inhabituel; conjugué à la mise en œuvre d'un processus de traitement des corps qui ne correspond pas à ce que l'on rencontre au Néolithique final, en tout cas pas sous cette forme-là, l'hypothèse d'un ensemble de catastrophe peut être évoquée. D'après J. Zammit, la domestication des espèces animales au Néolithique aurait provoqué des épidémies que l'on aurait tenté d'enrayer en brûlant les cadavres (Zammit, 1991) ; bien que personne n'ait jamais prouvé que la crémation soit particulièrement utiliséc en contexte d'épidémie, nous devons considérer cette éventualité. Il faut pour cela admettre qu'il s'agit d'une épidémic non sélective puisque la fosse comporte des adultes et des enfants, et qu'elle a touché 11 sujets, ce qui fait alors bien peu. Nous n'avons, mis à part le caractère simultané des décès, aucun argument pour privilégier une telle hypothèse ; peu d'éléments permettent en contrepartie de la réfuter entièrement. Comme il n'a pas été possible de reconstituer l'attitude des corps, il est difficile de dire 
s’ils ont été déversés sans ménagement sur le bûcher, bien qu'ils paraissent au contraire respecter une orientation définie, la tête dirigéc au centre de la fosse; toutefois, une disposition raisonnée des corps n'est pas exclusive d'un ensemble de catastrophe (Boura et al., 1992).

L'utilisation d'une fosse circulaire de type domestique pour pratiquer une crémation paraît un choix étonnant ; celui-ci s'inscrit manifestement dans la continuité de la pratique qui prévaut à l'époque précédente et, de plus, se rattache à la tradition des sépultures en fosses de type domestique d'Europe de l'Est, puisque ce phénomène est largement attesté de l'Allemagne jusqu'à la mer Noire durant le Néolithique final (Happ, 1991 ; Veit, 1996). D'autre part, les sépultures multiples sont relativement fréquentes dans ces régions au Néolithique final. Il s'agit toutefois systématiquement d'inhumations, et celles-ci sont pratiquées en " contexte domestique ". Les cultures de Salımünde (Fischer, 1956), d'Altheim (Maier, 1965) et de Baden (Nevizánsky, 1985 ; Mayer, 1991) en livrent de nombreux exemples (tabl. III). Les dépôts multiples existent également dans le Néolithique récent, dans la culture de Michelsberg (Lambach, 1986 ; Wahl, Höhn, 1988 ; Behrens, 1988), de Münchshöfen, site de Grossmehring-Eichstätt (Schröter, 1996), de Baalberg (Döhle et al., 1992), ou de Gatersleben (Coblenz, Fritzsche, 1976). Le nombre de dépôts primaires simultanés est généralement plus important au Néolithique final, surtout dans la culture de Baden où on trouve parfois entre 12 et 20 individus, par exemple sur les sites de Bronocice, de Dzbànice, et de Nitriansky Hràdok, (Horňanský, Skutil, 1950 ; Vlček, 1953 ; Trnácková, 1962 ; Kruk, Milisauskas, 1982) ; dans le Néolithique récent et dans les autres cultures du Néolithique final, on ne rencontre guère plus de 5 ou 6 sujets (Fischer, 1956, p. 240 ; Veit, 1996, p. 293). Dans plusieurs cas de tombes multiples, l'hypothèse de sacrifices humains a été proposéc d'après la mise en évidence de traces de coups ou de découpe sur les ossements. Mais l'interprétation de ces phénomènes est difficile; l'examen des ossements ne permet en effet pas toujours de différencier le rituel de mise à mort de celui dans lequel on aurait porté des coups sur des cadavres. Quant à de telles interprétations qui reposent parfois sur des " traces de découpe ", elles nous paraissent devoir être écartées, ce qui peut relever d'actes de nécropsie ne pouvant être assimilé à un sacrifice. À notre connaissance, seules les marques relevées sur les squelettes michelsberg du site de Heidelberg-Handschuhsheim (Wahl, Höhn, 1988) sont compatibles avec cette hypothèse, les anthropologues ayant démontré que les coups ont été portés sur des sujets se tenant debout; mais là encore, ils peuvent être l'indice d'une bataille et pas forcément d'un sacrifice. Ce sont l'association systématique des mêmes phénomènes (coups violents portés sur les corps, traitement particulier des cadavres, fosses de même type, dépôts ostentatoires, etc.) et l'analyse précise des contextes qui permettraient d'envisager un rituel spécifique et non pas un événement ponctuel. Or, toutes les sépultures multiples de ces cultures ne comportent pas des squelettes attestant d'actes de violence, ni d'offrandes spéciales.

À Reichstett, la crémation ne facilite pas la reconnaissance de tels traumatismes compte tenu de l'importante fragmentation des ossements. Nous avons toutefois soigneusement examiné les morceaux de crâne et d'os longs, et à aucun moment il n'est apparu de fractures pouvant avoir été causées par un outil contondant. Les cassures, souvent courbes, sont typiques de celles que l'on rencontre dans une crémation : sur les os longs, les bords sont arrondis, avec des arrachements de la surface de l'os cortical sur le plan horizontal (aucune fracture nette en biais). La morphologie des cassures des fragments crâniens exclut également une origine traumatique. Si ces individus ont fait l'objet d'un sacrifice, les os n'en portent aucune trace.

Nous ne disposons ainsi d'aucun argument décisif en faveur de l'une ou de l'autre hypothèse : sépulture ou rituel d'une autre nature. Les caractéristiques de la structure témoignent d'un recours à un dispositif relativement lourd qui semble assez mal s'accorder avec une gestion de cadavres dans l'urgence d'une catastrophe.

On soulignera de plus le caractère monumental que devait posséder cette structure, avec son bûcher surmonté de sa plate-forme, bien que l'on ne puisse restituer que certains aspects de son architecture. Celleci peut être perçue également à travers les effets de délimitation mis en évidence par la répartition au sol des ossements, qu'ils se rapportent à la phase active du bûcher ou à un aménagement postérieur. Dans le premier cas, on aurait une véritable architecture crématoire; dans le second c'est la notion de dévolution des vestiges de la crémation qui est privilégiée, dans le sens où ils passent dans un registre codifié à caractère 
définitif. Si l'on pouvait prouver que l'architecture se rattache à cette seconde phase de traitement, il serait possible d'envisager que la structure est véritablement marquée en tant que " tombe ». En effet, si l'ensemble de ce dispositif, dans lequel le dépôt du suidé pourrait être un élément significatif, révèle un acte raisonné et va audelà du simple débarras de cadavres, le terme de " sépulture " reste néanmoins peu certifiable sur la base de ces seules données, compte tenu de l'unicité de cette structure et de l'absence de sépultures connues en Alsace pour la période; si un rituel est attesté, son caractère funéraire est loin d'être indiscutable malgré la présence de squelettes.

Le Néolithique final livre tout de même quelques rares exemples de crémation primaire, qui font que cette structure n'est pas totalement isolée. Parmi les six exemples que nous avons relevés en Europe, quatre proviennent de sites de la culture de Baden en Slovaquie, en Hongrie, et en Basse-Autriche, et deux ont été trouvés en France, l'un dans l'Ain, ct l'autre en Lozère ( $c f$. annexe).

Les cultures dans lesquelles se placent ces exemples appartiennent à la première phase du Néolithique final, entre 3500 et 2500-2300 avant J.-C. environ (Jeunesse, Schneider, 1985 ; Forenbaher, 1993, p. 246). Les sépultures examinées se rapprochent de celles de Reichstett dans la mesure où il s'agit de crémations en place ${ }^{17}$. Elles s'en distinguent toutefois apparemment par le mode crématoire employé, puisque le foyer semble avoir été installé au-dessus des corps ${ }^{18}$. Pour la grotte du Gardon à Ambérieu-en-Bugey dans l'Ain (Voruz, 1996; Gatto, 1999), si la proposition d'une utilisation successive de la structure crématoire était confirmée après l'étude complète de la structure ( $c$. annexe), les différences seraient encore plus importantes puisqu'il s'agirait d'un bûcher ayant fonctionné sur une longue durée. Parmi les autres, seule la tombe de Sitzenberg (Basse-Autriche) constitue une crémration complète, danss le senss où le feu a affecté les ossements jusqu'à l'état de calcination (Neugebauer-Maresch, Teschler-Nicola, 1984; Mayer, 1991). D'après les informations dont nous disposons sur Budakalàs\% en Hongrie (Banner, 1956) et celles, plus

17. Celle d'Au am Leithaberge nous paraît néanmoins relever d'un autre type ( $c$. annexe).

18. Sans compter les structures de Nitriansky Hràdok et Dignas pour lesquelles nous n'avons pas d'information sur le mode crématoire. indigentes, sur Nitriansky Hràdok en Slovaquie (Vlček, 1953; Novotný, 1958; Tocik, 1978), la crémation n'est pas homogène et le degré d'ustion est relativement peu élevé. La fosse de Nitriansky Hràdok provient d'un espace domestique, celle de Budakalàsı d'un ensemble funéraire ( $c f$. annexe) ; toutes, mise à part la sépulture isolée du Gardon, constituent une pratique " marginale ", au sein d'ensembles dont les pratiques funéraires sont néanmoins diversifiées ${ }^{19}$ (inhumations, inhumations en fosses de type domestique, dépôts secondaires de crémation, etc.). On soulignera l'analogie entre les architectures trouvées en France d'une part, entre celles des fosses rencontrées à Budakalàs\% et Sitzenberg d'autre part, et enfin entre celles de Nitriansky Hràdok et de Reichstett (emploi de fosses de type domestique). Les structures du Gardon et de Dignas à Sainte-Énimie en Lozère (Fages, 1986; cf. annexe) entrent dans le modèle des constructions mégalithiques, ce qui donne une tout autre dimension à l'hypothèse d'une utilisation successive pour au moins l'une d'entre elles. À Nitriansky Hràdok, il s'agit d'un dépôt simultané de 11 sujets, les corps ont été disposés avec le crâne dirigé au centre de la fosse, tandis qu'un animal complet accompagne les individus ; en cela, elle présente, au delà de sa typologie (tombe en fosse), un certain nombre de ressemblances avec la fosse de Reichstett.

$$
* *
$$

Les pratiques funéraires mises en évidence sur le site de Reichstett, durant la première moitié du Néolithique final, ne trouvent aucun parallèle convaincant dans les groupes culturels qui ont occupé l'espace du territoire français actuel et les pays du Nord à la même époque. Elles se rattachent indiscutablement à des traditions de l'Europe de l'Est, tant dans le type de structure choisi (fosses de type domestique) ${ }^{20}$ que dans le mode de traitement du corps (dépôts multiples en masse, crémation primaire, dépôt d'un animal complet).

Il paraît plus difficile de caractériser les inhumations de la fin du Néolithique récent. Par certains aspects (fosse de type domestique, dépôts individuels ou

19. Seul le site de Sitzenberg n'a pas fait l'objet d'un décapage.

20. Cependant, des dépôts en fosses de type domestique sont connus par exemple en Ianguedoc au Chalcolithique (site de Beausert à Connaud dans le Gard, fouille programmée en cours de C. Georgeon, etude de F. Blaizot). 
doubles, attitudes non stéréotypées des corps, dépôt des corps en pleine terre dans la fosse 19) elles rappellent des traits présents dans les phases ancienne et moyenne des cultures de Munzingen et de Michelsberg ; mais par d'autres, elles rompent avec ces traditions, en témoignent la décomposition du corps en espace vide impliquant un aménagement de la fosse et, dans un cas, le dépôt probablement concomitant de l'inhumation d'un animal complet ${ }^{21}$. Ces deux derniers traits permettent de les comparer aux inhumations du Néolithique final de l'Est de l'Europe, où les dépôts en fosses de type domestique sont très fréquents, soit dans les groupes d'Altheim, de Salzmünde (Fischer, 1956), soit dans la phase dite classique de la culture de Baden (Němejcová-Pavúková, 1974). Rares y sont les exemples d'espaces vides attestés ${ }^{22}$, mais le cas d'une fosse de type silo de Bronocice (Pologne) datée autour de 2800-2700 avant J.-C. offre cependant une disposition comparable aux nôtres, puisque les corps ont été placés dans un espace vide aménagé par un couvercle de tiges de bois juxtaposées et couvertes d'argile (Kruk, Milisauskas, 1985, p. 40). Toutefois, les comparaisons précises avec le Néolithique d'Europe de l'Est doivent être pondérées par l'éventualité qu'à Reichstett l'occupation contemporaine n'ait pas pu être reconnue, et par la méconnaissance des modes d'inhumation du Néolithique récent dans ces régions ${ }^{23}$.

Mais peut-être est-il prématuré d'estimer que nous sommes déjà, autour de 3600-3500 avant J.-C., dans un autre système qui préfigure celui des civilisations non mégalithiques du Néolithique final oriental (tabl. III) ${ }^{24}$.

21. Dans la mesure où nous ignorons si l'on se trouve en périphérie ou à distance des zones domestiques, le critère de l'implantation de ces fosses d'inhumation à l'écart de l'habitat ne peut entrer dans l'argumentation. On est peut-être dans le cas des fosses à inhumation exhumées à Eschentzwiller, Katzenthal, Wetcolsheim, Ergersheim qui, en l'absence de décapage extensif, constituent des découvertes isolées de tout contexte.

22. I a démonstration nécessitant un enregistrement et une analyse adaptés (anthropologie de terrain).

23. I à aussi, les exemples proviennent en grande partie de fouilles anciennes, et la détermination du milieu de décomposition resté approximative, même pour les sépultures exhumées plus récemment.

24. Le dépót en fosse de type domestique, dans l'habitat ou non (problème des trouvailles isolées), semble caractériser les groupes non mégalithiques ; néanmoins, de très rares exemples - controversés - sont mentionnés sur des sites où le mobilier est caractéristique des cultures Bernburg-Walternienburg (Beier, 1984).
Il peut sembler également hasardeux d'établir des relations, pour ce qui concerne le bûcher funéraire, avec une culture aussi éloignée géographiquement ; elle reste cependant notre seule référence, et nous nous trouvons devant le même problème que souleva, en 1979, la découverte de la cabane funéraire SOM de Compiègne "Le Hazoy " dans l'Oise, qui présente d'indiscutables affinités avec les sépultures de Bernburg-Walternienburg en Allemagne (Blanchet el al., 1993). Là aussi, une identité des pratiques funéraires est reconnue entre deux populations qui ne possèdent pas la même culture matérielle et entre lesquelles aucun relais n'est attesté.

On reconnaît, malgré ces deux types de traitement (inhumation/crémation primaire), quelques traits communs. Ils se définissent par l'emploi d'une fosse circulaire de "type domestique ", par leur proximité géographique, et par le dépôt d'un suidé complet à deux reprises (SP152, SP143). Le premier élément reste peu pertinent puisque l'emploi de fosses non spécifiquement funéraires pour inhumer est rencontré du Néolithique ancien jusqu'à l'Âge du Fer. En revanche, le regroupement de ces fosses dans un secteur de l'emprise décapée parmi les structures Michelsberg en périphérie ou en dehors de l'habitat qui leur correspond ${ }^{25}$ et la présence d'un animal complet de même espèce ne semblent pas anodins. En effet, malgré l'écart chronologique attesté par les datations absolues et bien que les pratiques relatives au traitement stricto sensu du cadavre soient différentes, l'hypothèse d'une "identité " pourrait a priori être envisagée. Par ailleurs, la crémation primaire constituant un rituel exceptionnellement attesté au Néolithique final, elle ne saurait être discriminante d'un point de vue chronoculturel, d'autant que dans les exemples rencontrés dans la culture de Baden, elle coexiste avec toutes sortes d'inhumations dont un grand nombre en fosses de type domestique.

Le matériel des sépultures de Reichstett est trop pauvre pour livrer des informations culturelles. L'objet en bois de cerf qui provient du bûcher funéraire est particulièrement caractéristique, par sa facture, de la culture de Horgen, pour l'instant reconnue uniquement en haute Alsace; mais on rencontre aussi ce type d'objet fusiforme, avec quelques variantes, dans divers horizons du Néolithique final (Ambert, 1998, p. 188), parmi

25. Bien que la question de la survic archéologique de l'habitat néolithique final reste posée. 
lesquels la culture de Pfyn, dont les rapports avec le Munzingen qui précède et le Dachstein semblent par ailleurs assurés (Jeunesse, 1989 ; Jeunesse et al., 1998). Il n'existe, dans toute l'Alsace, aucun objet de production Ossarn. En contrepartie, si des éléments de culture matérielle de la culture de Baden sont présents en BasseBavière, comme l'attestent les découvertes des sites de Mamming (dont la céramique présente des affinités avec Altheim et Ossarn) et d'Eichendorf-Aufhausen (Kreiner, 1993a, 1993b; Blaich, 1997) (fig. 8), aucune sépulture n'y a pour l'instant été rencontrée et en tout cas aucune tombe-bûcher. La même remarque peut être formulée pour la Suisse puisque dans les sites d'Arbon-Bleiche, de Bodman et de Sipplingen sur les rives du lac de Constance (fig. 8), datés de la transition Pfyn récent/ Horgen (3384-3370 avant J.-C.), ont été reconnus entre $10 \%$ et $20 \%$ de céramiques correspondant à des importations de la phase ancienne de la culture de Baden : le groupe de Boleràz. (Maier, 1955; Capitani, Leuzinger, 1998). Ces exemples témoignent tout de même d'un jalon entre la Slovaquie, la Hongrie, l'Autriche et Reichstett, d'autant qu'à Eichendorf-Aufhausen, l'analyse archéométrique de la céramique a montré qu'elle a été non pas importée mais fabriquée localement, ce qui implique d'autres liens que de simples contacts entre ces régions éloignées (Blaich, 1997, p. 17-18).

A Reichstett, aussi bien pour les inhumations que pour la tombe-bûcher, toutes les comparaisons se rapportant aux rites funéraires et au mobilier nous ramènent aux mêmes régions de l'Est et à des cultures qui offrent des affinités certaines entre elles; leurs limites d'expansion les plus occidentales se situent à chaque fois au même point : le lac de Constance, la haute vallée du Rhin et la Basse-Bavière, voire la Suisse. La population qui a inhumé à la fin du Néolithique récent et celle qui, par la suite, a construit le bûcher présentent incontestablement une identité commune. L'obscure transition entre le Néolithique récent et le Néolithique final, définie par une actuelle solution de continuité documentairc tant cn Alsacc (Jcuncssc, Schncider, 1985, p. 127), qu'en Suisse (Voruz., 1991, p. 70) et qu'en Bavière méridionale (Capitani, Leuzinger, 1998, p. 245), semblerait marquée par des " relations " avec l'Europe de l'Est, précisément avec la culture de Baden. En témoignent les trouvailles réalisées sur les sites de Bodman, de Sipplingen, d'Arbon-Bleiche, d'Eichendorf-Aufhausen et de Reichstett.

\section{Remerciements}

Il m'est particulièrement agréable de remercier Nelly Le Meur, responsable de l'opération, de m'avoir confié la fouille et l'étude des restes humains du site.

Ma gratitude est grande envers Christian Jeunesse, conservateur du Patrimoine, qui m'a conseillée tout au long de cette étude et qui a relu intégralement ce texte. J'ai également bénéficié de l'aide et des conseils de Pierre Pétrequin, directeur de recherche au CNRS, et de Jean-Louis Voruz, néolithicien, pour l'analyse du mobilier. Merci aussi à Esther Gatto, qui m'a communiqué ses résultats sur la crémation de la grotte du Gardon.

Je remercie également Jaroslàv Bruzek, Laboratoire d'anthropologie de Bordeaux I, et Vojciech Widlak, AFAN Lyon, qui m'ont traduit les articles en tchèque et en polonais, ainsi que W. Pape, de l'Institut d'archéologie de Freiburg-am-Briesgau, qui m'a facilité l'accès à la bibliothèque.

Je n'oublie pas enfin Jean-Luc Issele et Frédéric Latron, qui ont réalisé une fouille de grande qualité des structures anatomiques complexes de la tombe-bûcher néolithique. Leur talent tient une part importante dans les résultats de ces études. 


\section{ANNEXE}

\section{NOTICES DES SITES DE COMPARAISON POUR LA FOSSE À CRÉMATION SP143}

\author{
Nitriansky Hràdok, Slovaquie (fig. 8) \\ Vlček, 1953; Novotný, 1958, p. 57 ; Tocik, 1978, \\ p. 24-25.
}

Dans le secteur du site occupé par des structures domestiques de la culture de Baden, se trouvent deux fosses en "forme de puits ", placées à peu de distance (?) l'une de l'autre. L'une (fosse 119), fouillée en 1952 , comporte une vingtaine d'inhumations simultanées, l'autre (fosse 107), fouillée en 1949, en contient onze; dans cette dernière, les individus ont été placés en position contractée, avec la tête orientée vers le centre de la fosse, et les os, " notamment ceux de la face ", sont brûlés. Au centre et " au-dessus " des os humains, se trouve le squelette complet d'un chien.

Les informations concernant cette fosse sont imprécises; on ne dispose d'aucun élément relatif aux modalités de la crémation, on ignore également si le chien est brûlé ou non.

\section{Budakalàsz, Hongrie (fig. 8)}

Banner, 1956, p. 111-128.

Dans la nécropole Baden de Budakalàsz, fouillée en 1952, deux inhumations doubles, pratiquées chacune dans une fosse de forme ovale, attestent des crémations en place.

La première (SP100), comporte les squelettes brûlés de deux adultes, l'un placé sur le côté gauche avec les membres inférieurs fléchis, l'autre posé sur le ventre avec les membres inférieurs fléchis et ramenés sous lui (Banner, 1956, p. 124). Le second squelette a brûlé de manière plus complète et à une température plus élevée que le premier; ses os sont noirs, tandis que ceux du premier sont brun foncé, à l'exclusion des jambes (tibiasfibulas) et des pieds qui sont intacts. Les squelettes reposent dans une couche de cendre de $8 \mathrm{~cm}$ à $10 \mathrm{~cm}$ d'épaisseur, dépourvue de charbons. Le centre du foyer a été reconnu comme se trouvant placé sur le tronc du second individu.

Il s'agit manifestement d'une crémation dans laquelle le foyer se trouve au-dessus des corps, la mise à feu s'effectuant par le haut. On ignore si les corps pouvaient se trouver un peu surélevés à l'origine, ce qui reste néces- saire même si le bûcher est placé au-dessus, afin de produire un appel d'air suffisant pour que la crémation puisse se faire. Il apparaît en tout cas que les os n'ont pas été portés à une température très élevée, comme l'indique leur couleur (autour de $350^{\circ}$ probablement).

La deuxième fosse (SP113) renferme deux squelettes placés sur le côté gauche, membres inférieurs fléchis (Banner, 1956, p. 126). Le foyer a été placé également sur les corps, mais nous n'avons aucun renseignement sur le degré d'ustion.

\section{Sitzenberg, VB Tulln, Basse-Autriche (fig. 8)}

Neugebauer-Maresch, Teschler-Nicola, 1984 ; Mayer, 1991.

C'est une découverte isolée de 1982, datée par le mobilier de la phase classique de la culture de Baden (Ossarn I), soit autour de 3100 avant J.-C. Il s'agit de la sépulture double de deux adultes, l'un féminin et l'autre masculin, pratiquée dans une fosse grossièrement rectangulaire. Les corps ont brûlé simultanément et sur place, à une température élevée $\left(650-800^{\circ}\right)$. Ils sont couverts d'une couche charbonneuse. Le sol et les parois ne sont pas rubéfiés. Les connexions anatomiques sont en partie préservées, et l'attitude des corps a pu être globalement restituée (fléchis sur le côté gauche). On note la présence d'une mandibule de suidé. Le mode crématoire n'a pas pu être interprété, mais les auteurs rejettent l'hypothèse d'un bûcher placé sous le corps et d'une mise à feu effectuée depuis le sol (Neugebauer-Maresh, Teschler-Nicola, 1984, p. 131) ; C. Mayer parle d'une crémation en meule (Mayer, 1991, p. 36).

\section{Au am Leithaberge, Basse-Autriche (fig. 8)}

Hahnel, 1992, 1993.

La sépulture provient d'un groupe de trois crémations de la culture de Baden (Ossarn), fouillées en 1983 et 1984. L'une d'entre elles est décrite comme une fosse rectangulaire dont les parois sont rubéfiées. Très peu d'ossements ont été recueillis, aucune connexion anatomique n'est relevée (petits fragments dans le remplissage). Pour l'auteur, cette structure est à rapprocher de celle de Sitzenberg (Hahnel, 1992, p. 82) et, dans un autre article, il emploie le terme de bustum, qui désigne généralement une tombe-bûcher chez les archéologues (Hahnel, 1993, p. 114). 
Si la rubéfaction des parois atteste une crémation en place, l'organisation et la rareté des ossements retrouvés nous incitent à privilégier l'hypothèse d'un ustrinum, plutôt que celle d'une tombe-bûcher.

\section{La grotte du Gardon, Ambérieu-en-Bugey, Ain (fig. 8) \\ Voruz, 1996 ; Gatto, 1999.}

Les ossements ont été datés par une analyse " $\mathrm{C}$ autour de cal. 3353-3049 avant J.-C. (LY 695 : $4530 \pm 50$ BP). La structure est conservée sur 2,6 m, alors que son extension initiale est estimée à $6 \mathrm{~m}^{2}$. Les squelettes reposent sur un lit de dalettes rubéfiées couvertes d'une pellicule de cendres. Autour, se trouve un aménagement de dalles placées de chant et de manière discontinue, probablement complétées à l'origine par des éléments en bois. L'ensemble est ceint d'une palissade. La fouille étant toujours en cours, une étude ponctuelle a été menée sur $2 \mathrm{~m}^{2}$ dans le cadre d'un mémoire de DEA au laboratoire d'anthropologie de Bordeaux (Gatto, 1999). Les squelettes brûlés de 18 individus ont été identifiés, et la température d'ustion est estimée autour de $700^{\circ}$. Deux hypothèses sont pour l'instant retenues; soit les corps ont brûlé simultanément sous un amas de feuillage surmonté d'une chape d'argile tassée, soit ils ont été brûlés successivement, sur une longue durée, les uns audessus des autres, des couches stériles de charbons ayant été ponctuellement observées entre les couches d'os. De nombreuses connexions anatomiques sont maintenues.

\section{Le tumulus de Dignas, Sainte-Énimie, Lozère}

Fages, 1986.

Une datation effectuée sur les ossements donne un résultat de cal. 2500 avant J.-C. Il existe une structure périphérique de blocs, aménageant un plan carré de $10,24 \mathrm{~m}^{2}$, qui comporte une auréole de dalles dressées installées dans un fossé. Leur rubéfaction et des connexions partielles attestent une crémation in situ. Le degré de crémation est variable suivant les squelettes: ceux qui sont près du foyer, au centre, sont plus brûlés que ceux qui se trouvent en périphérie. Le NMI est de 20, mais il a été établi sur la deuxième vertèbre cervicale. Le mode crématoire n'a pas été identifié. 


\section{BIBLIOGRAPHIE}

\section{AMBERT P.}

1998 : Réflexions sur la chronologie des statues-menhirs de l'aire saintponienne : relation entre objets réels et objets figurés, in: Actes du 2 colloque international sur la statuaire mégalithique, Archéologie en Languedoc, 1998, p. 183-195.

\section{ARBOGiAST R.-M.}

1993 : Les données archéozoologiques des sites chasséens et Michelsberg du nord de la France et des marges orientales : remarques préliminaires, in: Le Néolithique du nord-est de la France et des régions limitrophes, Actes du XIII" colloque interrégional sur le Néolithique, Metz, 10-12 oct. 1986, Paris, éd. de la Maison des sciences de l'homme, Documents d'archéologie française, 41, p. 151-154.

BANNER J.

1956 : Die Peceler Kultur, Budapest, Verlag des ungarischen Akademie der Wissenschaften, Archaeologia Hungarica, 35, 314 p., 124 pl.

BehrFNS $\mathrm{H}$.

1964 : Die neolitisch-frühmetallzeillichen Tierskelettfunde der alten Well, Berlin, Veröffentlichungen des Landesmuseums für Vorgeschichte im Halle, 9, $135 \mathrm{p}$.

1988 : Das Michelsberger Erdwerk im Gewann "Aue " in Bruchsal, Kreis Karlsruhe, Archäologische Ausgrabungen in Baden Württemberg, p. 4447.

\section{BEIER H.J.}

1984 : Die Grab- und Bestattungsitten der Walternienburger und der Bernburger Kultur, Neolitische Studien, III, 30, Halle, p. $1-46$.

BF.I. V.

1996 : Étude spatiale de sept incinérations primaires gallo-romaines de la région lyonnaise, in: Actes du colloque. $d u$ (GDR $742 d u$ CNRS " les ensembles funéraires, du terrain à linterprétation ", Bulletins et Mémoires de la Société d'anthropologie de Paris, 8, 3-4, p. 207-222.

Billand G., Guillot H., Lf Goff I., Malrain F., Pinard E., Talon M.

1995 : Trois structures funéraires collectives dans la moyenne vallée de l'Oise, Reoue archéologique de Picardie, 9, p. 121-129.

BIRKN.TR R.

1980 : Image radiologique typique $d u$ squeletle, Paris, Maloine, $564 \mathrm{p}$.

BLAICH F.

1997 : Neues zur Badener Kultur in Südostbayern, Bayerische VorgeschichtsBlätter, 62, p. 1-28.

\section{BLAIZOT F.}

à paraître : Contribution à la connaissance des modes de dislocation et de destruction du squelette pendant la crémation: l'apport du bûcher funéraire du Néolithique final de Reichstett-Mundolsheim (région de Strasbourg, Bas-Rhin), in: Rencontre autour du feu, table ronde organisée par le Groupe d'anthropologie et d'archéologie funéraire en Île-deFrance, Paris, 11 juin 1999.

Bianchet J.-C., Huysecom E., Woimant G.-P.

1993 : La cabane funéraire SOM de Compiègne " Le Hazoy " (Oise), Revue archéologique de Picardie, 3-4, p. 41-66.

Biolet V., Guil.alme C., Leesch D.

1982 : La grotte sépulcrale Michelsberg du "Rudemont " à Arnaville (Meurthe-et-Moselle), in: Le Néolithique de l'Est de la France, Société archéologique de Sens, cahier $n^{\circ} 1$, p. 135-143.
BoCH P., Lejeune M.

1984 : Le feu et l'argile, Pact, 10, p. 223-236.

Bonuciat E., Graziani G.

1975 : Comparative thermogravimetric, $x$-ray diffraction and electron microscope. Investigations of burnt bones from recent, ancient and prehistoric age, Academia Nazionale dei Lincei, Serie $8,59,5$, p. $518-533$.

Bol'R. F., AddM F., DLday H., Herift P., PIf(haCD) S.

1992 : Lorsque l'Archéologie traite du présent ou de l'histoire proche, Les Nouvelles de l'archéologie, 48-49, p. $55-70$.

BROCHIT.R J.-E.

1984 : Le problème de la genèse des limons holocènes d'abri sous roche, in: Actes du 8 colloque interrégional sur le Néolithique, Le Puy, 1981, ClermontFerrand, CREPA, p. 329-333.

BroguA C.

1998: Approche bayesienne et décision : application à une méthode d'estimation de l'âge au décès (Iovejoy et alii, 1985), mém. de DEA, univ. de Bordeaux I, 76 p.

BRU\%kK J.

1991 : Proposition d'une nouvelle méthode morphologique dans la détermination sexuelle de l'os coxal. Application à la ChausséeTirancourt, in: Méthodes d'étude des sépultures, Compte rendu de la table ronde des 8-10 mai 1991 du GDR 742 du CNRS, Saintes 1991, non publié, p. 13-22.

Bruzek J., Castex D., Majo T.

1996 : Evaluation des caractères morphologiques de la face sacro-pelvienne de l'os coxal : approche pour une proposition d'une méthode de diagnose sexuelle, in: Actes du colloque du GDR 
$742 d u$ CNRS "Les ensembles funéraires, du terrain à l'interprétation ", Bulletins et Mémoires de la Société d'anthropologie de Paris, t. 8, fasc. 3-4, p. 491502.

Buikstra J. E., Swegi.: M.

1989 : Bone Modification Due to Burning: Experimental Evidence, in: Bonnichsen R., Sorg M. H. (éds), Bone Modification, Orono, Maine, p. $247-258$.

Capitani A., Lleuzinger U.

1998 : Arbon-Bleiche 3, Siedlungsgeschichte, einheimische Traditionen und Fremdeinflüsse im Übergansfeld zwischen Pfyner und Horgener Kultur, Jahrbuch der schweizerischen Gesellschaft für Ur- und Frühgeschichte, 81, p. 237-249.

\section{Charras M.}

1979 : Et le feu t'emportera... Bali : de la mort à l'ultime purification, in: Les hommes et la morl, riluels funéraires à travers le monde, Objets et Mondes, Revue du Musée de l'Homme, $\mathrm{n}^{\circ}$ spécial, p. 151-160.

Coblexz. W., Fritzschr. K.

1976 : Neolithische Siedlungsbesttatung mit drei Skeletten und Resten weiterer Schädel aus Zauschwitz. Kr. Borna, Ausgrabungen und Funde, 18, 6, p. 277-281.

Colrty M.-A.

1984 : Formation et évolution des accumulations cendreuses, approche micromorphologique, in: Actes $d u 8^{*}$ colloque interrégional sur le Néolithique, Le Puy, 1981, Clermont-Ferrand, CREPA, p. 341-353.

Deblt A., Masset C.

1991 : Restes humains épars en milieu chasséen septentrional. Recherches en cours, in: Identité du Chasséen, Actes du colloque international de Nemours, 1989, Mémoires du musée de Préhistoire d'Ile-de-France, 4, p. 393-398.

\section{DE LAËT S.J.}

1967 : Quelques problèmes du Néolithique belge, Palaeohistoria, 12, p. 335-361.

1968 : La civilisation de Michelsberg en Belgique : à propos d'un livre récent, Helinium, 8, p. 259-269.

DE LoẼ A., RAHIR E.

1924 : Ottembourg et Boitsfort. Deux stations néolithiques du Brabant avec nécropole à incinération, Bulletin de la Société d'anthropologie de Bruxelles, 28, p. 249.

Dōhl. H. J., Wagner K., Wrigelt J.

1992 : Eine Opfergrube der Baalberger Kultur von Alsleben, Ldkr. Bernburg, Jahresschrift für Mitteldeutsche Vorgeschichte, 75, p. 51-69.

DOKIADAI. M.

1963 : Ein Beitrag zur Identifikation der Leichenbrände, in: Acta anthropologického Kongresu, Mikulov 1961, Anthropos, Brno, p. 29-38.

1967 : Ein Beitrag zur Morphologie verbrannter Menschenknochen, Anthropos, Brno, p. 80-82.

1970 : Ergebnisse experimenteller Verbrennungen zur Feststellung von Form und Grössenveränderungen von Menschenknochen unter dem Einfluss von hohen Temperaturen, Anthropologie, Brno, VIII, 2, p. 3-17.

DLDAY H.

1978 : Archéologie funéraire et anthropologie, application des relevés et de l'étude ostéologiques à l'interprétation de quelques sépultures pré- et protohistoriques du midi de la France, Cahiers d'anthropologie de Paris, 1, p. 55-101.

1987a : Contribution des observations ostéologiques à la chronologie interne des sépultures collectives, in: Duday H., Masset C. (éds), Anthropologie physique et archéologie, méthodes d'étude des sépultures, Actes du colloque de Toulouse, 4-6 nov. 1982, Paris, éd. du CNRS, p. 51-59.

1987b: La quantification des restes humains. Application à l'étude des sépultures à incinération ou des dif- férentiels autres que la conservation, in: Actes de la table ronde de la RCP 742 du CNRS, Saint-Germain-en-Laye, mai 1987, p. 17-21 (ronéotypé).

1989 : La nécropole du Peyrou à Agde (Hérault), étude anthropologique, in: Nickels A., Marchand G., Schwaller M. (éds), Agde, la nécropole du premier Âge du Fer, suppl. à la Revue archéologique de Narbonnaise, 19, Paris, p. 459-472.

1990 : Observations ostéologiques et décomposition du cadavre: sépulture colmatée ou en espace vide ?, Revue archéologique du Centre de la France, 29, 2, p. 193-196.

1996 : Considérations générales relatives à l'ensemble des tombes à incinération, in: Piningre J.-F. (éd.), Nécropoles el sociétés au premier Âge du Fer, Paris, éd. de la Maison des sciences de l'homme, Documents d'archéologie française, 54, p. 126.

Eckert W. G., James S., Katchs S.

1988 : Investigation of cremations and severely burned bodies, American Journal of forensic Medical Pathology, 9, 3, p. $188-200$.

\section{EICH-FRANCKE: E.}

1967 : Die Funde der Michelsberger Kultur aus dem westlichen Oberrheingebiet, Verlag Stadtbibliothek Worms, 22, $240 \mathrm{p}$.

FAcis $\mathrm{G}$.

1986 : Le tumulus de Dignas - commune de Ste Énimie (Lozère), in: Duday H., Masset C. (éds), Anthropologie physique et archéologie, méthodes d'étude des sépultures, Actes du colloque de Toulouse, 4-6 nov. 1982, Paris, éd. du CNRS, p. 367-378.

FISCHER U.

1956 : Die Gräber der Steinzeit im Saalegebiet, Berlin, Walter de Gruyter, Vorgeschichtliche Forschungen, 15, $327 \mathrm{p}$.

Forf.nbaher S.

1993 : Radiocarbon dates and absolute chronology of the central European 
Early Bronze Age, Antiquity, 67, 255, p. 218-256.

\section{FORRER R.}

1912 : Ein neolitischer Pfahlbau bei Erstein-Murgiessen und die werwandten Fundstellen im Elsass, Anzeiger für Elsässische Altertumskunde, 13-14, p. 243-267.

GaIT/sCh W., WERnkR A.

1993 : Rekonstruktion einer Brandbestattung vom Typ Bustum aufgrund archäologischer Befunde aus Siedlungen der Jülicher Lössbörde, in: Struck M. (éd.), Römerzeitliche Gräber als Quellen zu Religion, Bevölkerungsstrucktur und Sozialgeschichte, Archäologische Schriften des Instituts für Vor- und Frühgeschichte der Johannes Gutenberg-Universität Mainz, 3, p. 55-67.

\section{GatTo E.}

1999 : Une pratique originale au Néolithique final ? Vers l'interprétation de la structure crématisée de la grotte du Gardon (Ain), mémoire de DEA, Laboratoire d'anthropologie, univ. de Bordeaux I, $49 \mathrm{p}$.

\section{Grévin G.}

1997 : La crémation à l'époque romaine : un os resectum dans le monument funéraire de Marcus Nonius Balbus à Herculanum, in: Pappalardo U., Nuove testimonianze su Marco Nonio Balbo ad Ercolano, Mitteilungen des Deutschen Archaeologischen Instituts Roemische Abteilung, Mainz, 104, p. 429-433.

Grévin G., Baud C.-A., Susini A.

1990 : Étude anthropologique et paléopathologique d'un adulte inhumé puis incinéré provenant du site de Pincevent (Seine-et-Marne), in: Actes $d u$ colloque du GIDR $742 d u$ CNRS "Anthropologie et archéologie, dialogue sur les ensembles funéraires", $\mathrm{n}^{\circ}$ spécial des Bulletins et Mémoires de la Société d'anthropologie de Paris, 2, $n^{\circ} 3-4$, p. $77-87$.
Grimm P.

1937 : Die Baalberger Kultur in Mitteldeutschland, Mannus, 29, p. 155-187.

Gross E., Bueler E.

1992 : Zürich "Mozartstrasse ", neolitische und bronzezeitliche Ufersiedlungen, Tafeln, Zürich, Berichte der Zürcher Denkmalpflege, Monographien 17, 2, $297 \mathrm{pl}$.

Gross E., Brombachr.r C., Dick M.

1987 : Zürich "Mozartstrasse ", neolitische und bronzezeilliche Ufersiedlungen, Zürich, Berichte der Zürcher Denkmalpflege, Monographien 4, 1 , 255 p., 27 fig.

GÜNTHER, ScHMidI

1953 : Die Zerstörung des menschlichen Gebisses im Verlauf der Einwirkung hoher Temperaturen, Deutsche Zeitschrift für Gerichtliche Medizin, 42, p. 180-188.

HAHNEI, B.

1992 : Spätneolitische Gräber in Österreich, Fundberichte aus Österreich, 31, p. 79-94.

1993 : Frühneolithische Gräber in Österreich, Fundberichte aus Österreich, 32, p. 107-128.

HAPP G.

1991 : Bestattungen und Menschenreste in "Häusern" und Siedlungen des steinzeitlichen Mitteleuropa, Frankfurt, Europäische Hochschulschriften, Reihe 38, Archäologie 33, 423 p.

HÄUSLER A.

1994: Grab und Bestattungssitten des Neolithkums und der frühen Bronzezeit in Mitteleuropa, Zeitschrift für Archäologie, 28, 94, 1, p. 23-61.

HERRMANN B.

1972 : Zur Lage des Leichnams auf dem Scheiterhaufen, Zeitschrift für Morphologische Anthropologie, 64, p. $80-89$

1976 : Neuere Ergebnisse zur Beurteilung menschlicher Brandknochen, Zeitschrift für Rechtmedizin, 77, p. 191-200.
HORŇANSKÝ J., SKLTII.J.

1950 : Hromadný hrob kultury s keramikou malovanou ve džbánicích u Mor. Krumlova, Obzor Prhehistorický. Orgàn spolécnosti Ceskoslovenských Prehistoriku, Brno, XIV, 2, p. 333-356.

ITTEN M.

1970 : Die Horgener Kullur, Basel, Monographien zur Ur- und Frühgeschichte der Schweiz, 17, $112 \mathrm{p}$.

JE.UNESSE C.

1982 : La culture de Michelsberg en Alsace: essui de synthèse, mém. de Maîtrise, univ. des sciences humaines de Strasbourg, $150 \mathrm{p}$.

1989 : La culture de Munzingen dans le cadre du "Jungneolithikum " du sudouest de l'Europe centrale d'après les découvertes récentes des sites alsaciens de Didenheim (Haut-Rhin) et de Geispolsheim (Bas-Rhin), Cahiers de l'Association pour la promotion et la recherche archéologique en Alsace, 5, p. 155-184.

1992 : Il y a 7000 ans l'Alsace. Le site archéologique du lotissement Sainte Odile à Rosheim (Bas-Rhin) et les premiers agriculteurs de la Plaine d'Alsace, catalogue d'exposition, Rosheim 19-21 mars 1992, Strasbourg, 2-25 avril 1992, $75 \mathrm{p}$.

1993 : Les premiers agriculteurs, le Néolithique en Alsace, Strasbourg, Collection du musée archéologique, 2, 123 p.

Jeunesse C., Pétrequin P., Piningre J.-F. 1998 : I.'Fst de la France, in: Allas du Néolithique européen, l'Europe occidentale, Études et recherches archéologiques de l'université de Liège, 46, p. 501-584.

\section{Jelnesse. C., SAINTY J.}

1986 : Un nouvel habitat du Michelsberg récent (Groupe de Munzingen) à Geispolsheim (Bas-Rhin), les structures, Cahiers de l'Association pour la promotion et la recherche archéologique en Alsace, 2, p. 37-72. 
JFUNESSE C., SCHNEIDER M.

1985 : Le Néolithique final en Alsace: état des connaissances et premiers éléments de synthèse, in: $D u$ Néolithique moyen II au Néolithique final du nord-ouest des Alpes, Actes du 12 colloque interrégional sur le Néolithique, Lons-le-Saunier, 1985, Musée d'archéologie de Lons-leSaunier, p. 117-129.

KAUFMANN D.

1995 : Opferpraktiken im Neolithikum, Pravék, NR 5, p. 95-108.

KAT\% D., MYERS-SUCHEY J.

1986 : Age Determination of the Male Os Pubis, American Journal of Physical Anthropology, 69, p. 427-435.

$\mathrm{KI}$.APPKOTH $\mathrm{H}$.

1954-1955: Zur Theorie der fixierten Extremitätenversetzung bei Hitzeschrumpfleischen, Deutsche Teitschrift für Gerichtliche Medizin, 43, p. $428-438$.

KoREK J.

1951 : Ein Gräberfeld der Badener Kultur bei Alsonémedi, Acta Archaeologica Hungarica, 1, p. 35-51.

Kostka M., S.molíková M.

1997 : Casně eneolitické sidliště s pohřby v Praze - Nebušicích, Archaeologica Pragensia, 13, p. 3-27.

KRFINFR L.

1993a: Eine jungneolitische Siedlung mit Tieropfern von Mamming, Ldkr. Dingolfing-Landau, Niederbayern, Acta Praehistorica el Archaeologica, Berlin, 25, p. 16-55.

1993b: Eine jungneolitische Siedlung mit Opfergruben aus Mamming, Ldkr. Dingolfing-Landau, Niederbayern, Vorträge Niederbayerischer Archäologentag, Deggendorf, 11, p. $35-45$.

1995 : Grabfunde der Münchshöfener Kultur im Landkreis DingolfingLandau, Vorträge Niederbayerischer Archäologenlag, Deggendorf, 13, p. 71-84.
KROGMAN W. K.

1978 : The human Skeleton in forensic Medecine, Springfield, USA, Charles Thomas, $3^{\mathrm{e}}$ éd., $337 \mathrm{p}$.

KRUK J., Mil.ISALSKas S.

1982 : A Multiple Neolithic Burial at Bronocice, Poland, Germania, 60, 1, p. 211-221.

1985 : Bronocice, Osiedle obronne ludnosci kultury Luybelsko-Wolynskiej/2800-2700 lat p.n.e., Wroclaw, Ossolineum, $139 \mathrm{p}$.

KüHNLE-AuBRY G.

1994 : Holtzheim "Les Abattoirs" (BasRhin), Document final de synthèse, Service régional de l'Archéologie, Strasbourg, 55 p., 58 pl.

\section{KLNTER M.}

1989 : Leichenbranduntersuchungen in Wederath, in: Gräber, Spiegel des Lebens, Austellungskat, Trier, Mainz, $415 \mathrm{p}$.

\section{LAMBACH F.}

1986 : Les sépultures Michelsberg d'Alsace, quelques données nouvelles à propos des rites funéraires, catalogue des tombes, Cahiers de l'Association pour la promotion de la recherche archéologique en Alsace, 2, p. 16-36.

\section{LAMBOT B.}

1994 : Le bûcher expérimental d'AcyRomance, 11-12 août 1989, in: Lambot B., Friboulet M., Méniel P. (éds), Le site protohistorique d'AcyRomance (Ardennes) -II- Les nécropoles dans leur conlexte régional (ThugnyTrugny el tombes aristocratiques), Mémoires de la Société archéologique champenoise, 8 , suppl. au bulletin $n^{\circ} 2$, p. 25()$-261$.

LF. Mrur N.

1999-2000: Reichstett-MundolsheimSouffelweyersheim " rue Ampère " (BasRhin), Document final de synthèse, AFAN antennes Grand-Est, Méditerranée et Rhône-Alpes-Auvergne, Service régional de l'Archéologie d'Alsace, 8 t., 3 catalogues.
LEROI-GOLRHAN A.

1986 : Reconstituer la vie, in : Leroi-Gourhan A. (éd.), Le fil du temps, Paris, Le Seuil, coll. Points Histoire, 316 p. [p. 159-182].

\section{LICHARDUS J.}

1986 : Le rituel funéraire de la culture de Michelsberg dans la région du Rhin supérieur et moyen, in: Demoule J.-P., Guilaine J. (éds), Le Néolithique de la France, hommage à Gérard Bailloud, Paris, Picard, p. 343-458.

LOVEJOY C. O., MEINDI. R. S., PRYZBeck T. R., MENSForTh R. P.

1985 : Chronological Metamorphosis of the Auricular Surface of the Ilium : a New Method for the Determination of Adult Skeletal Age at Death, American Journal of Physical Anthropology, 68, p. 15-28.

LÜINING J.

1967 : Die Michelsberger Kultur. Ihre Funde in zeitlicher und räumlicher (iliederung, Berichte Römisch Germanischen Kommission, Berlin, 48, 2 vol., 350 et $111 \mathrm{p}$.

MACKINILY J.

1989 : Cremations: Expectations, Methodologies an realities, in: Robert C. A., Lee F., Bintliff J. (éds), Burial Archaeology, Current Research, Methods and Developments, BAR, Bristish Series, 211, p. 65-76.

1994a: Bone Fragment Size in British Cremations and the Implications for the Pyre Technology and Ritual, Journal of Archaeological Srience, 21, 3, p. 339-342.

1994b : Bone Fragment Size and Weights of Bone from Modern British Cremations and the Implications for the Interpretation of Archaeological Cremations, International Journal of Osteoarchaeology, 3, p. 283-287.

1997 : Bronze Age "Barrows " and Funerary Rites and Rituals of Cremation, Proceedings of the Prehistoric Society of London, 63, p. 129-145.

MAIFR R. A.

1955 : Keramik der Badener Kultur aus 
Lfersiedlungen des Bodensees, Germania, 33, p. 155-173.

1965 : " Michelsberg-Altheimer " Skelettgruben von Inningen bei Augsburg in Baverisch-Schwaben, Germania, 43, 1, p. 8-16.

Masset C.

1982 : Estimation de l'âge au décès par les sutures crâniennes, thèse de Doctorat d'État en sciences naturelles, univ: Paris VIII, 301 p. multigr.

Masset C., Baratin J.F.

1980 : La sépulture à incinćration de Maison-Rouge à Montigny (Loiret), in: Actes du colloque interrégional sur le Néolithique, Saint-Amand-Montrond (Cher), 28-30 oct. 1977, Cahiers archéologiques de Picardie, p. 141-147.

Masslet C., VAN-VIIITT B.

1974 : Une sépulture collective du Néolithique final à Montcourt (Aisne), Bulletin de la Sociélé préhistorique française, 71, 1, p. 8-9.

Mathiel: C., Stoops G.

1972 : Observations pétrographiques sur la paroi d'un four à chaux carolingien creusé en sol limoneux, Archéologie médiérale, 2, p. 347-354.

\section{Mattscink I.}

1991 : Grabenwerke des Spätneolithikums in Süddeutschland, Fundberichte aus Baden-Württemberg, 16 , p. 27-55.

MaYri C.

1991 : Bestattungen der Badener Kultur aus Österreich, Archaeologia Austriaca, 75, p. 29-61.

MÉNif. P.

1994 : Les restes animaux du bûcher, in : Lambot B., Friboulet M., Méniel P. (éds), Ie site protohistorique d'AcyRomance (Ardennes) -II- Les nécropoles dans leur contexte régional (ThugnyTrugny et tombes aristocratiques), Mémoires de la Société archéologique champenoise, 8 , suppl. au bulletin $\mathrm{n}^{\circ} 2$, p. 283-286.
Moorrees C. F. A., Faxing; E. A., HLNT E. E. JR

1963a: Formation and Resorption of three deciduous teeth in children, American Journal of Physical Anthropology; 21, p. $205-213$.

1963b : Age variation of formation stages for ten permanent teeth, Journal of Dental Research, 42, p. 1490-1502.

MLrkay A., Rose.J. C.

1993 : The analysis of cremains : a case study involving the inappropriate disposal of mortuary remains, Journal of Forensic Science, 38, 1, p. 98-103.

NF̆.Mejcolá-Patéková V.

1963 : Nové hroby kultùry s kanelovanou keramikou na Slovensku, Archeologické Rozhledy, XV, 6, p. 673-679.

1974 : Beitrag zum Kennen der Postboleràz Entwiklung der Badener Kultur, Slovenski Archaeológia, XXII, 2, p. $237-360$.

Nfuchibaurk-Maresch C., TeschierNicOLA M.

1984 : Eine spätneolitische Doppelbrandbestattung aus Sitzenberg, VB Tulln, NÖ, Fundberichte aus Österreich, 23, p. 129-142.

NEvTZÁNSKY G.

1985 : Grabfunde und Überbauerscheinungen der Träger der Badener Kultur im zentralen Gebiet des Karpatenbeckens, Slovenskí Archaeológia, XXXIII, 2, p. 249-270.

NickeI. C.

1998 : Michelsberger Skelettreste Gräber... oder was sonst ?, in : Biel J., Schlichtherle H., Strobel M., Zeeb A. (éds), Die Michelsberger Kultur und ihre Randgebiete -Probleme der Entstehung, Chromologie und des Siedlungswesens, Kolloquium Hemmenhofen, 21-23 fév. 1997, Stuttgart, Theiss, Materialhefte zur Archäologie im Baden-Württemberg, 43, p. 151-158.

\section{Novotixý B.}

1958 : Slovensko v mladlsej dobe kamennej, Bratislava, Vydavatel'svo slovenskej akadémie vied, $6 \check{5} \mathrm{p}$.
Paltrial J.-P.

1994 : Quelques aspects des crémations contemporaines en Asie du Sud-Est, in: Lambot B., Friboulet M., Méniel P. (éds), le site protohistorique d'Acy-Romance (Ardennes) -IILes nécropoles dans leur contexte régional (Thugny-Trugny el tombes aristocratiques), Mémoires de la Société archéologique champenoise, 8 , suppl. au bulletin $n^{\circ}$ 2, p. 306-315.

Petrisch J.

1985-1986 : Das Altheimer Erdwerk bei Alkofen, Gem. Bad. Abbach, Ldkr. Kolheim, Bericht der Bayerischen Bodendenkmalpflege, 26-27, p. 33-80.

PETREQQLT: P.

1989 : Les siles littoraux néolithiques de Clairvaux-Les-Lacs (jura) -II- L.e Néolithique moyen, Paris, éd. de la Maison des sciences de l'homme, $508 \mathrm{p}$.

\section{RAMSEYER D}

1982 : Auvernier 3. L'industrie en bois de cerf du site néolithique des Graviers, Cahiers d'archéologie romande, 23, p. 85-113.

Richiter A.

À paraître : Sépultures primaires à incinération: nouvelles données et nouvelles problématiques, in: Les pratiques funéraires à l'Âge du Bronze en France, table ronde de Sens-enBourgogne, 10-12 juin 1998.

\section{SCHAFFFir F. A.}

1925-1926: Sépultures d'accroupis et caves de cabanes néolithiques d'Achenheim (Bas-Rhin), Cahiers d'archéologie et d'histoire d'Alsace, 61-68, p. 273-285.

\section{S(HMOTZ K.}

1993 : Bestattungen des älteren Mittelneolithikums im Künzing L.kr. Deggendorf, Vortrüge Niederbayerischer Archäologentag, Deggendorf, 11, p. 15-30.

Schol'R I., MASSI.ER M.

1940 : Studies in tooth development : the 
growth pattern of the human teeth, Journal of American Dental Association, 27, p. 1778-1793 et 1918-1931.

\section{SCHRÖTER P.}

1996 : Eine Münchshöfener Gruppenbestattung aus Grossmehring, Das Archäologische Jahr in Bayern, Berlin, p. 36-40.

\section{SCHWEIT\%R J.}

1987 : Le site Michelsherg de Didenheim, Cahiers de l'Association pour la promotion el la recherche archéologique en Alsace, 3, p. 50-87.

\section{SchWEIT/ER J., FL'Ll.eringek B.}

1973 : Dëcouvertes de fosses du "Michelsberg "à Riedisheim, Bulletin du Musée hislorique de Mulhouse, 81, p. 23-40.

\section{SFIIDFI. U.}

1998 : Leonberg-Höfingen, L $\mathrm{kr}$. Böblingen, Eine jungneolitische Siedlung mit Bestattungen, in: Biel J., Schlichtherle H., Strobel M., Zeeb A. (éds), Die Michelsberger Kultur und ihre Randgebiete -Probleme der Entstehung, Chronologie und des Siedlungstwesens, Kolloquium Hemmenhofen, 21-23 fév. 1997, Stuttart, Theiss, Materialhefte zur Archäologie im Baden-Württemberg, 43 , p. 109-113.

ShipMan P., Foster G., Scolininc;ir M.

1984 : Burnt bones and teeth : an experimental study of color, morphology, crystal structure and shrinkage, Journal of Archaeological Science, 11, p. $307-325$.

\section{SLNDICK R. 1.}

1978 : Human skeletal growth and age determination, Homo, 29, p. 228-249.

Taffanel. J., Taffanel, O., Janin T. 1998 : La nécropole du Moulin à Mailhac (Aude), Monographies d'archéologie méditerranéenne, 2, $393 \mathrm{p}$.

THÉYENIN A.

1974 : Informations archéologiques, Gallia Préhistoire, 17, 2, p. 543-549.
1978 : Informations archéologiques, Gallia Préhisioire, 21, 2, p. 548-554.

Thévenin A., Sainiy J., Poulain T.

1977 : Fosses et sëpultures Michelsberg, sablière Maetz à Rosheim (Bas-Rhin), Bulletin de la Société préhistorique. française, 74, ét. et trav. 2, p. 608-621.

Tocik A.

1978 : Nitriansky-Hràdok-Zìme`cek, Nitra, Materiala Archaeologica Slovaca, I, 1, $287 \mathrm{p}$.

TrNÁcikovi Z.

1962 : Příspěvek $\mathrm{k}$ pohřebnímu ritu $\mathrm{v}$ mladším neolitickém období, Sbornik Ceskoslovenske Spolecnosti Archeologické, Brno, 2, p. 215-223.

VEIT U.

1996 : Studien zum Problem der Siedlungsbestaltung im europäischen Neolithikum, Tübinger Schriften zur Urund frühgeschichtlichen Archäologie, 1, Münster, Waxmann, $418 \mathrm{p}$.

Vigivald A., Prrnot P., Gelot J.

1997 : Reichstett-Mundolsheim, zone d'activité secteur "RMS voirie ", Bas-Rhin, Document final de synthèse d'opération d'archéologie préventive, Strasbourg, Service régional de l'Archéologie d'Alsace, Association pour les fouilles archéologiques nationales, $51 \mathrm{p}$.

Vičk.k E.

1953 : Hromadné kostrové pohřby $s$ kanelovanou keramikou v Nitrianském Hràdku na Slovensku, Archeologické Rozhledy, V, 6, p. 733-736.

VORL\% J.-L.

1984: Outillages osseux el dynamisme industriel dans le Néolithique jurassien, Lausanne, Cahiers d'archéologie romande, $29,533 \mathrm{p}$.

1991 : Le Néolithique suisse, bilan documentaire, Document du Département d'anthropologie et d'écologie de l'université de Genève, 16, 173 p.

1996 : La grotte du Gardon à Ambérieu-enBugey (Ain), rapport de fouilles 19941996, Lyon, Société préhistorique rhodanienne, Service régional d'Archéologie Rhône-Alpes, 307 p.

WAHII.J.

1981 : Beobachtungen zur Verbrennung menschlicher Leichname, Archäologisches Korrespondenzblatl, 11, p. $271-279$

WAHI. J., HÖHN B.

1988 : Eine Mehrfachbestattung der Michelsberger Kultur aus Heidelberg-Handschuhsheim, Rhein-Neckar-Kreis, Fundberichte aus Baden-Würtlemberg, 13, p. 123-198.

WaHL.J., WaHI, S.

1983 : Zur Technik der Leichenverbrennung, I, Verbrennungsplätze aus ethnologischen Quellen, Archäologisches Korrespondenzblatl, 13, p. 513-520.

WARRE.N M.-W., MAPI.ES W.-R.

1997 : The Anthropometry of Contemporary Commercial Cremation, Journal of Forensic Science, 42, 3, p. 417-423.

Weils C.

1960 : A Study of Cremation, Antiquity, XXXIV, p. 29-37.

\section{W'RNERT P.}

1958 : Informations Archéologiques, circonscription de Strasbourg, Gallia Préhistoire, I, p. 107.

Winigi:R J.

1971 : Das Fundmaterial von ThayngenWeier im Rahmen der Pfyner Kullur, Basel, Monographien für Ur- und Frühgeschichte der Schweiz, 18, 173 p., 86 fig.

1981 : Feldmeilen - Vorderfeld. Der Übergang von der Pfyner zur Horgenerkultur, Frauenfeld, Huber, Schweizerische Gesellschaft für Ur- und Frühgeschichte, Antiqua, 8, 285 p., 50 fig., $111 \mathrm{pl}$.

1985 : Das Neolithikum der Schweiz, eine Vorlesungsreihe zum Forschungsstand, Unverïenderte Neuauflage 1981, Basel, $323 \mathrm{p}$. 
WOI.F J.-J.

1979 : Nouveaux éléments du Michelsberg à Eschentzwiller et Magstatt-le-Bas, Bulletin du Musée historique de Mulhouse, 86, p. 29-38.

\section{Wrss R.}

1988 : Die jungsteinzeitlichen Bauerndörfer von Egolzwil $4 \mathrm{im}$ Wauwilermoos. Die Siedlungsreste, Zürich, Archäologische Forschungen, 3, Die Funde 1, 178 p., Die Funde 2, 272 p.
ZAMMIT J.

1991 : Les sépultures préhistoriques et le feu, utilisation rituelle, crémations et incinérations, Bulletin de la Société préhistorique française, 88,3 , p. 70-72. 